Universidad de Lima

Facultad de Ingeniería y Arquitectura

Carrera de Ingeniería Industrial

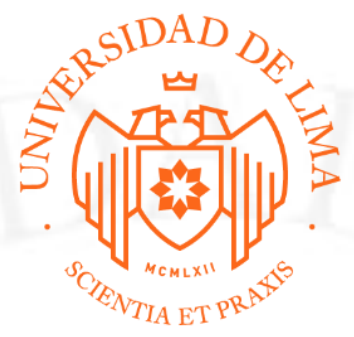

\title{
ESTUDIO DE PRE FACTIBILIDAD PARA LA INSTALACIÓN DE UNA PLANTA DE TANQUES DE AGUA CÓNICOS APILABLES DE POLIETILENO RECICLADO EN SU EXTERIOR
}

Trabajo de investigación para optar el Título Profesional de Ingeniero Industrial

\author{
Carlo Gino Strobbe Premrl \\ Código 20121240 \\ Franco Diego Valdivia Morón
}

Código 20112423

Asesor

Carlos Augusto Ahoki Pajuelo

Lima - Perú

Junio de 2019 


\section{PRE FEASIBILITY STUDY FOR THE}

\section{INSTALLATION OF PLANT WATER TANKS}

TAPER RECYCLED POLYETHYLENE STACKABLE ON ITS OUTER 


\section{TABLA DE CONTENIDO}

RESUMEN EJECUTIVO ...........................................................................1

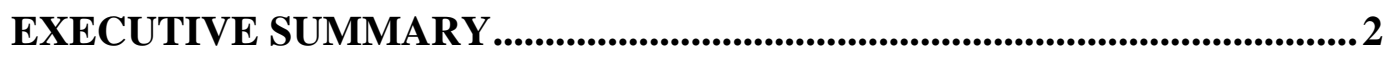

CAPÍTULO I: ASPECTOS GENERALES ......................................................3

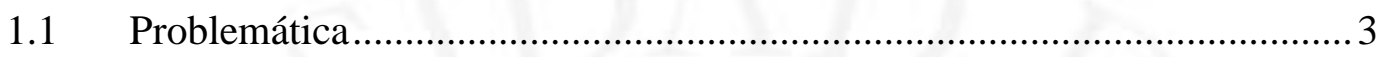

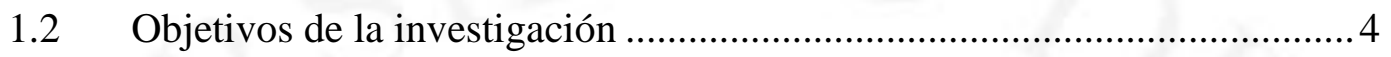

1.3 Alcance de la investigación ................................................................. 4

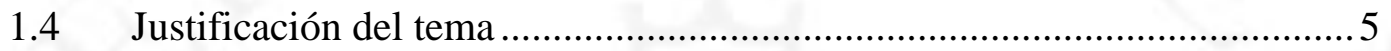

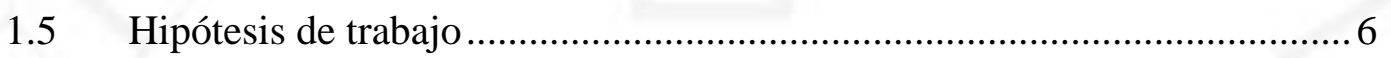

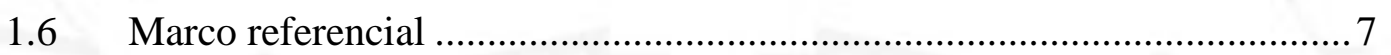

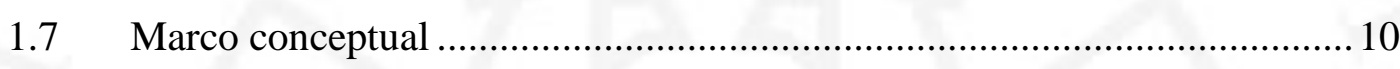

CAPÍTULO II: ESTUDIO DE MERCADO........................................................... 12

2.1 Aspectos generales del estudio de mercado ........................................... 12

2.1.1 Definición comercial del producto ......................................................... 12

2.1.2 Usos del producto, bienes sustitutos y complementarios …........................ 13

2.1.3 Determinación del área geográfica que abarcará el estudio....................... 14

2.1.4 Análisis del sector industrial ............................................................... 14

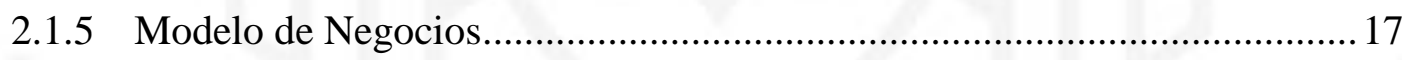

2.2 Metodología a emplear en la investigación de mercado ............................ 18

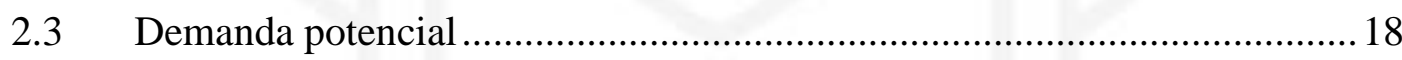

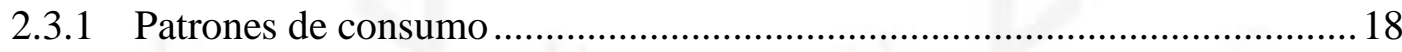

2.3.2 Determinación de la demanda potencial ................................................... 18

2.4 Determinación de la demanda de mercado ................................................ 19

2.4.1 Demanda del proyecto en base a data histórica......................................... 19

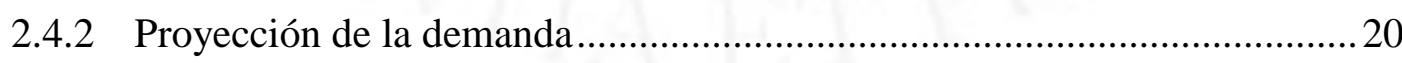

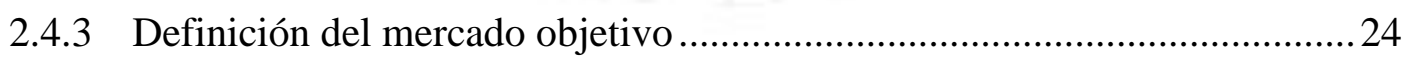

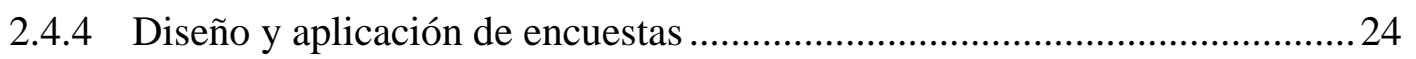

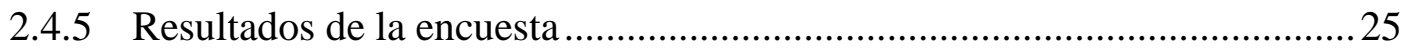

2.4.6 Determinación de la demanda del proyecto ..............................................2 27

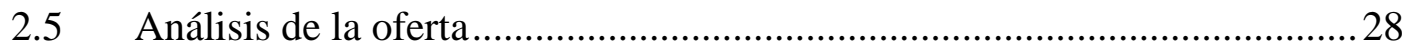


2.5.1 Empresas productoras, importadoras y comercializadoras .28

2.5.2 Participación de mercado de los competidores actuales ............................28

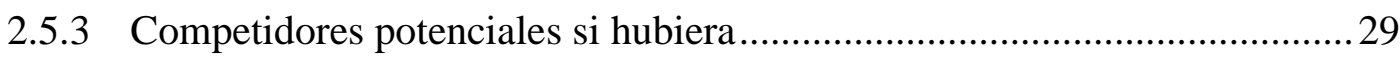

2.6 Definición de la estrategia de comercialización.........................................29

2.6.1 Políticas de comercialización y distribución ...............................................229

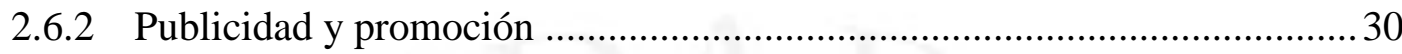

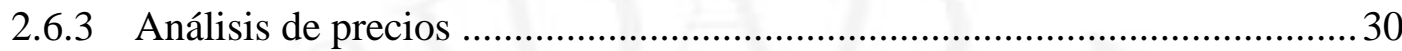

CAPÍTULO III: LOCALIZACIÓN DE PLANTA.................................................. 33

3.1 Identificación y análisis detallado de los factores de localización...............33

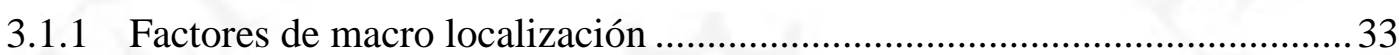

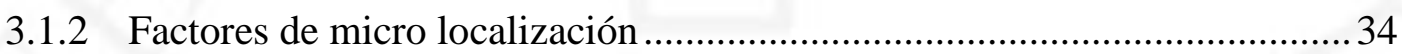

3.2 Identificación y descripción de las alternativas de localización ..................34

3.2.1 Alternativas de macro localización ............................................................ 34

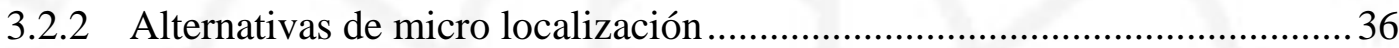

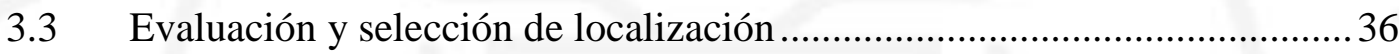

3.3.1 Evaluación y selección de la macro localización .........................................36

3.3.2 Evaluación y selección de micro localización.............................................. 37

CAPÍTULO IV: TAMAÑ̃ DE PLANTA........................................................39

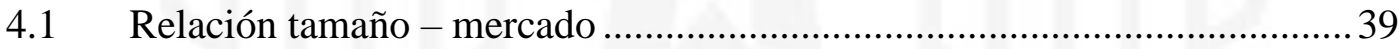

4.2 Relación tamaño - recursos productivos......................................................39

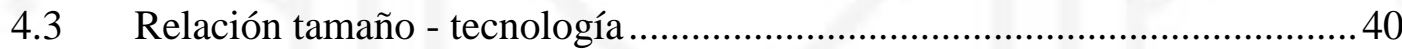

4.4 Relación tamaño - punto de equilibrio .................................................. 41

4.5 Selección del tamaño de planta ................................................................. 41

CAPÍTULO V: INGENIERÍA DEL PROYECTO................................................42

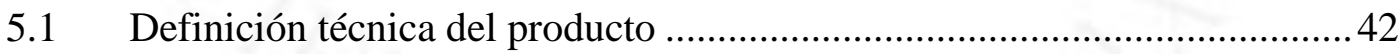

5.1.1 Especificaciones técnicas, composición y diseño del producto ..................42

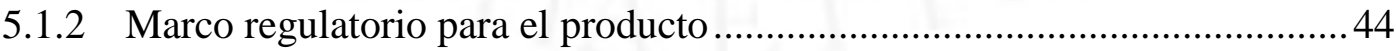

5.2 Tecnologías existentes y procesos de producción.......................................44

5.2.1 Naturaleza de la tecnología requerida ..................................................4 44

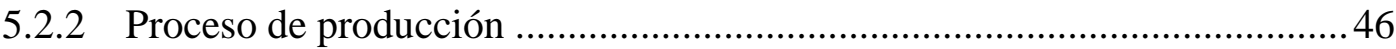

5.3 Características de las instalaciones y equipos ...........................................49

5.3.1 Selección de la maquinaria y equipos ......................................................49 
5.3.2 Especificaciones de la maquinaria 50

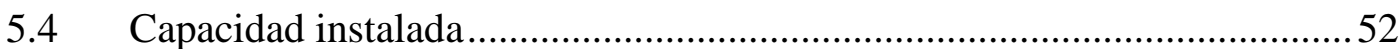

5.4.1 Cálculo detallado del número de máquinas y operarios requeridos............52

5.4.2 Cálculo de la capacidad instalada..........................................................5

5.5 Resguardo de la calidad y/o inocuidad del producto...................................55

5.5.1 Calidad de la materia prima, de los insumos, del proceso y del producto ..55

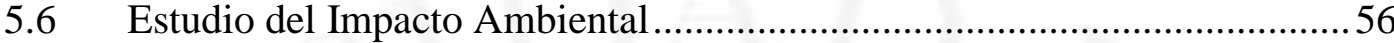

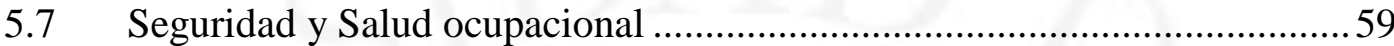

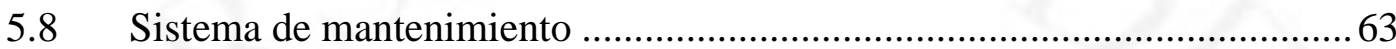

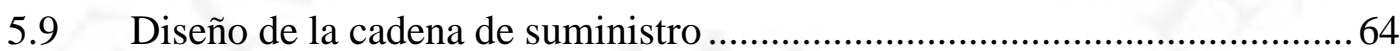

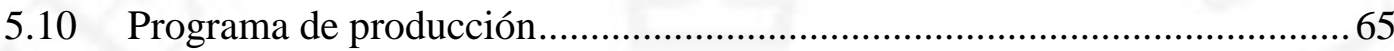

5.11 Requerimientos de insumos, servicios y personal indirecto ……................66

5.11.1 Servicios: energía eléctrica, agua, vapor, combustible .............................66

5.11.2 Determinación del número de trabajadores indirectos ..............................67

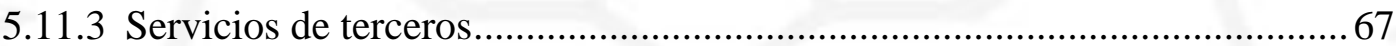

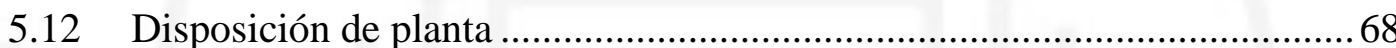

5.12.1 Características físicas del proyecto ….....................................................6 68

5.12.2 Determinación de las zonas físicas requeridas ........................................ 72

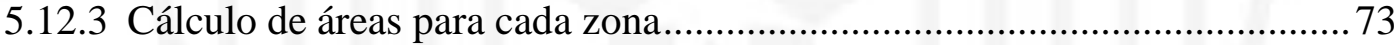

5.12.4 Dispositivos de seguridad industrial y señalización...................................74

5.12.5 Disposición de detalle de la zona productiva ........................................... 81

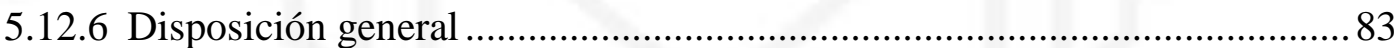

5.13 Cronograma de implementación del proyecto ......................................... 85

CAPÍTULO VI: ORGANIZACIÓN Y ADMINISTRACIÓN.............................86

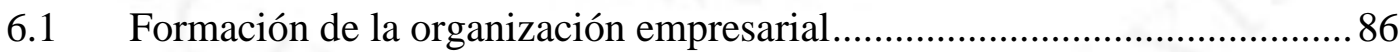

6.2 Requerimientos de personal directivo, administrativo y de servicios .........86

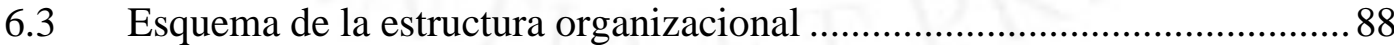

CAPÍTULO VII: PRESUPUESTOS Y EVALUACIÓN DEL PROYECTO.. 89

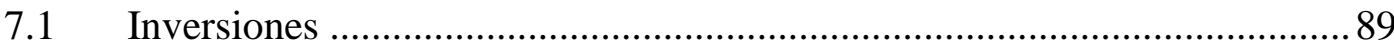

7.1.1 Estimación de las inversiones de largo plazo .............................................91

7.1.2 Estimación de las inversiones de corto plazo............................................93

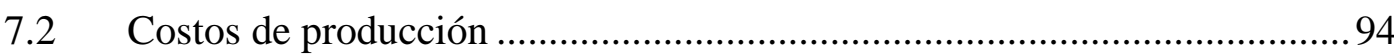




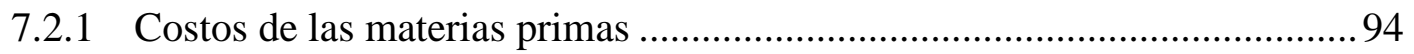

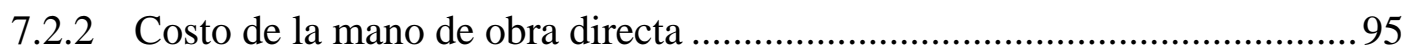

7.2.3 Costo Indirecto de Fabricación .................................................................. 95

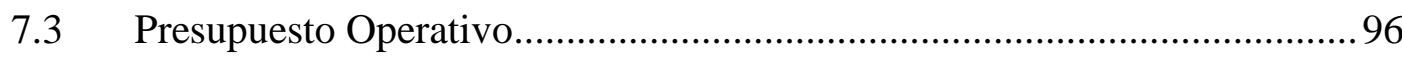

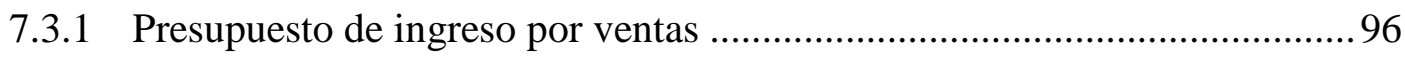

7.3.2 Presupuesto operativo de costos y gastos ................................................ 97

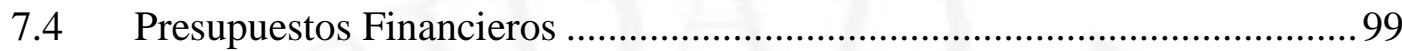

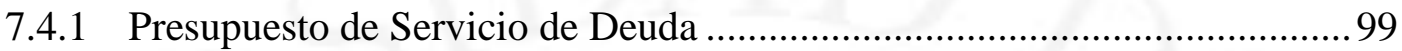

7.4.2 Presupuesto de estado de resultados........................................................... 100

7.4.3 Presupuesto de estado de situación financiera ........................................... 102

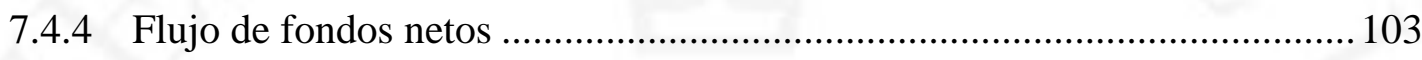

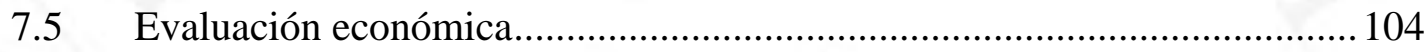

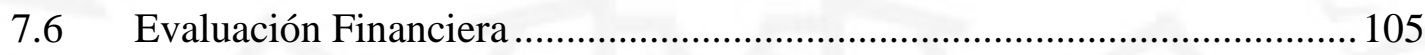

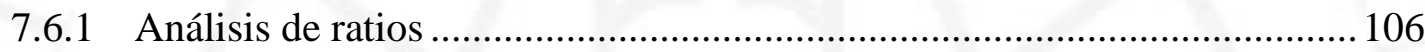

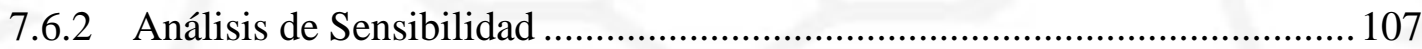

CAPÍTULO VIII: EVALUACION SOCIAL DEL PROYECTO ...................... 108

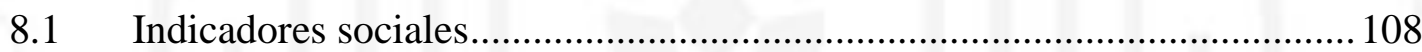

8.2 Interpretaciones de indicadores sociales .............................................. 108

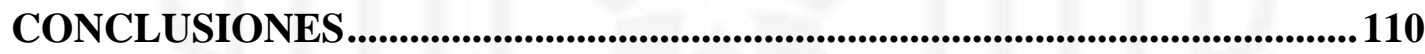

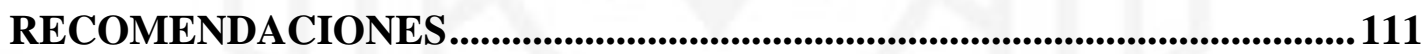

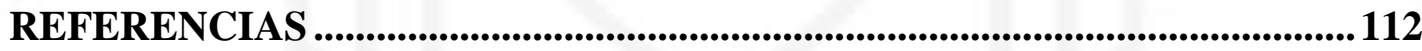

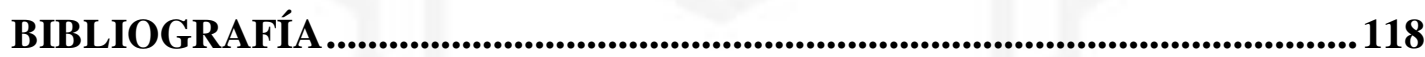




\section{ÍNDICE DE TABLAS}

Tabla 2.1.1 Líderes mundiales en la fabricación de plástico........................................ 15

Tabla 2.1.2 Rivalidad entre firmas establecidas en el mercado .................................... 16

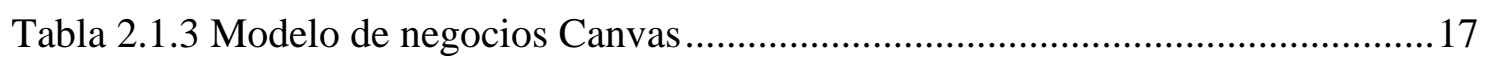

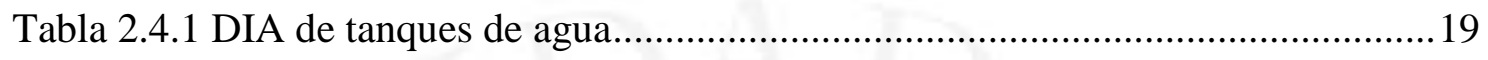

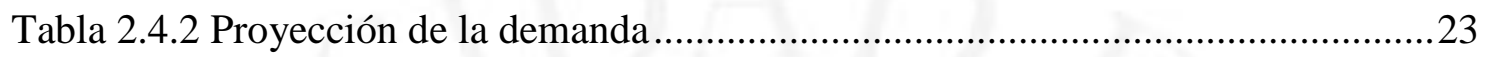

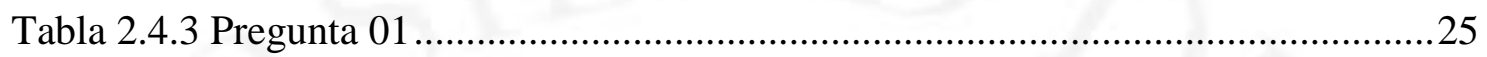

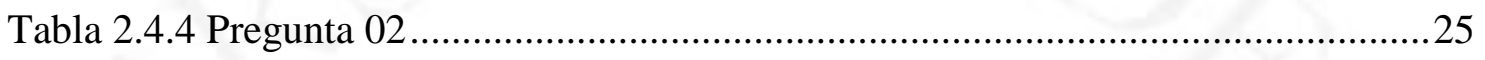

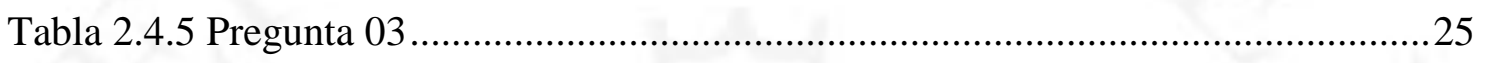

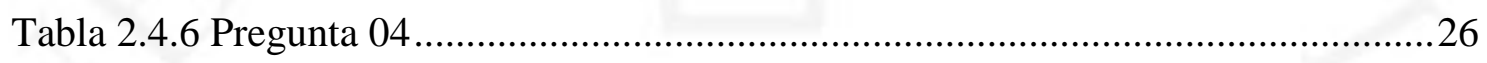

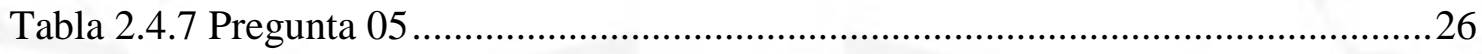

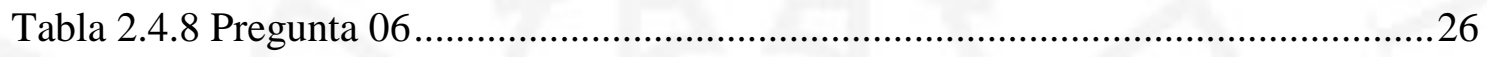

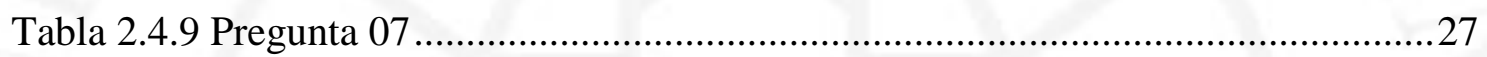

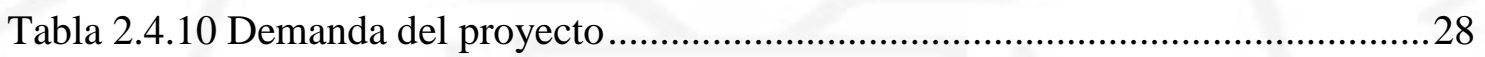

Tabla 2.5.1 Participación de mercado ..................................................................28

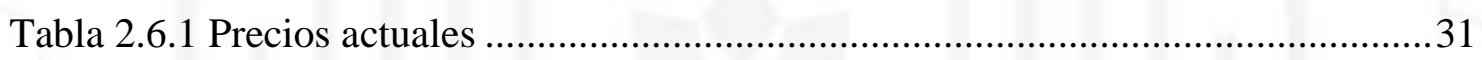

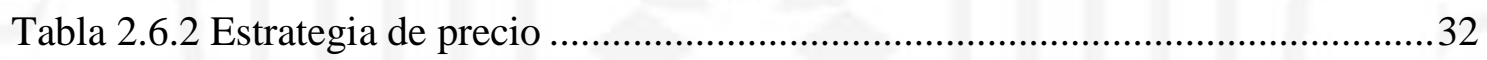

Tabla 3.2.1 Alternativas de la micro localización ............................................................36

Tabla 3.3.1 Enfrentamiento de factores - macro localización ......................................37

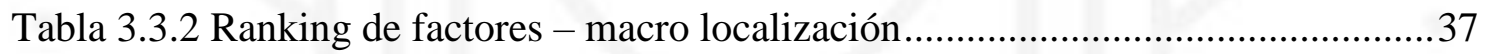

Tabla 3.3.3 Enfrentamiento de factores - micro localización........................................38

Tabla 3.3.4 Ranking de factores - micro localización ................................................ 38

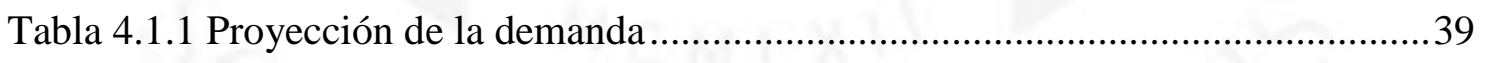

Tabla 4.2.1 Kilogramos de materia prima ............................................................. 40

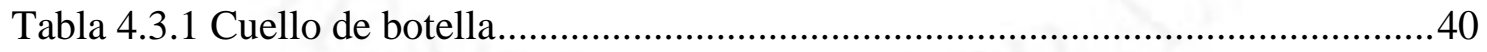

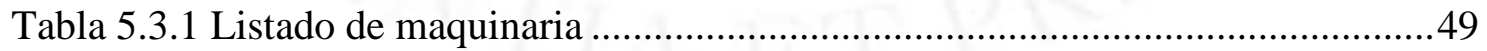

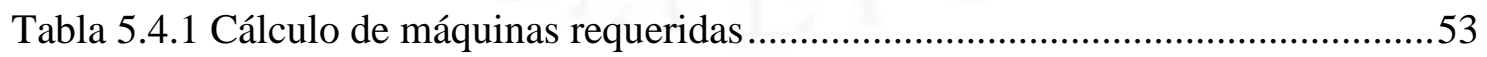

Tabla 5.4.2 Cálculo de la capacidad instalada .........................................................54

Tabla 5.6.1 Matriz de aspectos e impactos ambientales...............................................56

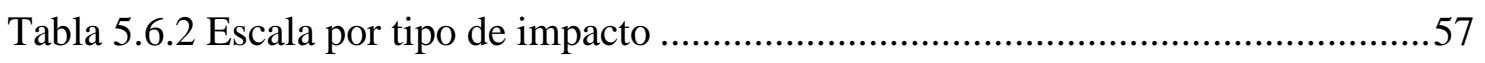

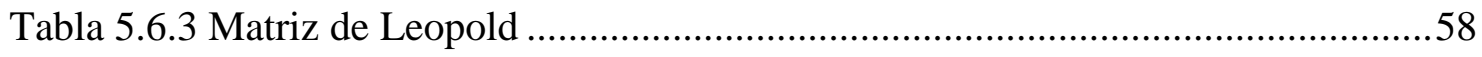


Tabla 5.7.1 Matriz IPERC

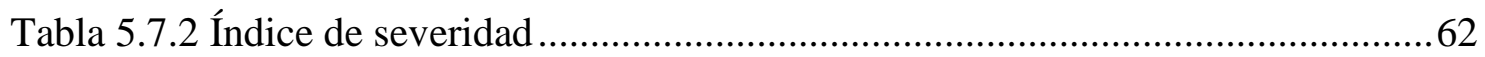

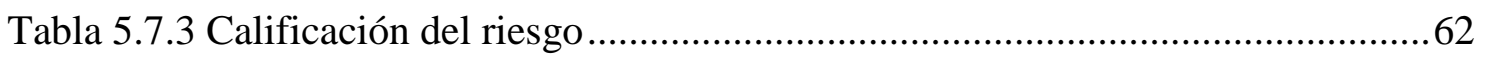

Tabla 5.8.1 Mantenimientos autónomos y preventivos...............................................63

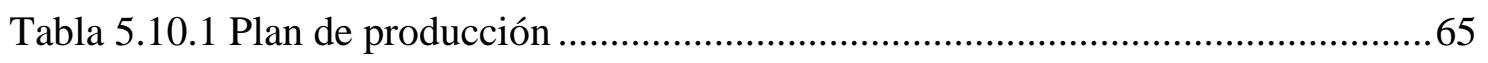

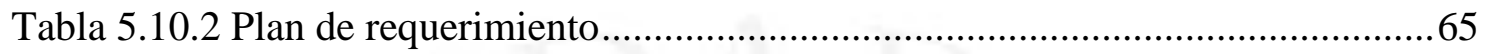

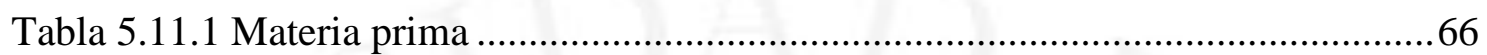

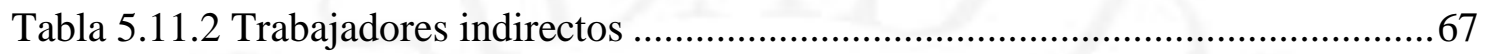

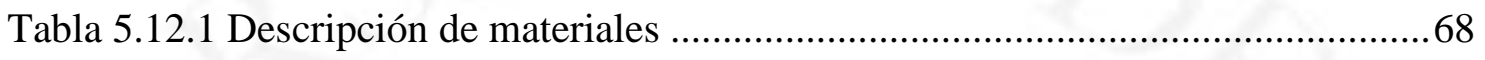

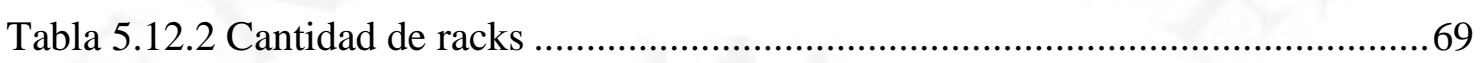

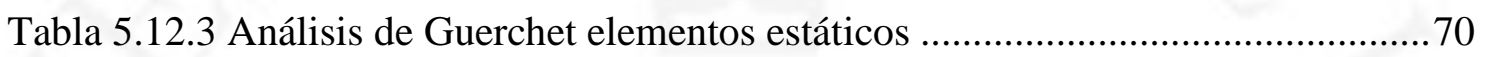

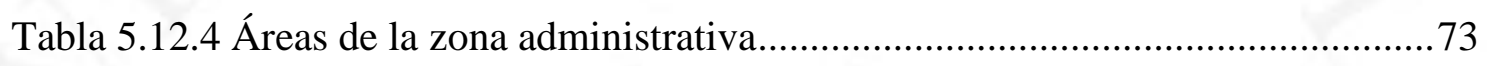

Tabla 5.12.5 Áreas de la zona de producción.................................................................74

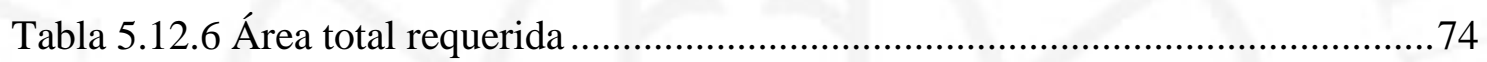

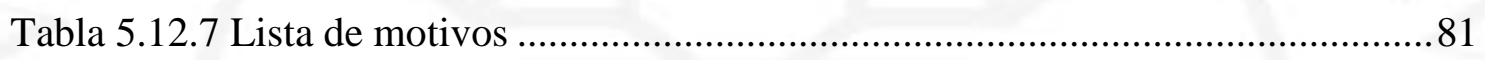

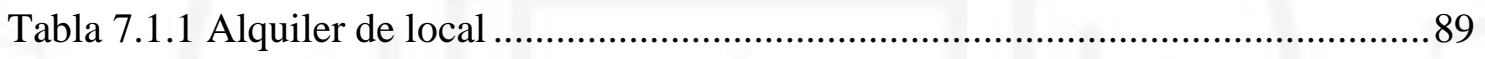

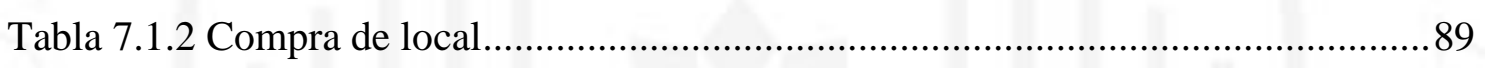

Tabla 7.1.3 Ciclo de conversión de efectivo .........................................................93

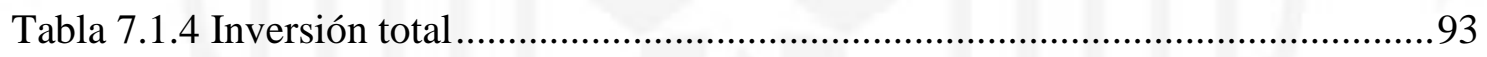

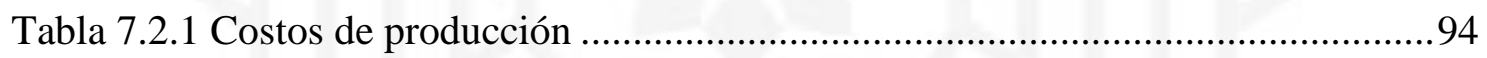

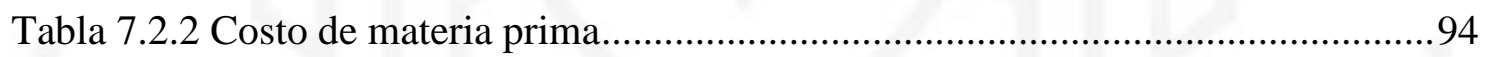

Tabla 7.2.3 Planilla de Remuneraciones MOB …..........................................................95

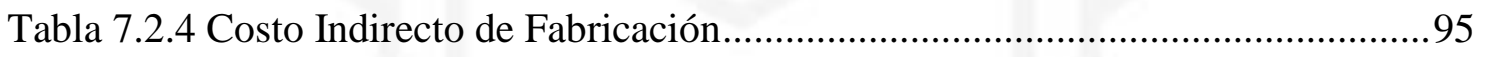

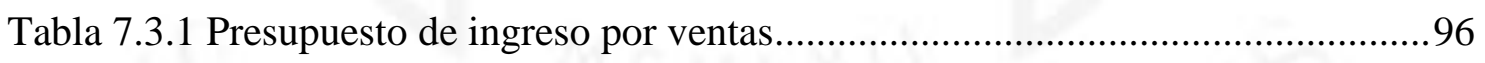

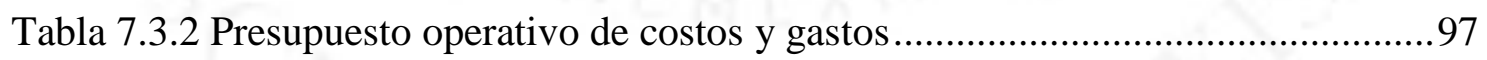

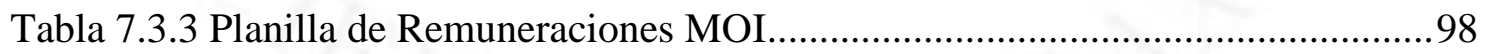

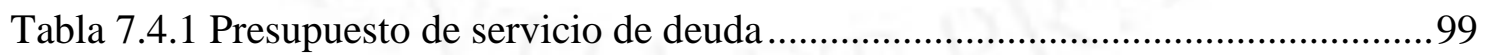

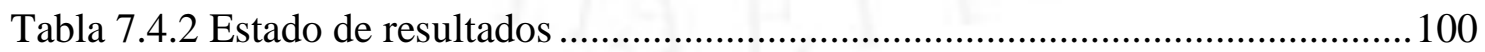

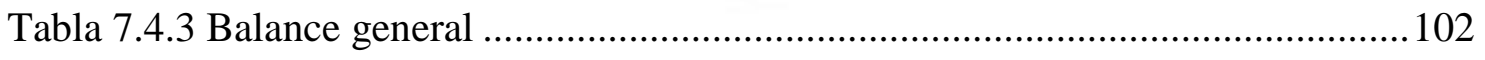

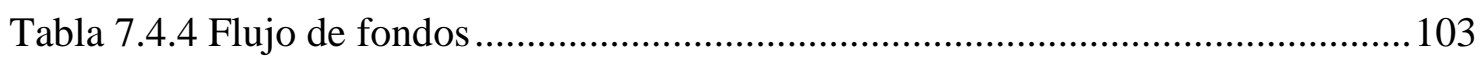

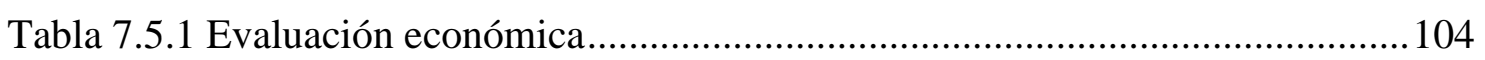

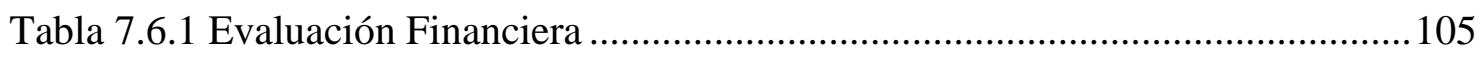

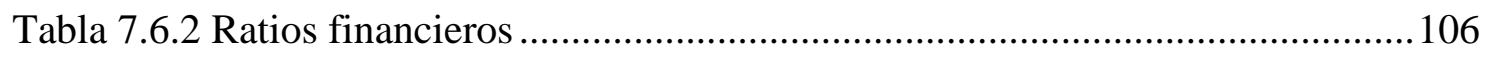


Tabla 8.1.1 Indicadores sociales.

108 


\section{ÍNDICE DE FIGURAS}

Figura 2.4.1 DIA de tanques de agua en el Perú ......................................................20

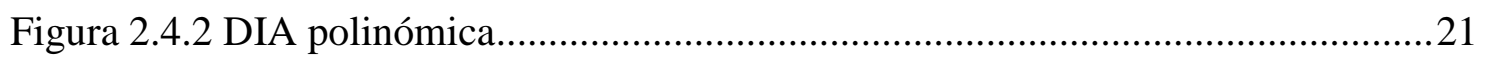

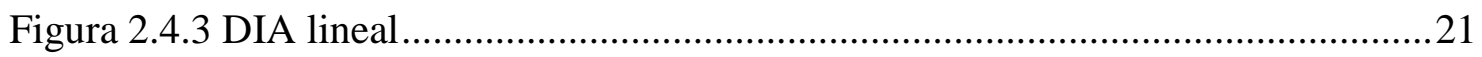

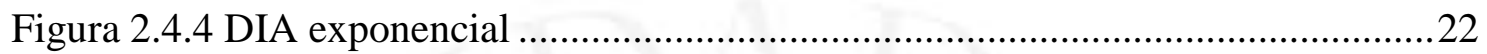

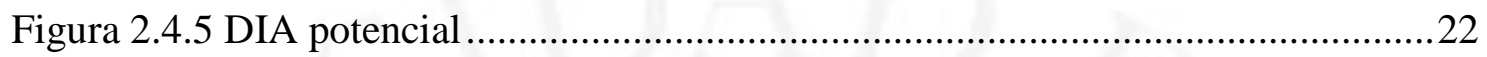

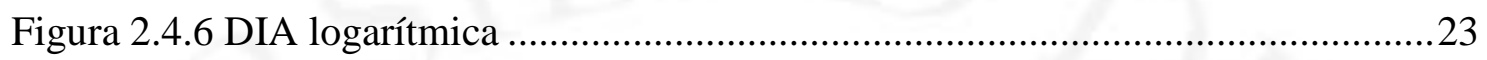

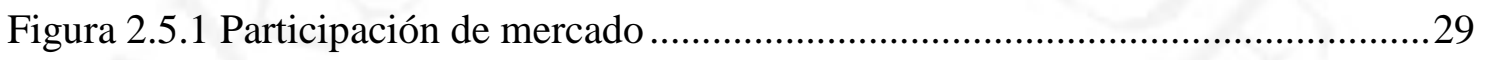

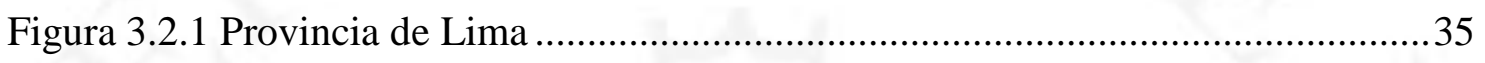

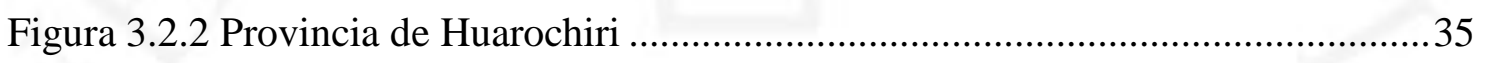

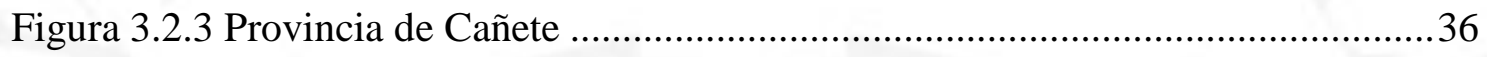

Figura 4.5.1 Selección del tamaño de planta ................................................................

Figura 5.1.1 Diseño del producto - Tanque de agua ................................................ 42

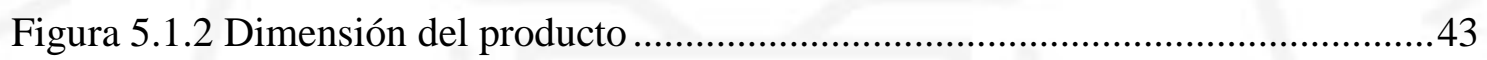

Figura 5.1.3 Diseño del producto - tapa del tanque de agua......................................43

Figura 5.3.1 Horno a llama abierta de roto moldeo para 2 moldes ..............................50

Figura 5.3.2 Molde de tanque de 1,200 Lts ...........................................................50

Figura 5.3.3 Ventilador industrial con aspersor de agua .........................................51

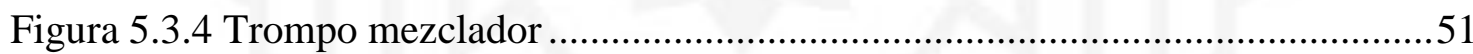

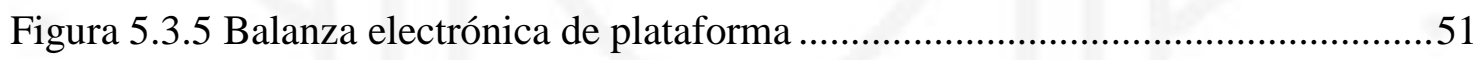

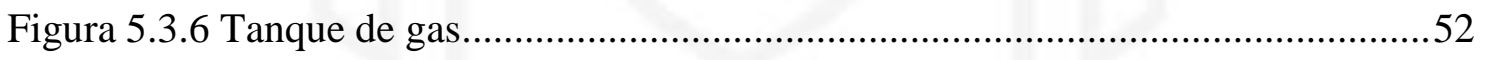

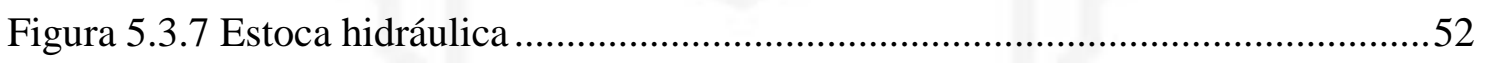

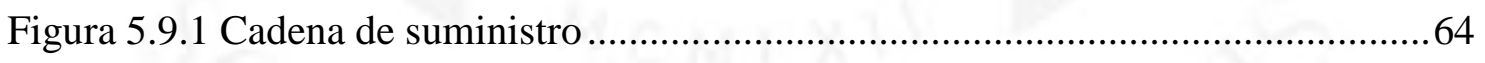

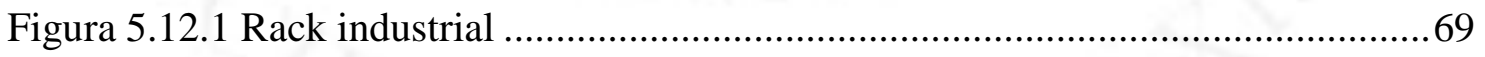

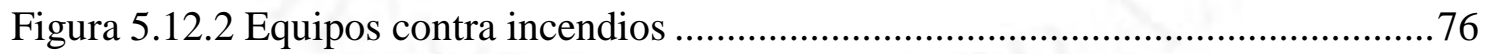

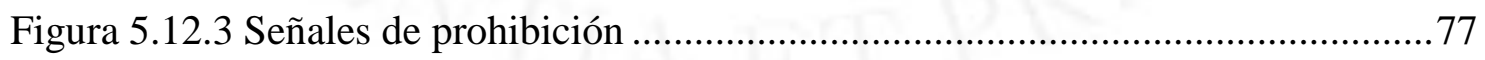

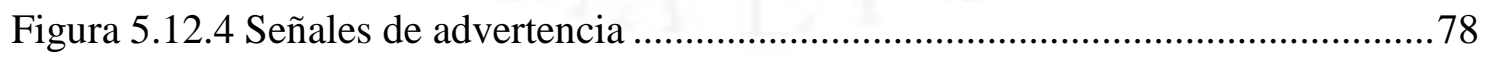

Figura 5.12.5 Señales de obligación .................................................................... 79

Figura 5.12.6 Señales de evacuación y emergencia ................................................ 80

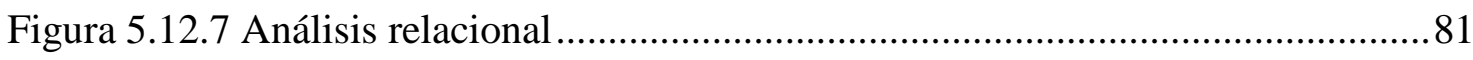

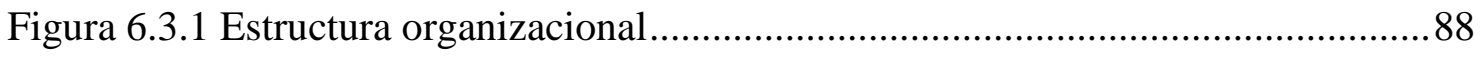




\section{RESUMEN EJECUTIVO}

El presente trabajo de investigación tiene como base el estudio preliminar para la instalación de una planta de tanques de agua cónicos apilables fabricados con polietileno reciclado en su capa exterior. El estudio abarca todos los puntos importantes que se deben considerar para la instalación de una planta nueva mediante el estudio económico, social, ambiental y de ingeniería. Bajo los puntos mencionados se desarrollará la viabilidad del proyecto mencionado.

En el Perú un gran porcentaje de peruanos de bajos recursos no cuenta con una conexión directa de agua potable en su hogar, usualmente tienen recipientes de plásticos no adecuados para almacenar agua que son llenados por camiones cisternas 1 vez a la semana. No todos los peruanos tienen la capacidad económica de adquirir un tanque de agua debido a su alto precio y alto costo en el transporte. El agua potable es un recurso fundamental que todas las personas necesitan para vivir, por ello el producto se enfoca en ser una alternativa accesible, confiable y amigable con el medio ambiente. El producto tiene 3 ventajas en relación a la competencia. Utiliza material reciclado en su exterior para poder disminuir costos en la materia prima, su forma cónica apilable permite reducir costos en el almacenamiento y transporte del mismo. De esta forma se puede lograr un buen producto a un bajo costo.

El presente estudio, apuesta por el desarrollo de una planta de tanques de agua cónicos apilables con material reciclado en su exterior para ayudar a almacenar agua potable a aquellas familias que la necesiten, garantizando que estarán protegidas de enfermedades como el dengue, zika y chikungunya.

Palabras clave:

- Polietileno de baja densidad

- Proceso de rotomoldeo

- Reciclado primario de plástico

- Tanque de agua cónico apilable de polietileno bicapa

- Estrategia de valor medio 


\section{EXECUTIVE SUMMARY}

The present research work is based on the preliminary study for the installation of a stackable conical water tank plant manufactured with recycled polyethylene in its outer layer. This study covers all the important to be considered for the installation of a new plant through economic, social, environmental, legal and engineering studies. Under these points, the viability of the project will be developed.

In Peru, a large percentage of low-income Peruvians do not have a direct connection to potable water in their home, they usually use unsuitable plastic containers to store water that are filled by tanker trucks once a week. Not all Peruvians have the economic capacity to acquire a water tank due to its high price. Drinking water is a fundamental resource that all people need for living, that is why this product is a good alternative, reliable and environmentally friendly. The product has 3 advantages in relation to the competition. It uses recycled material in its outer layer to reduce costs in the raw material, its stackable form allows to reduce costs in the storage and in transport. In this way you can achieve a good product at low cost.

The present study is committed to the development of a stackable conical water tank plant that can to help store potable water for those families that need it, guaranteeing that they will be protected from diseases such as dengue, zika and chikungunya.

Keywords:

- Low density polyethylene

- Rotational molding process

- Primary plastic recycling

- Bilayer polyethylene stackable conical water tank

- Medium value strategy 


\section{CAPÍTULO I: ASPECTOS GENERALES}

En el presente capítulo se detallarán aspectos tales como la problemática a resolver, el marco referencial, el marco conceptual, la hipótesis, los objetivos, el alcance de la investigación y la justificación tecnológica, económica y social.

\subsection{Problemática}

En el Perú el consumo de agua aproximado por persona es de 250 litros por día, alrededor de 50\% más que en Madrid (RPP Noticias, 2014). Este promedio de consumo se ve favorecido por los estratos de nivel socioeconómicos A1 y A2 que llegan a tener un consumo de hasta 447.5 litros por día (Sunass, 2017), cuando la cantidad mínima que se requiere por persona es de 50 litros diarios (ONU, 2013) y la cantidad óptima es de 100 litros diarios (ONU, 2013); sin embargo, el 85.4\% (APEIM, 2017) de la población peruana compuesta en su mayoría por los niveles socioeconómicos C, D y E, no llegan ni a la cantidad optima de 100 litros diarios, el consumo mínimo promedio es de hasta 15.2 litros en la ciudad de Lima.

En las ciudades fuera de Lima como en Utcubamba del departamento del Amazonas, las personas cuentan con servicio de agua potable solo dos horas por semana (RPP Noticias, 2017), esto los obliga a tomar agua del río Utcubamba, lo que les provoca enfermedades como diarrea, cólera y tifoidea (RPP Noticias, 2017). Del mismo modo, distintas familias en el Perú compran agua a los camiones cisternas y al no ser almacenadas en recipientes adecuados, se exponen a enfermedades como diarreas, hepatitis A, tifoidea, cólera, etc. También, al no ser recipientes con cierre hermético generan la proliferación de los mosquitos como el dengue, chikungunya y el zika.

Actualmente, en el Perú hay 32,019,925 habitantes y 8,616,618 hogares (APEIM 2017), de los cuales el $25.7 \%$ es de NSE C; $24.10 \%$ es de NSE D y $35.7 \%$ es de NSE E y el 43.6\% (APEIM, 2017) no cuentan con acceso directo a la red pública para el abastecimiento de agua potable. Por lo tanto, el producto buscará cubrir la necesidad de satisfacer a sus clientes al permitirles almacenar agua potable en un contenedor de gran 
capacidad, buena calidad y a un precio muy accesible, esto les permitirá almacenar agua y poder utilizarla las 24 horas todos los días.

\subsection{Objetivos de la investigación}

\section{- Objetivo general}

Determinar la viabilidad de mercado, tecnológica, social, económica y financiera para la implementación de una planta de tanques de agua cónicos apilables de polietileno reciclado en su exterior.

- Objetivos específicos

- Realizar un estudio de mercado para conocer usos y hábitos del público objetivo.

- Determinar la mejor localización para la implementación de una planta de tanques de agua cónicos apilables de polietileno reciclado en su exterior.

○ Evaluar la viabilidad tecnológica del proyecto.

- Evaluar económica y financieramente el proyecto.

\subsection{Alcance de la investigación}

- Unidad de análisis

La unidad de análisis del estudio, es un tanque de agua cónico apilable de polietileno reciclable en su exterior. El producto competirá con el tanque de agua de polietileno convencional que se vende actualmente en el mercado peruano.

- Población

La población a la que está dirigida el producto son personas con estilos de vida progresistas, adaptados y conservadoras de bajos recursos, que desean cubrir su necesidad de contar con agua potable todos los días del año.

\section{- Espacio}

El desarrollo del estudio de mercado y de la localización de la planta se realizará en Lima Metropolitana. 


\section{- Tiempo}

El tiempo estimado que tomara realizar el estudio de pre factibilidad es de 5 meses, el cual involucra varios aspectos como el tecnológico, económico, financiero y de mercado. Además, en el supuesto de implementar la planta del proyecto, se calculó un tiempo de 279 días, las etapas del proyecto de implementación son las siguientes:

○ Estudio de pre factibilidad

- Constitución de la empresa

○ Financiamiento

- Adquisición del terreno

- Licencia de construcción

- Instalaciones básicas

- Construcción de cimientos

- Construcción de la nave industrial

- Adquisición de maquinaria

○ Instalación de equipos

○ Equipamiento de toda la planta

- Instalaciones de servicios auxiliares

- Reclutamiento y selección de personal

○ Inducción y capacitación del personal

- Prueba de planta

\section{- Limitaciones de la investigación}

Las limitaciones que se presentarán durante la investigación son dos. La primera limitación es el de poder ubicar y llegar a las personas correctas para poder analizar al público objetivo. La segunda limitación es la de poder realizar un buen muestreo probabilístico que de un resultado que refleje con exactitud los diferentes escenarios del proyecto.

\section{$1.4 \quad$ Justificación del tema}

\section{- Técnica}

El proceso que más se adecua de la industria es el de roto moldeo. La ventaja de dicho método es su capacidad de fabricar productos grandes de una sola pieza. Usualmente la 
materia prima empleada en este proceso tiene mayor tiempo de vida útil, la mayoría de estas piezas luego de ser roto moldeadas son prácticamente productos terminados. Este proceso es muy usado para la fabricación de tanques de agua, casas de perros, kayaks, coolers, mesas, sofás, sillas, basureros, etc.

Otra ventaja es su capacidad de poder trabajar con distintos tipos de moldes y de colores. El cambio del molde es sencillo y rápido, se puede realizar en minutos y el cambio de color también, no necesita de limpieza previa. Finalmente, la máquina es sencilla de operar.

\section{- Económica}

El 70\% del producto será fabricado con material reciclado para poder disminuir el costo de fabricación. La forma cónica del producto permite poder apilarlos uno adentro del otro para poder disminuir los costos de distribución y de almacenaje. Por otro lado, no se necesita de personal calificado para el proceso de manufactura. Finalmente, se busca minimizar los costos del producto en diferentes aspectos, para poder ofrecer un precio bajo adecuado para el público objetivo.

- Social

El principal beneficio social es otorgarles a las personas de bajos recursos la posibilidad de almacenar agua en sus viviendas. Adicionalmente, se generarán puestos de trabajo de vigilantes, choferes, almaceneros, operarios no calificados, ayudantes, etc. Apoyando el desarrollo de la zona en la cual la fábrica se instale.

\section{- Ambiental}

El proyecto utilizara material reciclado como fuente de materia prima principal para fabricar tanques, lo que permite reducir la contaminación ambiental. Además, de contar con un proceso productivo limpio.

\subsection{Hipótesis de trabajo}

La implementación de una planta de tanques de agua cónicos apilables de polietileno reciclado en su exterior es factible, pues existe un mercado que tiene la necesidad de adquirir el producto y además es tecnológica, económica y financieramente viable. 


\subsection{Marco referencial}

- Tesis

Estudio de pre factibilidad para la implementación de una planta de producción y comercialización de escamas de PET reciclado. Juan José Marina Casique. Junio, 2009.

○ Resumen

Fabricación de escamas de PET reciclado utilizando como materia prima envases de material PET, utilizando como maquinaría principal una extrusora con un secador granulador para la fabricación de las escamas de PET reciclado.

○ Similitudes

Utilizar plástico reciclado como materia prima y ventas a todo el Perú.

○ Diferencias

No fabricar un producto para consumidor final, utilizar PET, importación de la maquinaria a utilizar, método de fabricación por extrusión y secador granulador y costo elevado de maquinaria.

- Tesis

Estudio de pre factibilidad para la elaboración de fibra de poliéster a partir de botellas desechadas de bebidas gaseosas. Ruiz Ruiz, Mariano Fernando. Mayo, 2001.

○ Resumen

Fabricación de fibra de poliéster utilizando como materia prima botellas de material PET, utilizando como maquinaria principal una extrusora para la fabricación de la fibra de poliéster.

○ Similitudes

Utilizar plástico reciclado como materia prima y ventas a todo el Perú.

○ Diferencias

No fabricar un producto para consumidor final, utilizar PET, importación de la maquinaria a utilizar, método de fabricación por extrusión y costo elevado de maquinaria.

\section{- Tesis}

Estudio de pre factibilidad para la instalación de una planta productora de parihuelas de madera plástica. Fernando Davia Vargas Figuero, Carlos Bismov Surco Valencia. Octubre, 2014. 
○ Resumen

Fabricación de parihuelas de madera plástica utilizando como materia prima polietileno y madera, utilizando como maquinaría principal una inyectora.

○ Similitudes

Utilizar plástico reciclado como materia prima, utilizar polietileno y producto voluminoso.

\section{○ Diferencias}

No fabricar un producto para consumidor final, utilizar madera reciclada como materia prima, método de fabricación por inyección, importación de la maquinaria a utilizar y costo elevado de maquinaria.

\section{- Publicación científica}

Bregar, B. (2010). Rotomolding called a low-cost process. Plastics News, 22(11), 151NULL. Recuperado de: http://search.ebscohost.com/login.aspx?direct=true\&db=b9h\&AN=51796100\&lang=es \&site=ehost-live

\section{○ Resumen}

La atracción más fuerte del roto moldeo siempre será su costo bajo tanto en sus máquinas como en los moldes. Lo bueno es la libertad de diseño, su fabricación flexible, la capacidad de fabricar diferentes tamaños de moldes en diferentes tamaños de brazo sin límites de tamaño de piezas. Lo malo son sus tiempos de ciclos lentos, depender de 1 solo material "Polietileno", la dependencia temperatura del aire, los cambios en la temperatura y en la humedad. Lo feo son que los fabricantes piden nuevas tecnologías, pero a menudo no están dispuestas a pagar por ella. La tecnología más eficiente es la IRT, que mide la temperatura del molde y envía la data al controlador.

\section{- Publicación científica}

Díaz, S., Ortega, Z., McCourt, M., Kearns, M. P., y Benítez, A. N. (2018). Recycling of polymeric fraction of cable waste by rotational moulding. Waste Management, 76, 199206. Recuperado de: https://doi.org/10.1016/j.wasman.2018.03.020 
○ Resumen

Cada año grandes cantidades de cables se convierten en residuos, recicladores de cables se han enfocado en recuperar los metales de estos residuos, y los polímeros los vierten en rellenos sanitarios o son incinerados. Por lo tanto, se realizaron diversos estudios utilizando estos residuos, con polietileno virgen, estudiando el comportamiento mecánico de las partes en su tracción, flexión e impacto. Se encontró que, aunque las propiedades mecánicas se reducen con la utilización del material reciclado, se puede utilizar hasta $35 \%$ de residuos sin una disminución importante en las propiedades mecánicas.

Finalmente, el uso de múltiples capas en las molduras permitió obtener una mejor apariencia externa sin comprometer las propiedades mecánicas.

\section{- Publicación científica}

Huda, Z. (2017). Chapter 6: Plastic Molding Processes. Foundations of Materials Science y Engineering, 93, 83-96. Recuperado de: http://search.ebscohost.com/login.aspx?direct=true \&db=egs\&AN=131446036\&lang=es $\&$ site $=$ ehost-live

\section{○ Resumen}

El moldeo rotacional es un proceso que se utiliza mayormente para fabricar piezas huecas. En este proceso la resina en polvo o en líquido se coloca dentro del molde hueco, que luego es rotada de forma biaxial dentro del horno. El proceso de roto moldeo finaliza cuando la resina se derrite y cubre todas las cavidades del molde. La fuerza centrífuga empuja el material derretido hacia las paredes del molde. Para poder mantener un espesor parejo en toda la pieza, el molde continúa girando durante todo el proceso tanto de calentado como de enfriado para evitar huecos y deformaciones. El moldeo rotacional puede utilizarse para fabricar: kayaks, tanques, juegos de niños, etc. Este proceso ofrece a los diseñadores la flexibilidad de fabricar moldes con insertos, curvas, contornos, así como también logos y huecos para insertar piezas plásticas o metálicas. El costo de las herramientas es bajo a comparación del inyectado o soplado. Los resultados son costos bajos para start-up’s y producción rentable. 


\subsection{Marco conceptual}

- Bicapa

Producto compuesto por 2 capas, capa interna en contacto con el agua potable y capa externa en contacto con el exterior.

\section{- Capa externa}

Capa exterior del producto que se fabricará con materia prima reciclada y estará en contacto con el exterior.

- Capa interna

Capa interior del producto que estará en contacto con el agua, se fabricará con materia prima $100 \%$ virgen.

\section{- $\quad$ Aditivo UV8}

Aditivo que protegerá el interior del producto hasta una escala de 8 en la intensidad de la radiación ultravioleta.

- Aditivo antimicrobiano

Aditivo que protegerá el interior del producto contra las bacterias y microbios.

- Fusión primaria

Primera fusión bajo el sistema de roto moldeo de la capa externa.

- Fusión secundaria

Segunda fusión bajo el sistema de roto moldeo de la capa interna, seguida de la fusión primaria.

- Cónico apilable

El producto tiene una forma cónica que le permite ser apilable.

- Polietileno de baja densidad (PEBD)

Polietileno ramificado que se obtiene a partir del etileno. Es flexible, no tóxico, liviano e inerte. 
- FDA

Agencia de los Estados Unidos que se encarga de regular los alimentos, medicamentos, cosméticos y aparatos o envases que tengan relación directa con los productos para el consumo humano.

- Reciclado primario de PEBD

PEBD puro reciclado en polvo que no ha sido degradado.

- TQ

Unidad de medida que se empleara para interpretar 01 tanque de agua cónico apilable con polietileno reciclado en su exterior. 


\section{CAPÍTULO II: ESTUDIO DE MERCADO}

En el presente capitulo se definirán los diferentes aspectos del estudio de mercado, se explicará la metodología a emplear para la investigación, se definirá la demanda del proyecto, se analizará la oferta y se definirá una estrategia de comercialización.

\subsection{Aspectos generales del estudio de mercado}

\subsubsection{Definición comercial del producto}

Tanque de agua cónico apilable de polietileno reciclado en su exterior y polietileno virgen en su interior para el almacenamiento de agua; con una capa negra externa reciclada que protege al tanque de los rayos UV, una capa blanca interna antimicrobiana que facilita su limpieza y evita la adherencia de cualquier tipo de bacterias, hongos o parásitos.

\section{- Básico}

Contenedor para almacenar agua y proveer a los hogares de la misma. Satisface la necesidad básica de contar con agua diariamente.

\section{- Real}

Tanque de agua cónico apilable de polietileno reciclado en su exterior de 1,200 Lts de capacidad. Este tanque es de color negro por fuera y blanco por dentro. Además, tiene el logo de la marca en alto relieve.

El tanque de polietileno consiste de una capa interna que estará en contacto con el agua y una capa externa que estará en contacto con el medio ambiente. La capa interna es de polietileno de baja densidad virgen aprobado por la FDA americana, su composición no altera el sabor u olor del agua. Esta tiene un aditivo de protección solar UV8 y un aditivo antimicrobiano que evita la adherencia de cualquier tipo de bacterias, hongos o parásitos. La capa externa es de polietileno reciclado con pigmento negro, este color genera más opacidad dentro del tanque para poder brindar mayor protección contra los rayos UV y evitar la formación de algas dentro de él. 
El tanque es resistente al sol, aire y a otros agentes, a los golpes, es liviano y apilable, lo que facilitará su transporte e instalación; cuenta con una tapa a presión que asegura el correcto cierre de la tapa para poder conservar el agua con la mejor calidad.

\section{- Aumentado}

Por último, el producto final contará con un código QR el cual, al ser escaneado mediante teléfonos celulares inteligentes, podrá mostrar la ficha técnica e información importante de usos, lo que facilitará la difusión de información durante el recorrido del bien por toda la cadena logística, además, se realizaran campañas publicitarias en diversas redes sociales y canales de emisión por internet explicando la correcta instalación y uso del producto, así, se promoverá su publicidad y servirá para capacitar a los futuros clientes que opten por adquirir el producto. Además, cuenta con una página web propia para tener mayor cercanía con los potenciales clientes. También contara con una garantía de 5 años.

\subsubsection{Usos del producto, bienes sustitutos y complementarios}

El producto se utiliza para almacenar agua, además, puede usarse como tanque elevado en los techos de las viviendas conectado directamente a la red pública, en ambos casos estará protegida de hongos y bacterias.

Los tanques cónicos apilables de agua son un bien sustituto de los tanques de agua tradicionales porque cumple con la misma función de almacenar agua. Durante la investigación de mercado surgió un producto con el mismo concepto, pero de material $100 \%$ virgen, es cónico apilable con capacidad de almacenar 2,000 litros de agua, de cuatro capas y de color beige, su marca es "AcquaPlas" y se ofrece en las tiendas de canal moderno al precio de S/ 629.90 (SODIMAC, 2019) y está dirigido a los segmentos NSE A y B. A comparación del producto en mención que va dirigido a los niveles socioeconómicos complementarios. Finalmente, se concluye que la aparición del producto mencionado no representa una amenaza para el proyecto. Los complementos para el tanque son diversos accesorios ferreteros, por ejemplo: filtro con porta filtro, multiconector, tubo visor, tubos de agua y tubos de desagüe. 


\subsubsection{Determinación del área geográfica que abarcará el estudio}

El estudio abarcará la población de Lima Metropolitana. El presente estudio determinará si será posible y viable la fabricación y venta del producto considerando la población limeña actual.

\subsubsection{Análisis del sector industrial}

- Riesgo de ingreso de competidores potenciales

Se requiere de una alta inversión en máquinas, local y camiones para poder llevar a cabo la operación y fabricación de los productos. También, se requiere de un buen conocimiento sobre la fabricación en roto moldeo. La principal barrera de ingreso para los competidores sería la técnica debido a que se requiere de bastante conocimiento sobre el polietileno, sus características y el adecuado proceso de fabricación.

En conclusión, se considera que la amenaza de nuevos participantes es baja debido a que se requiere de dinero y de un buen conocimiento en el proceso de fabricación.

- Poder de negociación de proveedores

La oferta de polietileno, que es la principal y única materia prima del tanque de agua es alta debido a la gran demanda del producto, sin embargo, el poder de negociación de los proveedores es alto, a pesar de que existen diversos proveedores en distintos lugares terminan ofreciendo precios similares. Los líderes en fabricación de plásticos y resinas se presentan en la siguiente tabla. 
Tabla 2.1.1 Líderes mundiales en la fabricación de plástico

\begin{tabular}{|c|c|c|}
\hline Fabricante & Ventas globales & Trabajadores \\
\hline Dow Chemical & $\$ 49$ billones. & 49500 personas. \\
Lyondell Basell & $\$ 33$ billones. & 13000 personas. \\
Exxon Mobil & $\$ 236$ billones. & 75600 personas. \\
SABIC & $\$ 35.4$ billones. & 40000 personas. \\
INEOS & $\$ 60$ billones. & 19000 personas. \\
BASF & $\$ 63.7$ billones & 113000 personas. \\
ENI & $\$ 61.6$ billones & 33000 personas. \\
LG Chem & $\$ 17.8$ billones & 14000 personas. \\
Chevron Phillips & $\$ 13.4$ billones & 5000 personas. \\
Lanxess & $\$ 7.9$ billones & 16700 personas. \\
\hline
\end{tabular}

Fuente: Polymer Database (2019)

\section{- Poder de negociación de compradores}

Los clientes tienen varias marcas de las cuales pueden elegir la que mejor les parezca, a diferentes precios, tamaños y capacidades, no existe sólo una marca de tanques de agua, sino varias en el mercado.

En conclusión, el poder de negociación de los clientes es alto debido a que existen diversas marcas en el mercado.

\section{- Amenaza de productos sustitutos}

Antiguamente se producían tanques de fibra de vidrio, sin embargo, cuando se popularizo el uso de plástico, se comenzó a fabricar tanques de polietileno, sustituyendo la fibra de vidrio y hasta el momento no ha surgido otro material que sustituya al polietileno.

En conclusión, la amenaza de los sustitutos es baja debido a que no existe otra materia prima que pueda reemplazarlo. 


\section{- Rivalidad entre firmas establecidas en el Mercado}

Tabla 2.1.2 Rivalidad entre firmas establecidas en el mercado

\begin{tabular}{|c|c|}
\hline Rotoplast & $\begin{array}{l}\text { Marca mexicana de alto reconocimiento en el mercado peruano. Posee un precio } \\
\text { muy alto y un producto de muy buena calidad. Presencia a nivel nacional. Vende a } \\
\text { través del canal tradicional, canal moderno y directo con el consumidor final por } \\
\text { internet. Hacen envío a domicilio. Son los líderes en el mercado peruano. Solo se } \\
\text { dedican al rubro para almacenaje de agua potable. Segmento de mercado: A1, A2, } \\
\text { B1, B2, C1 y C2. }\end{array}$ \\
\hline Eternit & $\begin{array}{l}\text { Marca del grupo Etex, transnacional europea (Bélgica). Posee un precio alto y un } \\
\text { producto de buena calidad. No tiene presencia a nivel nacional. Vende a través del } \\
\text { canal tradicional y del canal moderno, no vende directo con el consumidor final ni } \\
\text { por internet. No hacen envío a domicilio. Se dedican al rubro de construcción. } \\
\text { Segmento de mercado: A1, A2, B1, B2, C1 y C2. }\end{array}$ \\
\hline Nicoll & $\begin{array}{l}\text { Marca del grupo Aliaxis, transnacional europea (Francia). Posee un precio regular y } \\
\text { un producto de buena calidad. No tiene presencia a nivel nacional. Vende a través } \\
\text { del canal tradicional y del canal moderno, no vende directo con el consumidor final } \\
\text { ni por internet. No hacen envío a domicilio. Se dedican al rubro de conducción de } \\
\text { fluidos. Segmento de mercado: A1, A2, B1, B2, C1 y C2. }\end{array}$ \\
\hline Farplast & $\begin{array}{c}\text { Marca } 100 \% \text { peruana. Posee un precio regular y un producto regular. No tiene } \\
\text { presencia a nivel nacional. Vende a través del canal tradicional, no vende directo } \\
\text { con el consumidor final ni por internet. No hacen envío a domicilio. Solo se } \\
\text { dedican al rubro de tanques de agua, cisternas y biodigestores. Segmento de } \\
\text { mercado: A1, A2, B1, B2, C1 y C2. }\end{array}$ \\
\hline Rotoper & $\begin{array}{l}\text { Marca } 100 \% \text { peruana. Posee un precio regular y un producto regular. No tiene } \\
\text { presencia a nivel nacional. Vende a través del canal moderno, no vende directo con } \\
\text { el consumidor final ni por internet. No hacen envío a domicilio. Son los fabricantes } \\
\text { de las marcas de retail como Sodimac, Promart, Maestro. Segmento de mercado: } \\
\text { A1, A2, B1, B2, C1 y C2. }\end{array}$ \\
\hline
\end{tabular}

Elaboración propia

En conclusión, la rivalidad entre los competidores es baja, ya que ninguno de los competidores actuales ofrece un producto especializado para cubrir la necesidad de almacenar agua potable a un precio accesible para familias de escasos recursos de los NSE C, NSE D y NSE E. 


\subsubsection{Modelo de Negocios}

Tabla 2.1.3 Modelo de negocios Canvas

\begin{tabular}{|c|c|c|c|c|}
\hline Socio clave & Actividades clave & Propuesta de valor & Relaciones con el cliente & Segmento objetivo \\
\hline \multirow[t]{3}{*}{$\begin{array}{c}\text { Proveedor Mexicano de } \\
\text { polietileno virgen. } \\
\text { Proveedor Chino de } \\
\text { polietileno reciclado. } \\
\text { Canales indirectos: ferreterías } \\
\text { y venta online. }\end{array}$} & $\begin{array}{l}\text { Importación de polietileno y } \\
\text { compra local de insumos. } \\
\text { Fabricación del producto } \\
\text { clave. } \\
\text { Distribución a cliente final. }\end{array}$ & \multirow[t]{3}{*}{$\begin{array}{l}\text { Tanques a menor precio que } \\
\text { el mercado con mayor } \\
\text { volumen que la competencia. } \\
\text { Producto con forma cónica } \\
\text { apilable }\end{array}$} & $\begin{array}{c}\text { Crear un vínculo con el } \\
\text { hombre y mujer, el producto } \\
\text { se presenta con practicidad y } \\
\text { seguridad a la hora de } \\
\text { contener el agua de cada día } \\
\text { en los hogares de las personas } \\
\text { o empresas. } \\
\text { Comunicación por redes } \\
\text { sociales, tiendas online. } \\
\text { Folletería con mensajes de los } \\
\text { beneficios del producto, } \\
\text { beneficiando el } \\
\text { posicionamiento del producto. }\end{array}$ & \multirow[t]{3}{*}{$\begin{array}{c}\text { Familias que necesiten un } \\
\text { tanque de agua o estén } \\
\text { dispuestos a adquirir uno. } \\
\text { Personas del NSE C, D y E } \\
\text { que viven en Lima. }\end{array}$} \\
\hline & Recursos clave & & Canales & \\
\hline & $\begin{array}{c}\text { Recursos físicos: maquinaria, } \\
\text { local, almacén, vehículos de } \\
\text { transporte. } \\
\text { Recursos financieros, gastos } \\
\text { de marketing y publicidad. } \\
\text { Recursos humanos: operarios, } \\
\text { vendedores, administradores. }\end{array}$ & & $\begin{array}{l}\text { Canal Indirecto: ferreterías y } \\
\text { venta online. } \\
\text { Canal directo: venta a clientes } \\
\text { finales (personas naturales) }\end{array}$ & \\
\hline \multicolumn{3}{|c|}{ Estructura de costos } & \multicolumn{2}{|c|}{ Fuente de ingresos } \\
\hline \multicolumn{3}{|c|}{$\begin{array}{l}\text { Costos fijos: remuneraciones administrativas (planillas). Gas, luz, agua, internet, teléfono. } \\
\text { Mantenimiento de local. Pago de impuestos. } \\
\text { Costos variables: importación de materia prima. } \\
\text { Comisiones por ventas: Costo de producción y transporte. }\end{array}$} & \multicolumn{2}{|c|}{ Venta de tanques a los clientes finales cubriendo su demanda } \\
\hline
\end{tabular}

Elaboración propia 


\subsection{Metodología a emplear en la investigación de mercado}

En el presente estudio se emplearán encuestas, información de textos y pruebas de campo para poder justificar la viabilidad del estudio. Se realizarán encuestas al público objetivo para poder averiguar si estarían interesados en adquirir el producto y cuál es el precio que pagarían para poder cubrir su necesidad.

Para poder hallar el tamaño de mercado y la participación de la competencia se utilizará la plataforma de Veritrade, de la cual se descargará toda la información acerca de la importación y exportación del polietileno de baja densidad y se filtrará solo a las empresas que están dentro del rubro de la fabricación y comercialización de tanques de agua de polietileno. El proyecto tomará referencias de las empresas Rotoplast, Eternit, Nicoll, Farplast y Rotoper. En la importación de materia prima se considerará un peso de $20 \mathrm{Kg}$. por cada tanque, es decir, la importación total en kilogramos de polietileno de baja densidad se dividirá entre 20 para poder pasar la información en unidades de tanques de agua.

\subsection{Demanda potencial}

\subsubsection{Patrones de consumo}

Existen diversos patrones de consumo que se ven asociados al consumo de tanques de agua en el Perú. La estacionalidad afecta al consumo de los tanques, en los meses de verano, que en el Perú son diciembre, enero, febrero, marzo y abril, se genera un patrón de consumo alto debido a la alta demanda del agua, el resto del año existe un consumo sin estacionalidad. Otro patrón de consumo se genera cuando ocurre algún desastre natural. En el Perú es muy común que se generen huaicos y corten el agua en el área afectada y en esa localidad aumenten las ventas de tanques.

\subsubsection{Determinación de la demanda potencial}

Después de realizar la encuesta al público objetivo, se obtuvo de resultado la siguiente información. De las 384 personas encuestadas 63 afirmaron contar con un tanque de agua en su domicilio y 321 afirmaron no contar con uno. Por ende, el $83.50 \%$ de los hogares limeños es la demanda potencial del proyecto. Según APEIM hay aproximadamente 
2,713,165 hogares en el Lima, de estos hogares el 41\% pertenecen al NSE C, $23.3 \%$ al NSE D y $6.3 \%$ al NSE E. La demanda potencial es la suma de porcentajes del NSE C, D y E que es $70.6 \%$ con el $83.50 \%$ de hogares que mencionaron en la encuesta no contar con un tanque de agua en su hogar. Por ende, la demanda potencial es 1,599,438 hogares en Lima que son personas del NSE C, D y E que no cuentan con un tanque de agua en sus hogares.

\subsection{Determinación de la demanda de mercado}

\subsubsection{Demanda del proyecto en base a data histórica}

Para poder determinar la demanda interna aparente del proyecto se descargó la información completa de la base de datos Veritrade desde enero del 2012 a diciembre del 2018. La partida arancelaria 3901100000 corresponde a la importación de PEBD en kilogramos que solo realizaron los fabricantes de tanques de agua, es decir, Rotoplas, Eternit, Nicoll, Farplast, Rotoper. Se procedió a dividir la cantidad importada en kilogramos entre $20 \mathrm{Kg}$. que es el peso aproximado de cada tanque de agua para pasarlo a unidades de tanques de agua. La partida 3925100000 corresponde la importación y exportación de tanques de agua. En la tabla a continuación se presenta la demanda interna aparente en unidades de los tanques de agua en el Perú desde el año 2012 al 2018.

Tabla 2.4.1 DIA de tanques de agua

\begin{tabular}{|c|c|c|c|c|c|}
\hline Año & Producción & Importación & Exportación & DIA & $\begin{array}{c}\text { \% } \\
\text { Crecimiento }\end{array}$ \\
\hline $\mathbf{2 0 1 2}$ H & 260,891 & 11 & 62 & 260,840 & \\
$\mathbf{2 0 1 3}$ H & 252,758 & 27 & 33 & 252,752 & $-3.20 \%$ \\
$\mathbf{2 0 1 4}$ H & 296,990 & 20 & 65 & 296,945 & $14.88 \%$ \\
$\mathbf{2 0 1 5}$ H & 333,571 & 9 & & 333,580 & $10.98 \%$ \\
$\mathbf{2 0 1 6}$ H & 464,711 & 23 & & 464,734 & $28.22 \%$ \\
$\mathbf{2 0 1 7}$ H & 525,382 & 482 & & 525,864 & $11.62 \%$ \\
$\mathbf{2 0 1 8}$ H & 571,615 & & 87 & 571,528 & $7.99 \%$ \\
\hline
\end{tabular}

Nota: Unidades están en tanques de agua. Fuente: Veritrade (2019)

Elaboración propia

En la siguiente figura se puede observar la demanda interna aparente de los últimos 7 años de los tanques de agua en Perú. 
Figura 2.4.1 DIA de tanques de agua en el Perú

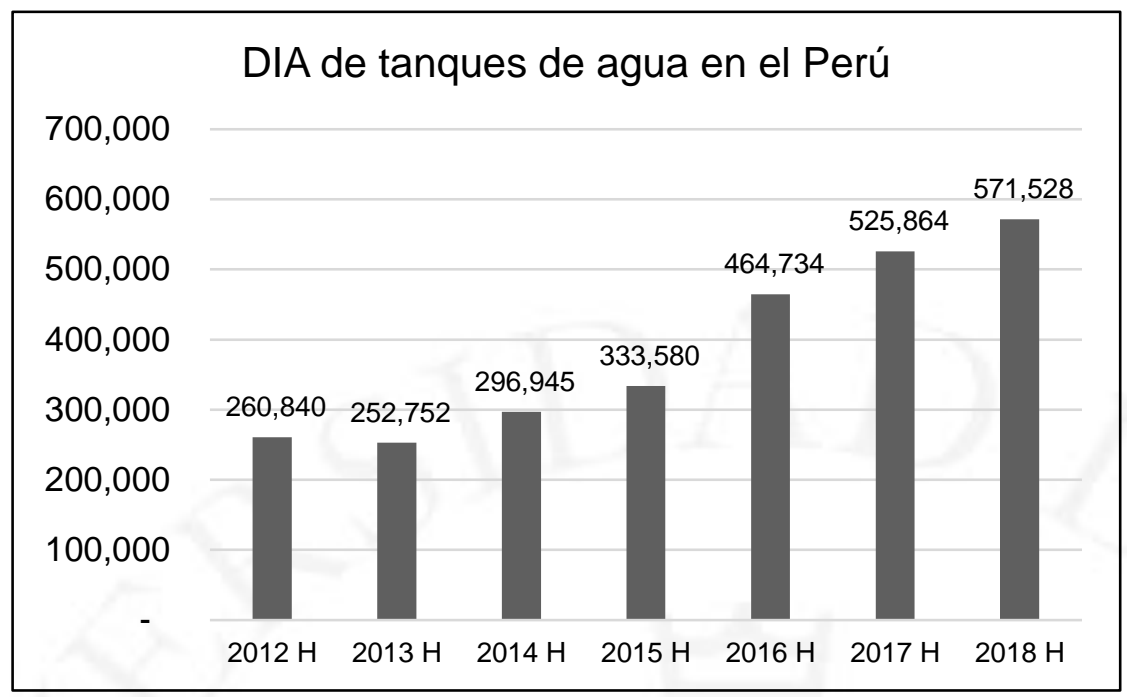

Nota: Unidades están en tanques de agua.

Fuente: Veritrade (2019)

Elaboración propia

\subsubsection{Proyección de la demanda}

Para calcular la demanda del proyecto se utilizará como variable la demanda interna aparente de los últimos 7 años de los tanques de agua en el Perú. Se analizarán diferentes métodos de regresión para la proyección y se utilizará el método que tenga un mejor coeficiente de determinación con un valor no menor a 0.9 entre las variables de tiempo y DIA. 
- Proyección de la demanda utilizando el método de regresión polinómica

Figura 2.4.2 DIA polinómica

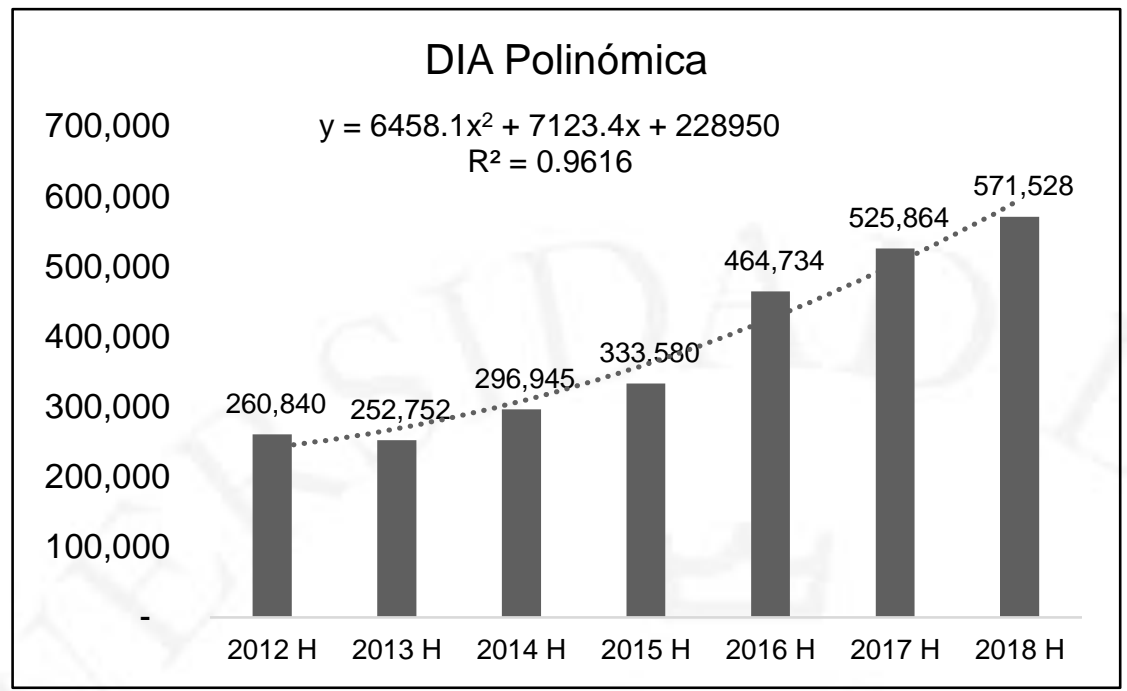

Nota: Unidades están en tanques de agua.

Elaboración propia

- Proyección de la demanda utilizando el método de regresión lineal

Figura 2.4.3 DIA lineal

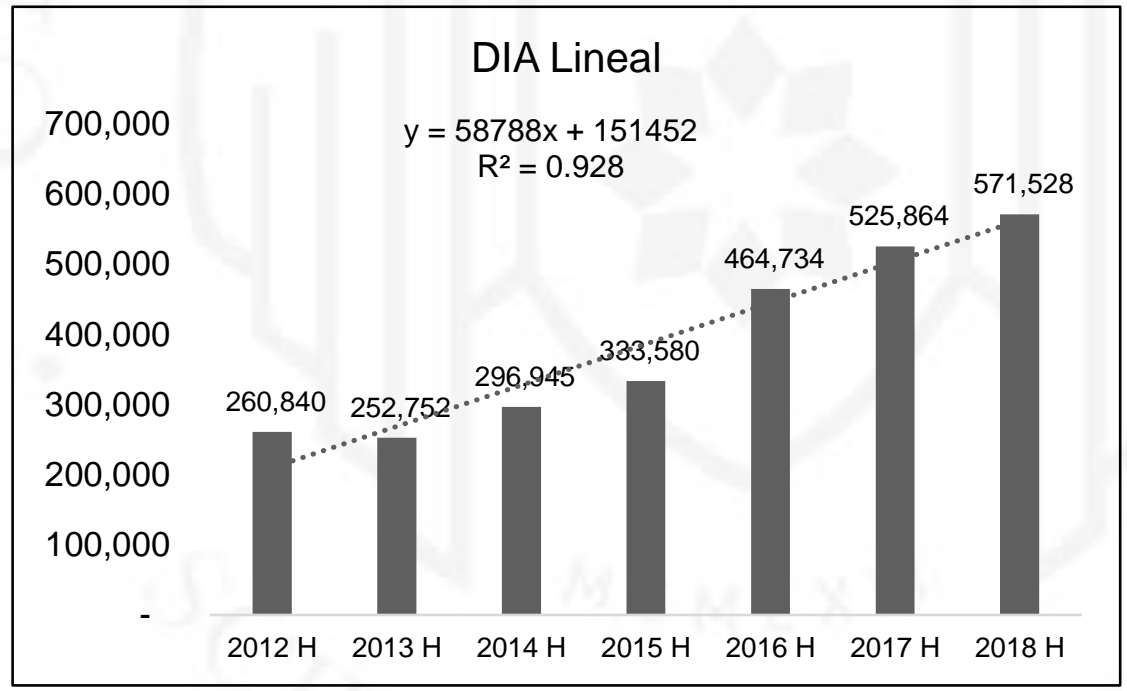

Nota: Unidades están en tanques de agua.

Elaboración propia 
- Proyección de la demanda utilizando el método de regresión exponencial

Figura 2.4.4 DIA exponencial

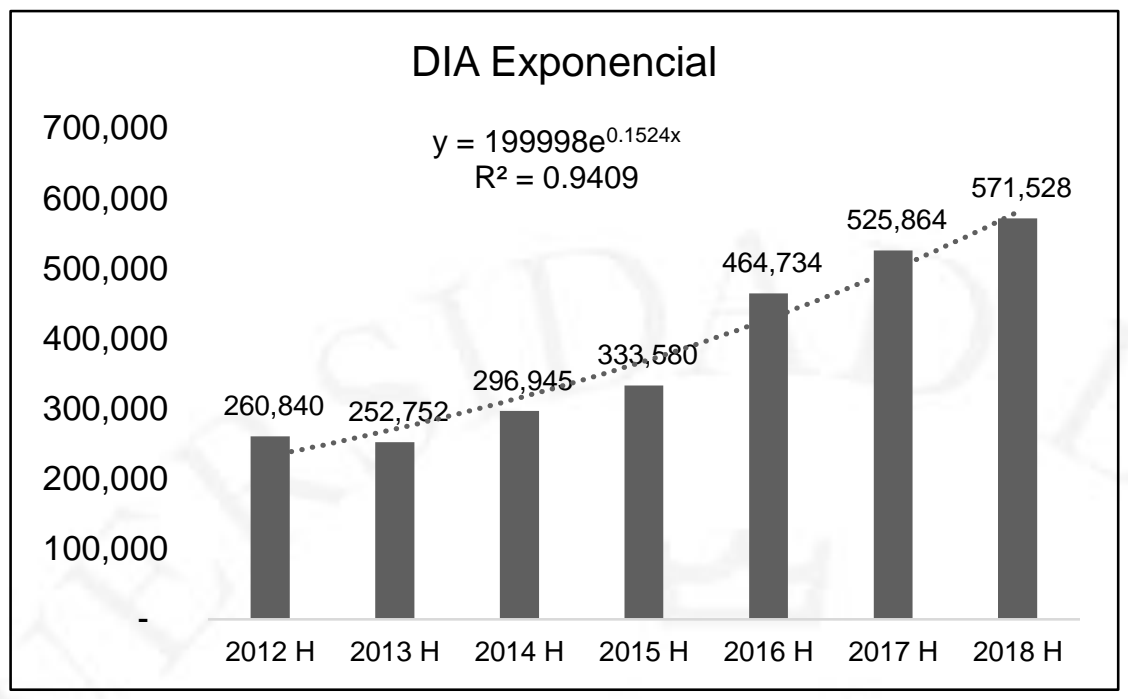

Nota: Unidades están en tanques de agua.

Elaboración propia

- Proyección de la demanda utilizando el método de regresión potencial

Figura 2.4.5 DIA potencial

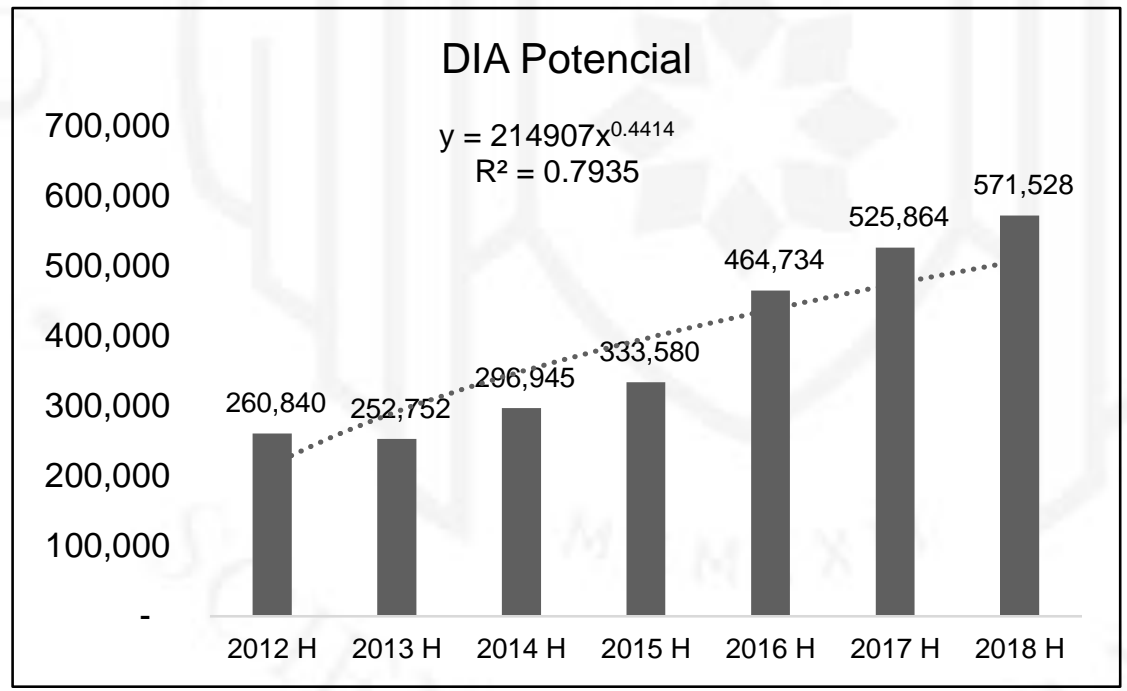

Nota: Unidades están en tanques de agua.

Elaboración propia 
- Proyección de la demanda utilizando el método de regresión logarítmica

Figura 2.4.6 DIA logarítmica

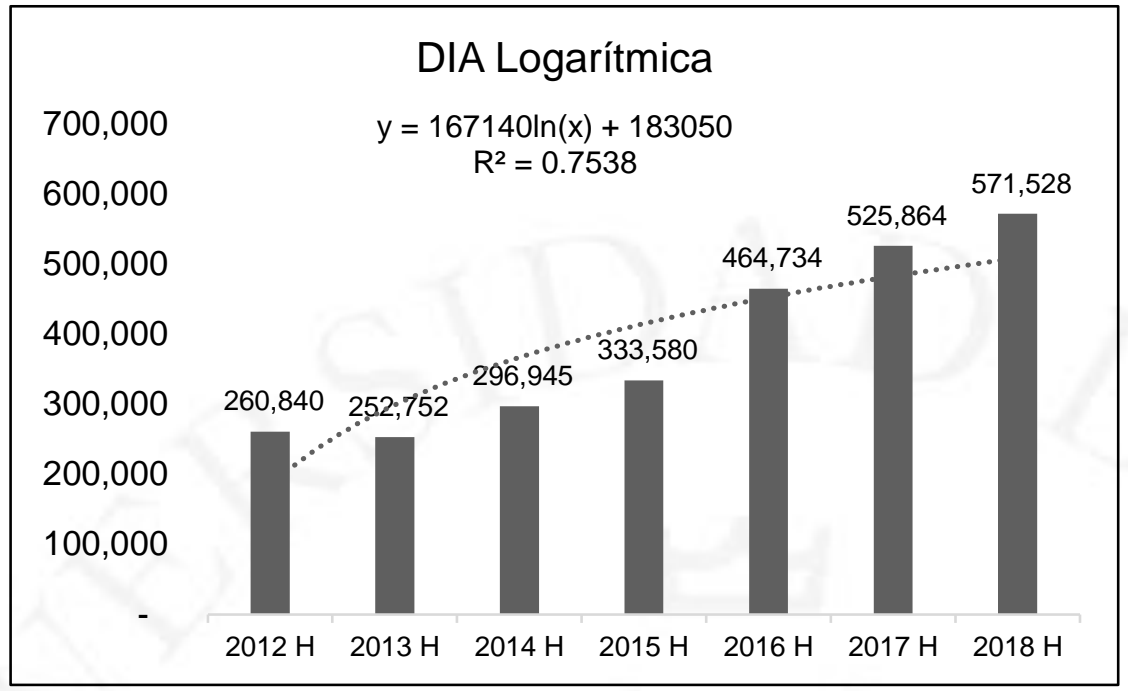

Nota: Unidades están en tanques de agua.

Elaboración propia

Finalmente, la regresión polinómica es la regresión que tiene un coeficiente de determinación mayor con un valor de 0.9616. Siendo su formula la siguiente:

$$
\begin{gathered}
y=6458.1 x^{2}+7123.4 x+228950 \\
R^{2}=0.9616
\end{gathered}
$$

Al reemplazar los años de proyección en la demanda se obtienen los siguientes valores en unidades.

Tabla 2.4.2 Proyección de la demanda

\begin{tabular}{|c|c|c|}
\hline Año & Proyección & $\begin{array}{c}\text { \% } \\
\text { Crecimiento }\end{array}$ \\
\hline $\mathbf{2 0 1 9}$ P & 699,317 & $18.27 \%$ \\
$\mathbf{2 0 2 0}$ P & 816,175 & $14.32 \%$ \\
$\mathbf{2 0 2 1}$ P & 945,953 & $13.72 \%$ \\
$\mathbf{2 0 2 2}$ P & $1,088,652$ & $13.11 \%$ \\
$\mathbf{2 0 2 3}$ P & $1,244,271$ & $12.51 \%$ \\
$\mathbf{2 0 2 4}$ P & $1,412,810$ & $11.93 \%$ \\
$\mathbf{2 0 2 5}$ P & $1,594,270$ & $11.38 \%$ \\
\hline
\end{tabular}

Nota: Unidades están en tanques de agua. Elaboración propia 


\subsubsection{Definición del mercado objetivo}

El producto está dirigido a los NSE C, D y E. En Lima Metropolitana estos segmentos se ubican en las zonas 1, 2, 3, 4, 5, 8, 9 y 10 según la clasificación de APEIM. En cuanto a los estilos de vida el producto estará enfocado a hombres progresistas que son $21 \%$ de la población, hombres adaptados que son el $20 \%$ y a mujeres conservadoras que son el $19 \%$. Por ende, al aplicar esta segmentación el mercado objetivo es de 607,013 hogares en Lima Metropolitana.

\subsubsection{Diseño y aplicación de encuestas}

La encuesta compuesta por 9 preguntas se realizó para adquirir información importante para la elaboración de este proyecto. El propósito es de poder segmentar la demanda del proyecto para determinar el factor de corrección a través de la intensión e intensidad de compra de nuestro público. Además, permitirá elaborar la estrategia comercial para poder llegar al público objetivo ofreciendo un precio que puedan pagar y el lugar de compra donde le gustaría obtener su producto. A los encuestados se les explicó la información completa acerca del producto.

Con la siguiente fórmula de muestreo se procedió a hallar el factor de corrección.

$$
\begin{gathered}
n=\frac{0.5 \times 0.5 \times 607013 \times 1.96^{2}}{0.05^{2} \times 607013+0.5 \times 0.5 \times 1.96^{2}}=384 \\
384=\frac{0.5 \times 0.5 \times 607013 \times 1.96^{2}}{e^{2} \times 607013 \times 0.5 \times 0.5 \times 1.96^{2}} \\
e=0.0499 \\
e \cong 5 \%
\end{gathered}
$$

En conclusión, el error teórico tiene un valor del 5\%. 


\subsubsection{Resultados de la encuesta}

A continuación, se mostrarán los resultados de la encuesta realizada:

¿Cuenta con algún tanque de agua elevado en su casa?

Tabla 2.4.3 Pregunta 01

\begin{tabular}{|c|c|}
\cline { 2 - 2 } \multicolumn{1}{c|}{} & Respuestas \\
\hline $\mathrm{Si}$ & 63 \\
$\mathrm{No}$ & 321 \\
\hline Total & 384 \\
\hline
\end{tabular}

Elaboración propia

¿En qué distrito vive?

Tabla 2.4.4 Pregunta 02

\begin{tabular}{|c|c|}
\cline { 2 - 2 } \multicolumn{1}{c|}{} & Respuestas \\
\hline Zona 1 & 71 \\
Zona 2 & 52 \\
Zona 3 & 22 \\
Zona 4 & 67 \\
Zona 5 & 30 \\
Zona 6 & 38 \\
Zona 7 & 0 \\
Zona 8 & 0 \\
Zona 9 & 0 \\
Zona 10 & 41 \\
\hline Total & 321 \\
\hline
\end{tabular}

Elaboración propia

¿Requiere de un tanque de agua?

Tabla 2.4.5 Pregunta 03

\begin{tabular}{|c|c|}
\cline { 2 - 2 } \multicolumn{1}{c|}{} & Respuestas \\
\hline $\mathrm{Si}$ & 280 \\
No & 41 \\
\hline Total & 321 \\
\hline
\end{tabular}

Elaboración propia 
¿Compraría un tanque de agua con material reciclado en su exterior?

Tabla 2.4.6 Pregunta 04

\begin{tabular}{|c|c|}
\cline { 2 - 2 } \multicolumn{1}{c|}{} & Respuestas \\
\hline $\mathrm{Si}$ & 254 \\
$\mathrm{No}$ & 26 \\
\hline Total & 280 \\
\hline
\end{tabular}

Elaboración propia

¿Cuál sería su probabilidad de compra?

Tabla 2.4.7 Pregunta 05

\begin{tabular}{|c|c|}
\cline { 2 - 2 } \multicolumn{1}{c|}{} & Respuestas \\
\hline 1 & 0 \\
2 & 0 \\
3 & 0 \\
4 & 0 \\
5 & 26 \\
6 & 52 \\
7 & 75 \\
8 & 49 \\
9 & 37 \\
10 & 15 \\
\hline Total & 254 \\
\hline
\end{tabular}

Elaboración propia

¿Qué capacidad de tanque compraría?

Tabla 2.4.8 Pregunta 06

\begin{tabular}{|c|c|}
\cline { 2 - 2 } \multicolumn{1}{c|}{} & Respuestas \\
\hline $650 \mathrm{Lts}$ & 26 \\
$1200 \mathrm{Lts}$ & 254 \\
\hline Total & 280 \\
\hline
\end{tabular}

Elaboración propia 
¿Cuánto está dispuesto a pagar considerando que el tanque de 1100 Lts tiene un precio de mercado de S/. 450.00?

Tabla 2.4.9 Pregunta 07

\begin{tabular}{|c|c|}
\cline { 2 - 2 } \multicolumn{1}{c|}{} & Respuestas \\
\hline S/. 250 & 30 \\
S/. 280 & 56 \\
S/. 350 & 168 \\
S/. 380 & 0 \\
\hline Total & 254 \\
\hline
\end{tabular}

Elaboración propia

Luego de haber analizado las encuestas, la intensidad de compra del público objetivo es del $72.50 \%$ y la intención de compra es del $90.67 \%$.

\subsubsection{Determinación de la demanda del proyecto}

Para calcular la demanda del proyecto se tomaron diferentes factores. Luego de realizar la proyección de la demanda interna aparente en unidades se segmento esta cantidad con el público objetivo de hogares en el Perú que pertenecen a los NSE C, D y E que representan el 70.6\% de hogares en Lima. En seguida se segmento por los estilos de vida progresistas, adaptados y conservadores que representan el 60\% de los hogares en Lima y se aplicó la intensidad e intención halladas en las encuestas.

Finalmente se halló le demanda del proyecto aplicando un $1.72 \%$, esto debido a que de la competencia actual Rotoper es la empresa con menor participación de mercado que se dedica únicamente a la producción y comercialización de tanques elevados de agua de polietileno de baja densidad. 
Tabla 2.4.10 Demanda del proyecto

\begin{tabular}{|c|c|c|c|c|c|c|}
\hline Año & Proyección & NSE C, D y E & $\begin{array}{c}\text { Estilo de } \\
\text { vida }\end{array}$ & Intensidad & Intención & $\begin{array}{c}\text { Demanda del } \\
\text { proyecto } \\
\text { (un.) }\end{array}$ \\
\hline $\mathbf{2 0 1 9}$ P & 699,317 & 493,718 & 296,231 & 268,583 & 194,723 & 3,352 \\
$\mathbf{2 0 2 0}$ P & 816,175 & 576,220 & 345,732 & 313,464 & 227,262 & 3,912 \\
$\mathbf{2 0 2 1}$ P & 945,953 & 667,843 & 400,706 & 363,307 & 263,398 & 4,534 \\
$\mathbf{2 0 2 2}$ P & $1,088,652$ & 768,589 & 461,154 & 418,113 & 303,132 & 5,218 \\
$\mathbf{2 0 2 3}$ P & $1,244,271$ & 878,456 & 527,074 & 477,881 & 346,464 & 5,964 \\
$\mathbf{2 0 2 4}$ P & $1,412,810$ & 997,444 & 598,467 & 542,611 & 393,393 & 6,771 \\
$\mathbf{2 0 2 5}$ P & $1,594,270$ & $1,125,555$ & 675,333 & 612,302 & 443,919 & 7,641 \\
\hline
\end{tabular}

Nota: Unidades están en tanques de agua.

Fuente: Instituto Nacional de Estadística e Informática, INEI (2017).

Elaboración propia

\subsection{Análisis de la oferta}

\subsubsection{Empresas productoras, importadoras y comercializadoras}

Actualmente las marcas como Rotoplast, Eternit, Nicoll, Farplast, Rotoper importan su propia materia prima, producen y comercializan sus propios tanques. La marca Rotoplas es la que lidera el mercado.

\subsubsection{Participación de mercado de los competidores actuales}

La participación de mercado se ha determinado según las importaciones en $\mathrm{kg}$ de polietileno de baja densidad según cada fabricante de los últimos 7 años desde el 2012 al 2018

Tabla 2.5.1 Participación de mercado

\begin{tabular}{|c|c|}
\hline Competidores & $\begin{array}{c}\text { Participación } \\
\text { de mercado }\end{array}$ \\
\hline Rotoplast & $49.88 \%$ \\
Eternit & $23.58 \%$ \\
Nicoll & $22.48 \%$ \\
Farplast & $2.33 \%$ \\
Rotoper & $1.72 \%$ \\
\hline
\end{tabular}

Fuente: Veritrade (2019)

Elaboración propia 
Figura 2.5.1 Participación de mercado

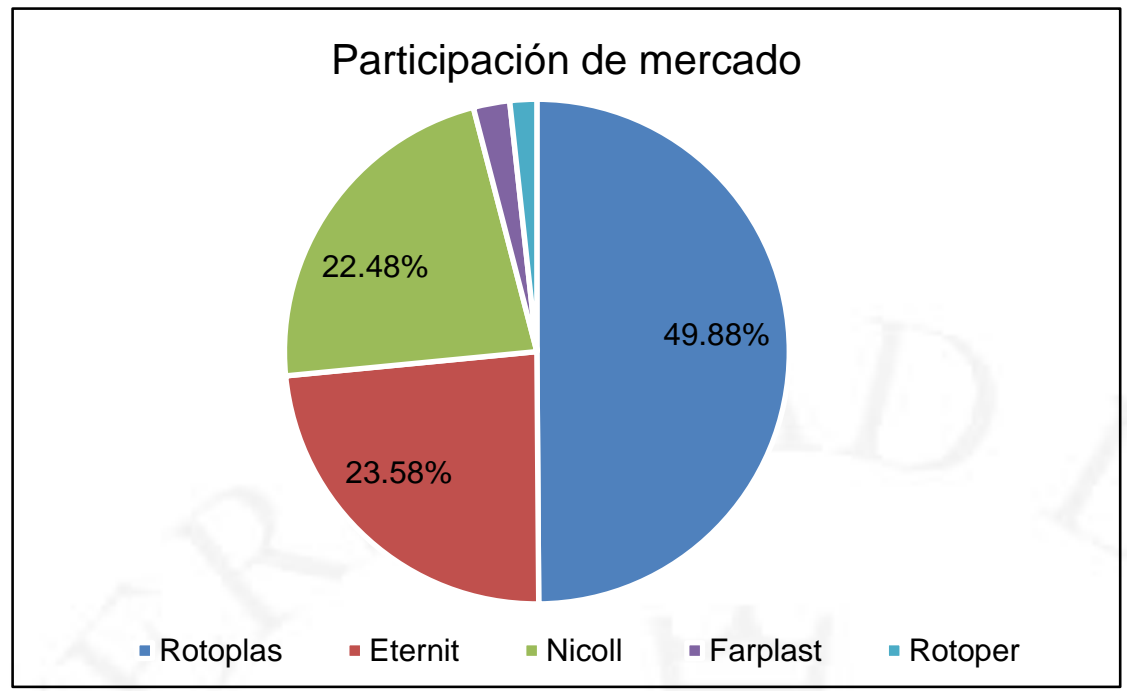

Fuente: Veritrade (2019)

Elaboración propia

\subsubsection{Competidores potenciales si hubiera}

Producir tanques de agua no es una tarea complicada si se cuenta previamente con la maquinaria, el equipo adecuado y el conocimiento previo, por lo tanto, cualquiera de las marcas presentadas en el punto 2.5.2 son competidores potenciales porque ya cuentan con la maquinaría, con el personal, la marca, la experiencia y la fuerza de ventas para introducir el producto.

\subsection{Definición de la estrategia de comercialización}

\subsubsection{Políticas de comercialización y distribución}

Se utilizarán dos canales de venta distinta para realizar la comercialización de este producto. Cada uno de estos canales tendrá sus propias políticas y precios.

- Venta directa

- Ferreterías

Actualmente, los modelos que existen en el mercado de tanque de agua no son apilables y tienen aproximadamente $1 \mathrm{~m}$ de diámetro por lo que ocuparía $1 \mathrm{~m}^{2}$ de espacio. En el Perú las ferreterías son pequeñas tiendas, con espacios muy reducidos. El $70.3 \%$ de ferreterías tiene un tamaño de hasta $28 \mathrm{~m}^{2}$ (IPSOS, 2007). Luego de nuestro análisis de mercado con las ferreterías concluimos que marginan S/ 25.00 por cada tanque de agua 
que venden ocupando $1 \mathrm{~m}^{2}$ de espacio de su ferretería y por lo menos deben comprar 6 unidades para poder obtener buenos precios. La propuesta del proyecto es de incluir el envío del producto en el precio y entregar el producto en el local de la ferretería. En el 2007 había un total de 7,483 ferreterías en todo Lima Metropolitana (IPSOS, 2007). Para la venta directa se trabajará mediante correos, WhatsApp y teléfono directo a la oficina para tomar las ordenes de los pedidos de los clientes.

\subsubsection{Publicidad y promoción}

Para promover el producto se utilizarán diferentes medios digitales para publicitar la marca y el producto. También se publicará una página en la plataforma Facebook para tener un contacto directo con nuestros clientes, mantenerlos al tanto de las últimas ofertas y cuidados del agua y el consumo de la misma. También se utilizará una fuerza de ventas constituidas por 2 vendedores para realizar visitas periódicas a los clientes ferreteros, un vendedor se dedicará a la zona de Lima Metropolitana centro-norte y el otro a la zona de Lima Metropolitana centro-sur. De igual manera, se utilizará la plataforma de Google AdWords y Facebook para promover la página web de compras en línea y así dar a conocer el producto.

\subsubsection{Análisis de precios}

\subsubsection{Tendencia histórica de los precios}

Las marcas de tanques de agua existentes cuentan con dos tipos de tanques, los de color arena simbolizan la línea premium, y de color negro simbolizan la línea estándar.

\section{- Rotoplast}

La marca extranjera Rotoplast tiene un precio fijo de S/. 535.00 (SODIMAC, 2019) sin oferta en su tanque de 1100 Lts. De color arena. Durante el año lanza diferentes campañas y descuentos en donde este precio puede bajar hasta S/.480.00 (SODIMAC, 2019). En el tanque de 1100 Lts. de color negro tiene un precio fijo de S/.425.00 (SODIMAC, 2019) y cuando está en descuento un precio de S/. 380.00 (SODIMAC, 2019). 


\section{- $\quad$ Eternit}

La marca extranjera Eternit tiene un precio fijo de S/. 469.50 (SODIMAC, 2019) sin oferta en su tanque de 1100 Lts. de color arena. Durante el año lanza diferentes campañas y descuentos en donde este precio puede bajar hasta S/. 399.90 (SODIMAC, 2019). En el tanque de 1100 Lts. de color negro tiene un precio fijo de S/.425.00 (SODIMAC, 2019) y cuando está en descuento un precio de S/. 390.00 (SODIMAC, 2019).

- Nicoll

La marca extranjera Nicoll en su tanque de 1100 Lts de color negro tiene un precio fijo de S/.429.90 (Nicoll, 2019), y en el tanque de 1100 Lts de color negro un precio fijo de S/.379.90 (Nicoll, 2019).

- Farplast

La marca nacional Farplast en su tanque de 1100 Lts de color negro tiene un precio fijo de S/.419.00 (Farplast, 2019) y en el tanque de 1100 Lts de color negro un precio fijo de S/.379.90 (Farplast, 2019).

- Rotoper

La marca Rotoper en su tanque de 2000 Lts de color arena tiene un precio fijo de S/.629.90 (SODIMAC, 2019). No cuenta con tanque de agua de 2000 Lts de color negro.

\subsubsection{Precios Actuales}

Los precios actuales en el mercado de la competencia son los siguientes.

Tabla 2.6.1 Precios actuales

\begin{tabular}{|c|c|c|c|c|c|}
\hline Capacidad & Rotoplast & Eternit & Nicoll & Farplast & Rotoper \\
\hline 1100 Lts Negro & S/ 425.00 & S/ 425.00 & S/. 379.90 & S/ 379.90 & S/ - \\
1100 Lts Arena & S/ 535.00 & S/ 469.00 & S/. 429.90 & S/ 419.90 & S/ 629.90 \\
\hline
\end{tabular}

Fuente: SODIMAC (2019); Nicoll (2019); Farplast (2019); Rotoper (2019)

Elaboración propia

\subsubsection{Estrategia de precio}

Luego de realizar la encuesta y comparar los precios analizados de la oferta, lo que busca el proyecto es brindar precios bajos para satisfacer la necesidad del público objetivo sin perjudicar la rentabilidad del negocio. La estrategia de precio que se utilizará será la de 
valor medio debido a que será un producto de calidad media a un precio medio. El tanque de 1200 Lts tendrá un precio de venta fijo de S/ 329.90.

Tabla 2.6.2 Estrategia de precio

\begin{tabular}{|c|c|c|c|c|}
\hline \multirow{5}{*}{ 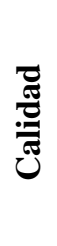 } & \multicolumn{4}{|c|}{ Precio } \\
\hline & & Alto & Medio & Bajo \\
\hline & Alto & Superior & Valor Alto & Súper valor \\
\hline & Medio & Sobre cobro & Valor medio & Buen valor \\
\hline & Bajo & Imitación & Economía falsa & Economía \\
\hline
\end{tabular}

Elaboración propia 


\section{CAPÍTULO III: LOCALIZACIÓN DE PLANTA}

En el presente capitulo se evaluará primero la macro localización y luego la micro localización para poder encontrar la mejor localización para el posicionamiento de la planta.

\subsection{Identificación y análisis detallado de los factores de localización}

\subsubsection{Factores de macro localización}

- Proximidad al terminal portuario (A)

La materia prima de los tanques es el polietileno, tanto virgen como reciclado, los cuales se consiguen mediante la importación y la cercanía de las instalaciones al puerto del Callao es un factor crítico para el análisis.

\section{- Cercanía al Mercado (B)}

El segundo factor más influyente para el proyecto a desarrollar es la cercanía al mercado potencial al que el proyecto tiene como objetivo ingresar, el cual es lima-Metropolitana, debido a su alto desarrollo económico con relación a otras partes del país lo hace una zona muy atractiva para la comercialización de tanques de agua. La cercanía al mercado ofrecerá múltiples beneficios al proyecto, tales como reducir costos de transportes entre otros.

\section{- Requerimientos de infraestructura industria (C)}

Es necesario un adecuado suministro de energía ya que se necesita para todo el proceso, adecuadas vías y caminos amplios de acceso, disponibilidad de mano de obra, etc.

- Número de habitantes (D)

El número de habitantes de las regiones es importante para poder encontrar una amplia disponibilidad de mano de obra. 


\subsubsection{Factores de micro localización}

- Proximidad al terminal portuario (A)

La materia prima considerada para el análisis es el polietileno importado, componente más importante para la elaboración de tanques.

- $\quad$ Seguridad (B)

En términos de seguridad los distritos con una percepción mayor de inseguridad son, Ate con un $86.6 \%$, Lurín tiene un $89.3 \%$ y Puente Piedra un $89.2 \%$ (INEI, 2015).

- Cercanía a los clientes (C)

Se medirá según la cercanía al mercado objetivo de una manera cualitativa.

- Número de habitantes (D)

Puente piedra cuenta con 320,837 habitantes, Lurín con 87,256 y ventanilla alberga 372,899 habitantes (INEI, 2015).

- Disponibilidad de terrenos (E)

Disponibilidad de locales en alquiler o venta.

- Costo por $m^{2}(\mathrm{~F})$

El precio por $m^{2}$ en puente piedra es de 244.4 dólares en promedio (Mantyobras, 2017), el de Lurín es 241 dólares en promedio (Mantyobras, 2017) y el de ventanilla 263.9 dólares en promedio (Mantyobras, 2017), según una encuesta hecha en la zona, además, los tres precios se consideran accesibles para implementar una planta manufacturera.

\subsection{Identificación y descripción de las alternativas de localización}

\subsubsection{Alternativas de macro localización}

- Provincia de Lima

Cuenta con aproximadamente 10,190,922 habitantes (APEIM, 2017). Es un departamento que se encuentra en el centro del Perú y cuenta con un terminal portuario en Callao. 
Figura 3.2.1 Provincia de Lima

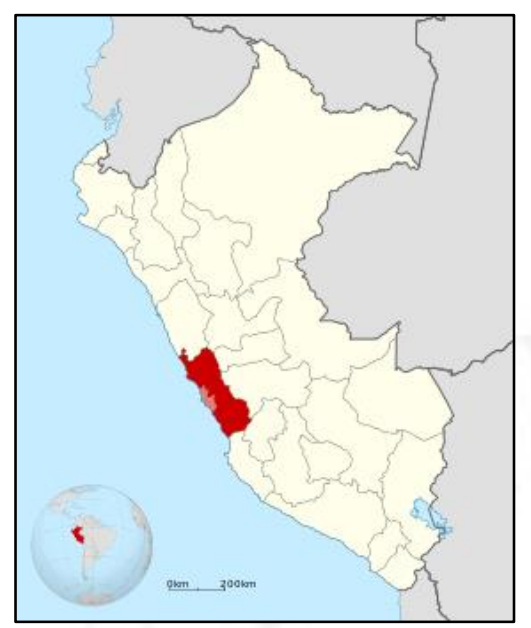

Fuente: Intertournet (2018)

\section{- Provincia de Huarochirí}

Se encuentra al este del departamento de Lima, cuenta con 32 distritos siendo su capital

"Matucana", su número de habitantes es aproximadamente 83,600 y dispone de terrenos para implementar plantas manufactureras (CPI, 2017).

Figura 3.2.2 Provincia de Huarochiri

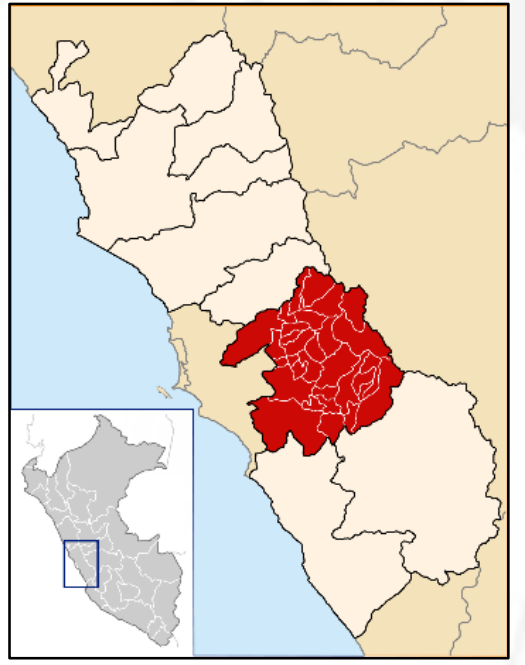

Fuente: Intertournet (2018) 
- Provincia de Cañete

Se encuentra al sur del departamento de Lima, siendo su capital "San Vicente de Cañete", cuenta con aproximadamente 239,700 habitantes y posee terminales portuarios (CPI, 2017).

Figura 3.2.3 Provincia de Cañete

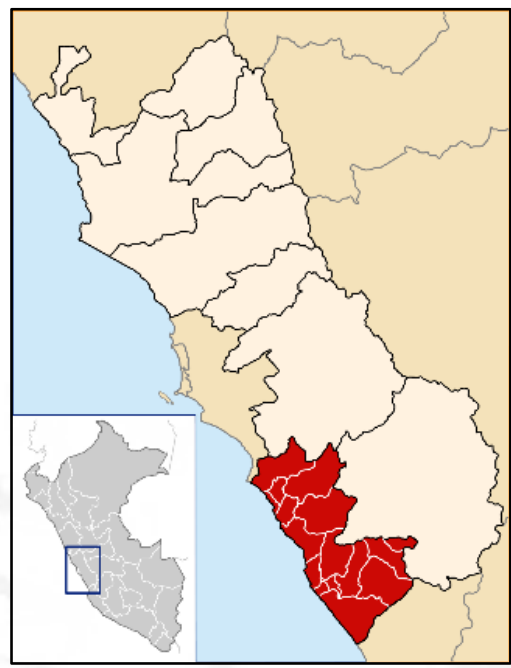

Fuente: Intertournet (2018)

\subsubsection{Alternativas de micro localización}

Tabla 3.2.1 Alternativas de la micro localización

\begin{tabular}{|c|c|c|}
\hline Puente Piedra & Lurín & Ventanilla \\
\hline Costo por $\boldsymbol{m}^{2}$ va entre 244.4\$ & $\begin{array}{c}\text { Costo por } m^{2} \text { va entre 241.0\$ } \\
\text { Percepción de inseguridad: }\end{array}$ & $\begin{array}{c}\text { Costo por } m^{2} \text { va entre 263.9\$ } \\
\text { Percepción de inseguridad: }\end{array}$ \\
$89.2 \%$ & $89.3 \%$ & $89.2 \%$ \\
Número de habitantes: 320,837 & Número de habitantes: 87,256 & Número de habitantes: 372,899 \\
Norte de Lima & Sur de Lima & Centro de Lima \\
Disponibilidad de terrenos: Alta & Disponibilidad de terrenos: & Disponibilidad de terrenos: \\
& Media Baja. & Baja. \\
\hline
\end{tabular}

Elaboración propia

\subsection{Evaluación y selección de localización}

\subsubsection{Evaluación y selección de la macro localización}

Después de desarrollar cada factor de localización, se tiene que calificar cada uno de ellos asignándole un puntaje de acuerdo a la información antes dada. 
Tabla 3.3.1 Enfrentamiento de factores - macro localización

\begin{tabular}{|c|cccc|c|c|}
\cline { 2 - 7 } \multicolumn{1}{c|}{} & A & B & C & D & Puntos & \% Pond \\
\hline A & 1 & 1 & 1 & 1 & 4 & $36.36 \%$ \\
B & 1 & 1 & 1 & 1 & 4 & $36.36 \%$ \\
C & 0 & 0 & 1 & 1 & 2 & $18.18 \%$ \\
D & 0 & 0 & 0 & 1 & 1 & $9.09 \%$ \\
\hline \multicolumn{5}{c|}{ Total } & $\mathbf{1 1}$ & $\mathbf{1 0 0 . 0 0 \%}$ \\
\hline
\end{tabular}

Elaboración propia

Primero se realizó la tabla de enfrentamientos de factores para obtener el porcentaje de importancia que tiene cada uno de ellos. Seguidamente, se realiza el ranking de factores para calificar a los posibles departamentos utilizando la escala de calificación dada en el punto 3.1 .

Tabla 3.3.2 Ranking de factores - macro localización

\begin{tabular}{|c|c|cc|cc|cc|}
\hline \multirow{2}{*}{$\begin{array}{c}\text { Factores de } \\
\text { localización }\end{array}$} & \multirow{2}{*}{$\begin{array}{c}\text { Ponderación } \\
\text { \% }\end{array}$} & \multicolumn{2}{|c|}{$\begin{array}{c}\text { Lima } \\
\text { Metropolitana }\end{array}$} & \multicolumn{2}{c|}{ Huarochirí } & \multicolumn{2}{c|}{ Cañete } \\
\cline { 3 - 8 } & Calif. & Punt. & Calif. & Punt. & Calif. & Punt. \\
\hline A & $36.36 \%$ & 10 & 3.64 & 2 & 0.73 & 8 & 2.91 \\
B & $36.36 \%$ & 10 & 3.64 & 6 & 2.18 & 6 & 2.18 \\
C & $18.18 \%$ & 8 & 1.45 & 8 & 1.45 & 6 & 1.09 \\
D & $9.10 \%$ & 10 & 0.91 & 6 & 0.55 & 6 & 0.55 \\
\hline Total & $100.00 \%$ & \multicolumn{3}{|c|}{$\mathbf{9 . 6 4}$} & \multicolumn{2}{|c|}{4.91} & \multicolumn{2}{c|}{6.73} \\
\hline
\end{tabular}

Elaboración propia

Según el análisis, la región más adecuada es Lima metropolitana con un puntaje de 9.64.

\subsubsection{Evaluación y selección de micro localización}

Después de desarrollar cada factor de localización, se tiene que calificar cada uno de ellos asignándole un puntaje de acuerdo a la información antes dada. Se efectuará la tabla de enfrentamientos de factores para obtener el porcentaje de importancia que tiene cada uno de ellos. 
Tabla 3.3.3 Enfrentamiento de factores - micro localización

\begin{tabular}{|c|cccccc|c|c|}
\cline { 2 - 8 } \multicolumn{1}{c|}{} & A & B & C & D & E & F & Puntos & \% Pond \\
\hline A & 1 & 1 & 1 & 1 & 1 & 1 & 6 & $37.50 \%$ \\
B & 0 & 1 & 0 & 0 & 0 & 0 & 1 & $6.25 \%$ \\
C & 0 & 1 & 1 & 1 & 0 & 0 & 3 & $18.75 \%$ \\
D & 0 & 1 & 0 & 1 & 0 & 0 & 2 & $12.50 \%$ \\
E & 0 & 1 & 1 & 1 & 1 & 0 & 4 & $25.00 \%$ \\
F & 1 & 1 & 1 & 1 & 1 & 1 & 6 & $37.50 \%$ \\
\hline \multicolumn{5}{|c|}{ Total } & & $\mathbf{1 6}$ & $\mathbf{1 0 0 . 0 0 \%}$ \\
\hline
\end{tabular}

Elaboración propia

A continuación, se realiza el ranking de factores para calificar a los posibles departamentos utilizando la escala de calificación dada en el punto 3.1.

Tabla 3.3.4 Ranking de factores - micro localización

\begin{tabular}{|c|c|cc|cc|cc|}
\hline \multirow{2}{*}{ Factor } & \multirow{2}{*}{$\begin{array}{c}\text { P } \\
\text { Pond }\end{array}$} & \multicolumn{2}{|c|}{ Puente Piedra } & \multicolumn{2}{c|}{ Lurín } & \multicolumn{2}{c|}{ Ventanilla } \\
\cline { 3 - 8 } & Calif. & Punt. & Calif. & Punt. & Calif. & Punt. \\
\hline A & $37.50 \%$ & 8 & 3.00 & 4 & 1.50 & 10 & 3.75 \\
B & $6.25 \%$ & 6 & 0.38 & 8 & 0.50 & 6 & 0.38 \\
C & $18.75 \%$ & 6 & 1.13 & 4 & 0.75 & 8 & 1.50 \\
D & $12.50 \%$ & 6 & 0.75 & 4 & 0.50 & 8 & 1.00 \\
E & $25.00 \%$ & 8 & 2.00 & 6 & 1.50 & 4 & 1.00 \\
F & $37.50 \%$ & 8 & 3.00 & 6 & 2.25 & 4 & 1.50 \\
\hline Total & $100 \%$ & \multicolumn{3}{|c|}{$\mathbf{1 0 . 2 5}$} & \multicolumn{3}{|c|}{7.00} \\
\hline
\end{tabular}

Elaboración propia

Según el análisis, el lugar más adecuado es Puente Piedra con un puntaje de 10.25. 


\section{CAPÍTULO IV: TAMAÑO DE PLANTA}

En el presente capitulo se evaluará la relación tamaño - mercado, tamaño recursos productivos, tamaño - tecnología y tamaño - punto de equilibrio para poder seleccionar el tamaño de planta más adecuado.

\subsection{Relación tamaño - mercado}

El tamaño máximo de mercado será de 7,641 tanques de agua en el año 2025.

Tabla 4.1.1 Proyección de la demanda

\begin{tabular}{|c|c|c|}
\hline Año & Demanda (TQ.) & \% de crecimiento \\
\hline $\mathbf{2 0 1 9} \mathbf{P}$ & 3,352 & - \\
$\mathbf{2 0 2 0} \mathbf{P}$ & 3,912 & $16.71 \%$ \\
$\mathbf{2 0 2 1} \mathbf{P}$ & 4,534 & $15.90 \%$ \\
$\mathbf{2 0 2 2} \mathbf{P}$ & 5,218 & $15.09 \%$ \\
$\mathbf{2 0 2 3} \mathbf{P}$ & 5,964 & $14.30 \%$ \\
$\mathbf{2 0 2 4} \mathbf{P}$ & 6,771 & $13.53 \%$ \\
$\mathbf{2 0 2 5} \mathbf{P}$ & 7,641 & $12.85 \%$ \\
\hline
\end{tabular}

Elaboración propia

\subsection{Relación tamaño - recursos productivos}

La materia prima principal para la fabricación de los tanques será de polietileno virgen y polietileno reciclado de baja densidad. Este material resulta fácilmente accesible, ya que existen una gran cantidad de industrias en el extranjero que se dedican a procesar y comercializar el polietileno virgen y el polietileno reciclado. El tanque pesará $20 \mathrm{Kg}$. De los cuales $14 \mathrm{~kg}$. Serán de material reciclado y $6 \mathrm{~kg}$. Serán de material virgen.

El presente proyecto tendrá como principal proveedor de polietileno de baja densidad reciclado a la empresa Zhengzhou Mahaco Commercial Co., Ltd. Localizada en Henan, China. A esta empresa se le comprará un máximo de 72,384 kilogramos de materia prima reciclada, para lograr satisfacer la demanda esperada. Este volumen de material reciclado representa un pequeño porcentaje del que dispone la empresa seleccionada. La capacidad de suministro de la empresa es de 6,500 toneladas mensuales. Según la demanda hallada se requiere del $1.11 \%$ de lo que vende esta empresa al año. 
Como principal proveedor de polietileno de baja densidad virgen se tendrá a la empresa "Polímeros Mexicanos S.A." localizada en Nezahualcóyotl, México. A esta empresa se le comprará un máximo de 48,256 kilogramos de polietileno reciclado, para lograr satisfacer la demanda esperada. Esta empresa exporto hacia el Perú en el año 2017 3,648,560 kg. De polietileno virgen de alta densidad según la fuente de Veritrade, lo que sería un $1.32 \%$ de nuestro requerimiento anual.

Tabla 4.2.1 Kilogramos de materia prima

\begin{tabular}{|c|c|c|c|}
\hline Año & $\begin{array}{c}\text { Demanda } \\
\text { (TQ.) }\end{array}$ & $\begin{array}{c}\text { PEBD } \\
\text { Reciclado } \\
\text { (kg.) }\end{array}$ & $\begin{array}{c}\text { PEBD } \\
\text { Virgen (kg.) }\end{array}$ \\
\hline $\mathbf{2 0 1 9}$ P & 3,352 & 46,928 & 20,112 \\
$\mathbf{2 0 2 0}$ P & 3,912 & 54,768 & 23,472 \\
$\mathbf{2 0 2 1}$ P & 4,534 & 63,476 & 27,204 \\
$\mathbf{2 0 2 2}$ P & 5,218 & 73,052 & 31,308 \\
$\mathbf{2 0 2 3}$ P & 5,964 & 83,496 & 35,784 \\
$\mathbf{2 0 2 4}$ P & 6,771 & 94,794 & 40,626 \\
$\mathbf{2 0 2 5}$ P & 7,641 & 106,974 & 45,846 \\
\hline
\end{tabular}

Elaboración propia

\subsection{Relación tamaño - tecnología}

La relación tamaño-tecnología se determina según los tipos de maquinaria que se utilizarán en los procesos de producción. Por lo tanto, se calculará un tamaño de planta teórico en base a la producción anual de cada proceso por independiente para determinar el cuello de botella dentro de la línea.

Tabla 4.3.1 Cuello de botella

\begin{tabular}{|c|c|c|c|c|c|c|}
\hline Operación & Capacidad & Horas/día & Turnos/día & Días/año & Producción & TQ/año \\
\hline Pigmentar & $500 \mathrm{~kg} / \mathrm{hora}$ & 8 & 3 & 312 & $\begin{array}{c}\text { 3,744000 } \\
\text { kg/año }\end{array}$ & 187,200 \\
\hline $\begin{array}{c}\text { Pesar y roto } \\
\text { moldear }\end{array}$ & $80 \mathrm{~kg} /$ hora & 8 & 3 & 312 & $\begin{array}{l}599,040 \\
\text { kg/año }\end{array}$ & 29,952 \\
\hline Enfriar & $5 \mathrm{TQ} /$ hora & 8 & 3 & 312 & $\begin{array}{l}37,440 \\
\text { TQ/año }\end{array}$ & 37,440 \\
\hline Colocar & $\begin{array}{c}12 \\
\text { pzas/hora }\end{array}$ & 8 & 3 & 312 & $\begin{array}{c}89,856 \\
\text { pzas/año }\end{array}$ & 89,856 \\
\hline
\end{tabular}

Elaboración propia

En la tabla se puede apreciar que los procesos de pesar y roto moldear serán los que marquen el cuello de botella. 


\subsection{Relación tamaño - punto de equilibrio}

Para hallar el punto de equilibrio, se debe considerar los costos fijos y variables de la producción, así como el precio de venta para el primer año.

Costos fijos y variables anuales $\quad$ S/. 320,545

Valor de venta unitario: $\quad$ S/ 267.00

Costo variable unitario: $\quad$ S/ 116.00

$$
P . E=\frac{320545}{267-116}=2,123 \text { tanques }
$$

Para el primer año el punto de equilibrio de 2,123 tanques.

\subsection{Selección del tamaño de planta}

Después de haber analizado los distintos tamaños de planta, se opta por elegir el de tamaño - mercado. El tamaño - recurso productivo tampoco será un limitante debido a que existe abundancia de materiales. El tamaño - punto de equilibrio tampoco será un factor limitante debido a que la demanda está por encima del valor encontrado.

Finalmente, luego de haber analizado los distintos tamaños de planta se opta por elegir la relación de tamaño - mercado.

Figura 4.5.1 Selección del tamaño de planta

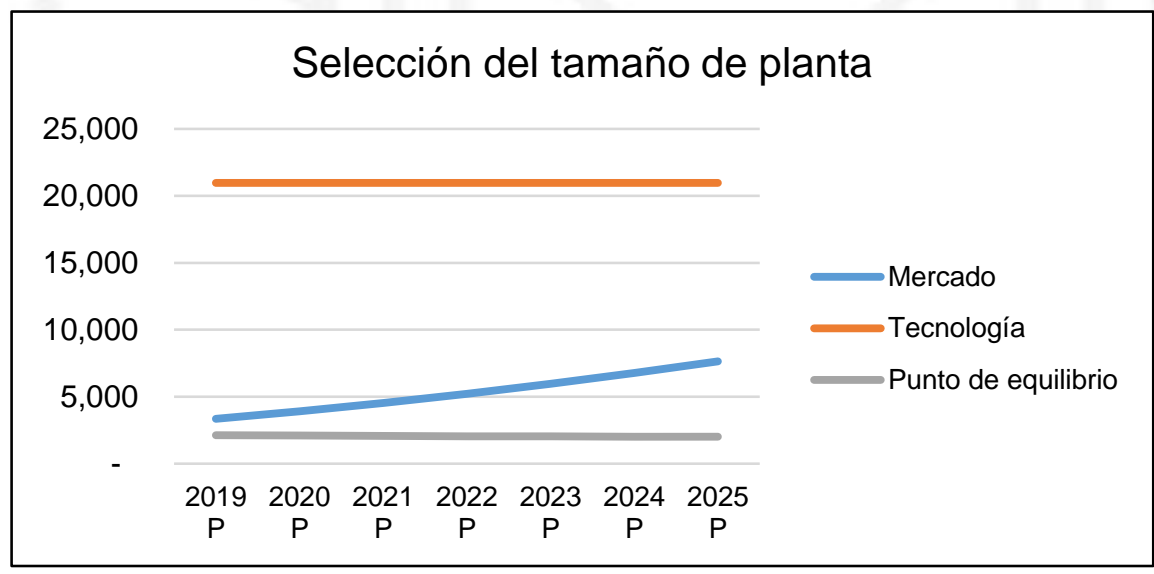

Elaboración propia 


\section{CAPÍTULO V: INGENIERÍA DEL PROYECTO}

En el presente capítulo se presentarán los detalles técnicos del producto, así mismo, como la maquinaria que se requiere utilizar y la selección de la mejor técnica de fabricación.

\subsection{Definición técnica del producto}

\subsubsection{Especificaciones técnicas, composición y diseño del producto}

El tanque de agua fabricado por roto moldeo debe tener apariencia cónica para poder ser apilable. Su composición no altera el sabor u olor del agua. Los tanques cuentan con una capa interna antimicrobiana que evita la adherencia de cualquier tipo de bacterias, hongos o parásitos.

El polietileno reciclado será pigmentado con pigmento negro, al ser de este color genera más opacidad dentro del tanque y brinda mayor protección contra los rayos UV del sol y evita la formación de algas, la tapa cuenta con un seguro hermético en el cierre para conservar el agua.

Figura 5.1.1 Diseño del producto - Tanque de agua

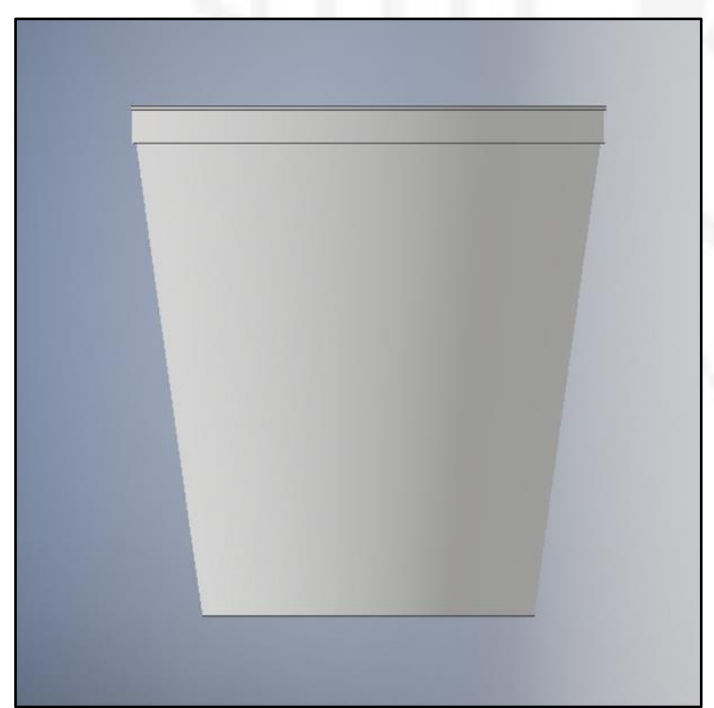

Elaboración propia 
Figura 5.1.3 Diseño del producto - tapa del tanque de agua

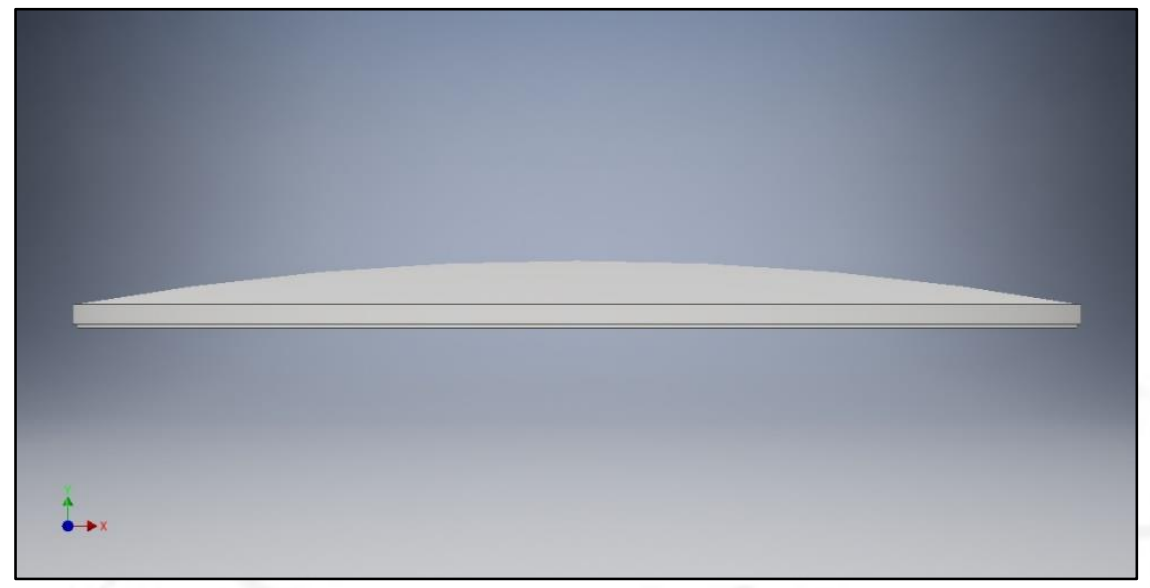

Elaboración propia

Figura 5.1.2 Dimensión del producto

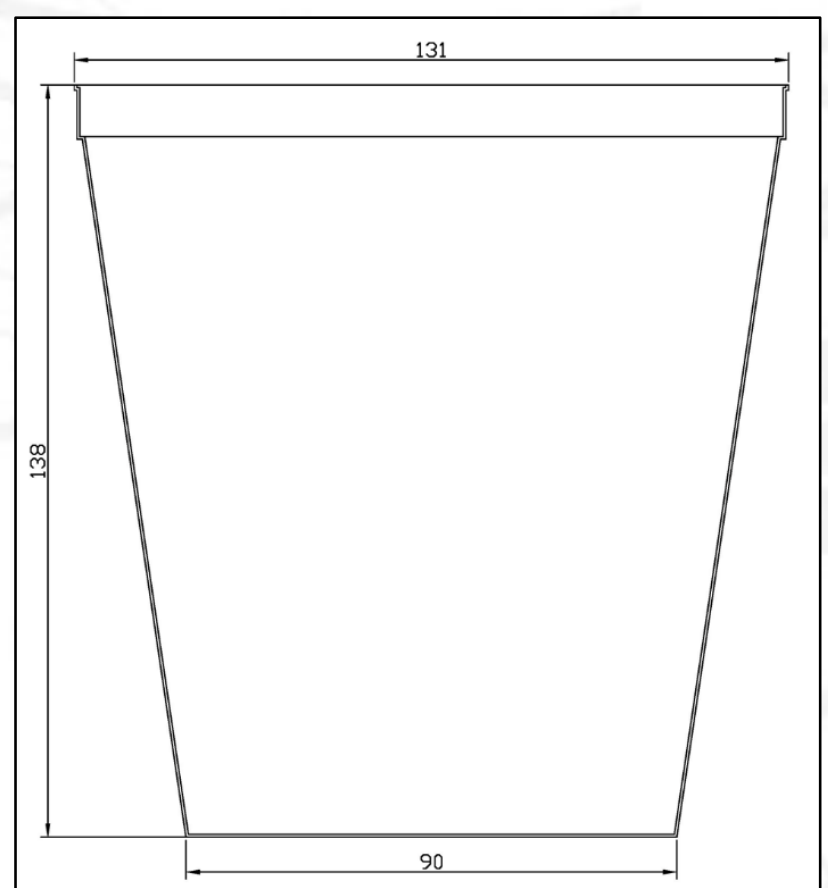

Elaboración propia 


\subsubsection{Marco regulatorio para el producto}

No existe un marco regulatorio en el Perú para este producto. Sin embargo, la materia prima virgen que estará en contacto con el agua es aprobada por la FDA la cual la certifica como apta para el almacenamiento de productos para el consumo humano.

\subsection{Tecnologías existentes y procesos de producción}

\subsubsection{Naturaleza de la tecnología requerida}

\subsubsection{Descripción de las tecnologías existentes}

En el sector industrial del plástico existen 3 procesos productivos que son los más usados. Estos son la extrusión, inyección y roto moldeo. El proceso más adecuado para el producto investigado es el de roto moldeo (Automotive, 2018). A continuación, explicaremos cada una de las tecnologías.

\section{- $\quad$ Extruido}

Las ventajas del método de extrusión es su habilidad de producir perfiles con secciones transversales o productos sin fin de producción continua. Este proceso es muy usado para la fabricación de canaletas, tuberías, bolsas, perfiles, tarugos, láminas, barras, etc.

Una desventaja es su capacidad de trabajar con distintos tipos de productos, debido a que el cambio de troquel demora horas, aparte de la configuración requerida para adaptar el nuevo troquel. El cambio de color materia prima también requiere de una limpieza previa para no mezclarse con materia prima utilizada previamente. El precio de una extrusora puede ser entre regular y alto depende del tamaño de máquina que se requiera según la capacidad de extrusión en $\mathrm{kg} / \mathrm{hora}$. El troquel utilizado en la extrusora suele tener un precio regular.

\section{- Inyección}

Las ventajas del método de inyección es su habilidad de fabricar piezas de plástico pequeñas con un alto nivel de productividad, alta velocidad y bajos costos de producción. Este método suele utilizarse para productos masivos y piezas pequeñas de alta rotación con geometrías complicadas. La gran mayoría de estas piezas luego de ser inyectadas son prácticamente productos terminados. Este proceso es muy usado para la fabricación de envases, toma todos, botellas, tapa roscas, bandejas, basureros, jaboneras, vasos, pastilleros, etc. Una desventaja es su capacidad de trabajar con distintos tipos de 
productos, debido a que el cambio del molde demora horas, aparte de la configuración requerida para adaptar el nuevo troquel. El cambio de color o materia prima también requiere de una limpieza previa para no mezclarse con materia prima utilizada previamente. El precio de una inyectora puede ser entre regular y alto depende del tamaño de máquina que se requiera según la capacidad de inyección en $\mathrm{kg} / \mathrm{hora}$. El molde de inyección suele tener un precio entre regular y alto.

\section{- Roto moldeo}

Las ventajas del método de roto moldeo es su habilidad de fabricar productos grandes de una sola pieza. Usualmente la materia prima empleada en este proceso tiene mayor duración de vida útil. La gran mayoría de estas piezas luego de ser roto moldeadas son prácticamente productos terminados. Este proceso es muy usado para la fabricación de tanques de agua, casas de perro, kayaks, coolers, mesas, sofás, sillas, basureros, etc. Otra ventaja es su capacidad de trabajo con distintos tipos de moldes y de colores. El cambio del molde es sencillo y rápido, se puede realizar en minutos y el cambio de color también, no necesita de limpieza previa. El precio de una máquina de roto moldeo suele ser bajo a comparación de las otras tecnologías. El molde de roto moldeo suele tener un precio bajo.

\subsubsection{Selección de la tecnología}

Luego de revisar las tecnologías existentes que se suelen utilizar para la producción de plásticos, para el proceso de fabricación de un tanque de agua se puede utilizar el método de inyección o de roto moldeo. El método de extrusión para este caso está descartado debido al tamaño del tanque, el cual es muy grande, este se desempeña mejor en una producción de perfiles continuos. Las buenas prácticas de la industria de los plásticos han demostrado que mientras más pequeña es la pieza a fabricar, es necesario utilizar una inyectora y mientras más grande es la pieza utilizar, una máquina de roto moldeo sería lo más adecuado (Automotive, 2018). Finalmente, se puede concluir que el mejor método de fabricación a emplear es el de roto moldeo. 


\subsubsection{Proceso de producción}

\subsubsection{Descripción del proceso}

- Pigmentar

El polietileno reciclado es pigmentado de color negro, debido a que el reciclado viene en diversos colores. Por cada $18 \mathrm{~kg}$ de material reciclado se utilizará 200 gramos de pigmento negro. El polietileno virgen no se pigmenta.

- Pesar y roto moldear

Luego de pigmentar el polietileno reciclado, este se pesa y se separa en bolsas de $14 \mathrm{~kg}$. y polietileno virgen se pesa y se separa en bolsas de $6 \mathrm{~kg}$. Primero se ingresan los $14 \mathrm{Kg}$. de polietileno reciclado para la fusión primaria y luego se ingresan los $6 \mathrm{Kg}$. de polietileno virgen para la fusión secundaria. Finalmente, se completa el proceso de roto moldeo en 15 minutos.

\section{- Enfriar}

Luego de roto moldear los tanques, se dejan enfriar dentro del molde con ventiladores por 12 min. Finalmente, se retiran los tanques finalizados del molde.

\section{- Cortar}

Se corta en la parte superior la tapa del tanque, de esta manera se logra separar la tapa de la base apilable.

- Colocar

Finalmente, se coloca la brida en la parte inferior del tanque. 


\subsubsection{Diagrama de proceso: DOP}

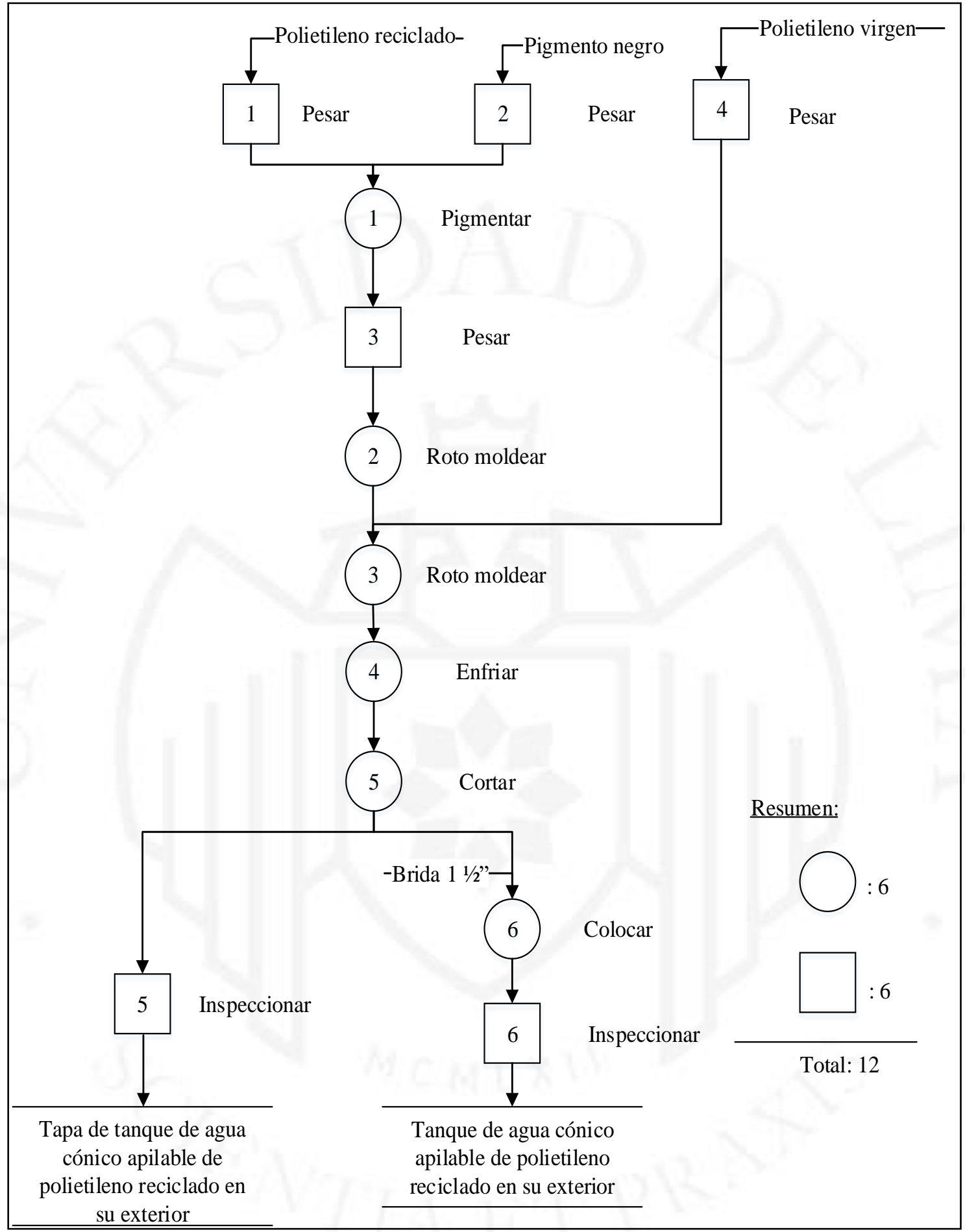

Elaboración propia 
5.2.2.3 Balance de materia

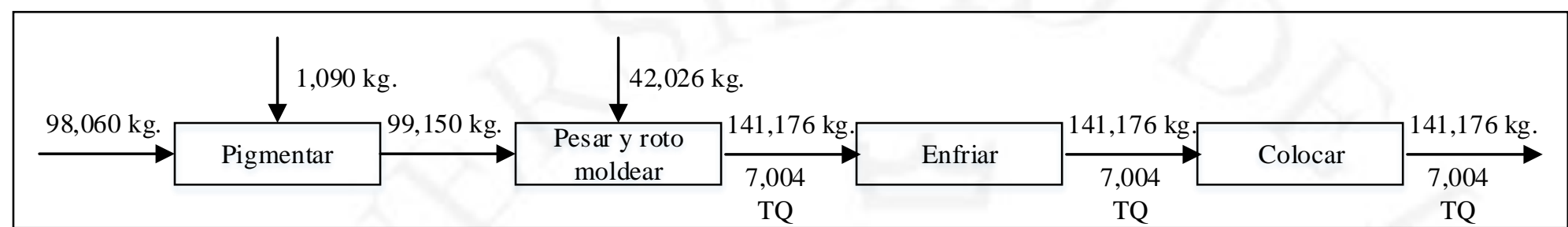

Elaboración propia 


\subsection{Características de las instalaciones y equipos}

\subsubsection{Selección de la maquinaria y equipos}

Las maquinarias que se requieren para realizar las actividades previamente explicadas serán:

Tabla 5.3.1 Listado de maquinaria

\begin{tabular}{|c|}
\hline Listado de maquinaría \\
\hline Horno a llama abierta de roto moldeo \\
Moldes de tanque de 1,200 Litros \\
Ventiladores Industriales con aspersor de agua \\
Trompo Mezclador \\
Balanza electrónica de plataforma $300 \mathrm{Kg}$ \\
Tanque de gas GLP \\
Estoca hidráulica \\
\hline
\end{tabular}

Elaboración propia 


\subsubsection{Especificaciones de la maquinaria}

Figura 5.3.1 Horno a llama abierta de roto moldeo para 2 moldes

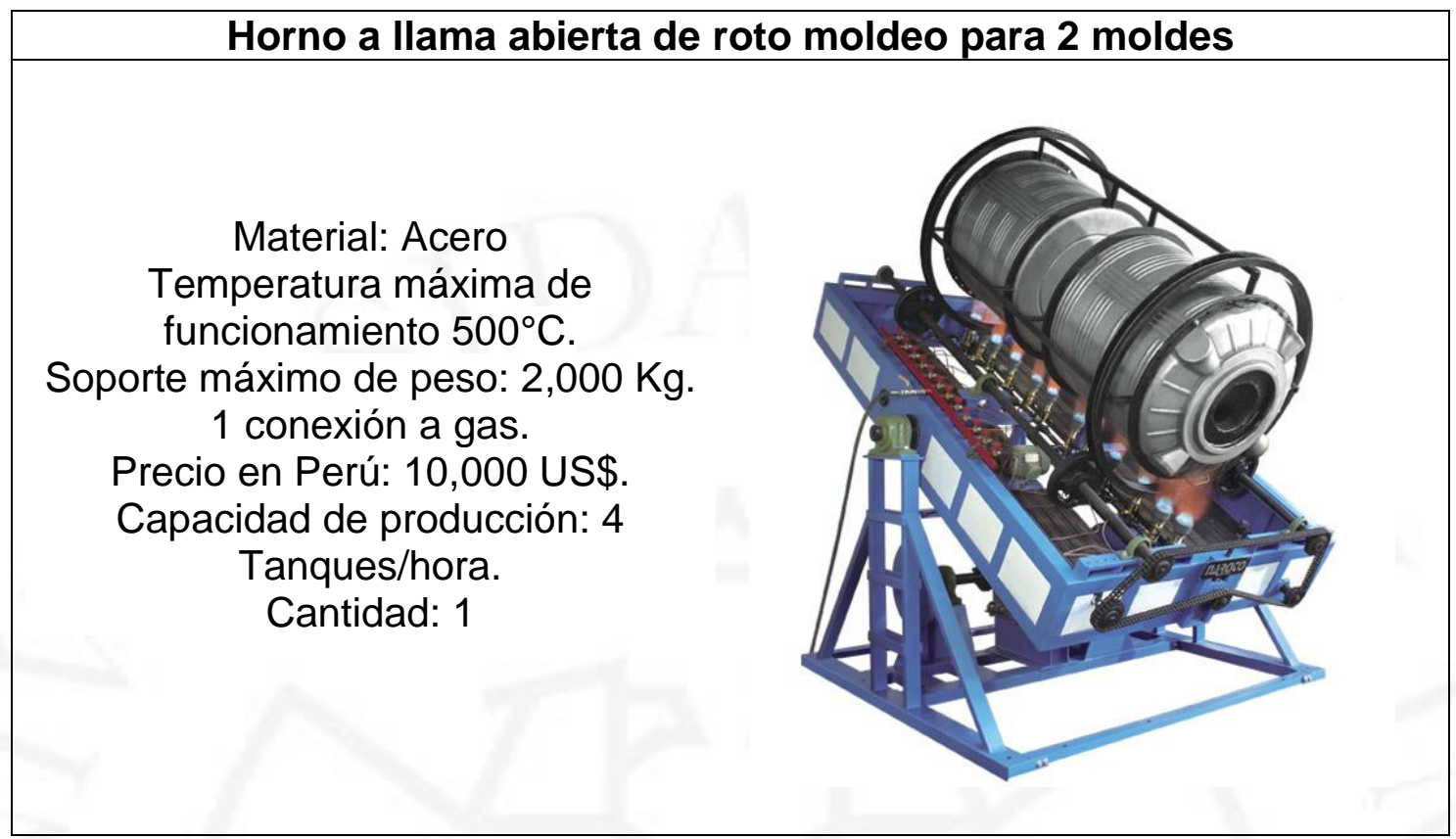

Fuente: textoscientificos (2012)

Figura 5.3.2 Molde de tanque de 1,200 Lts

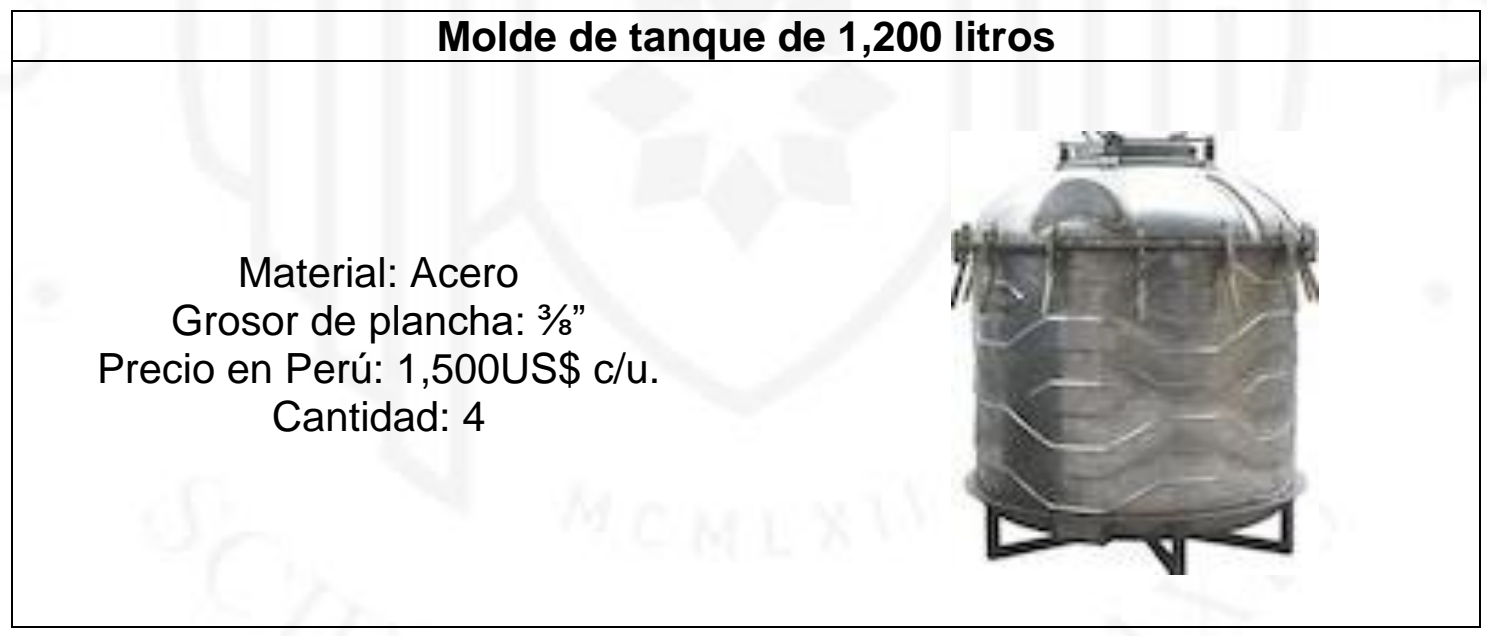

Fuente: Indiamart (2015) 
Figura 5.3.3 Ventilador industrial con aspersor de agua

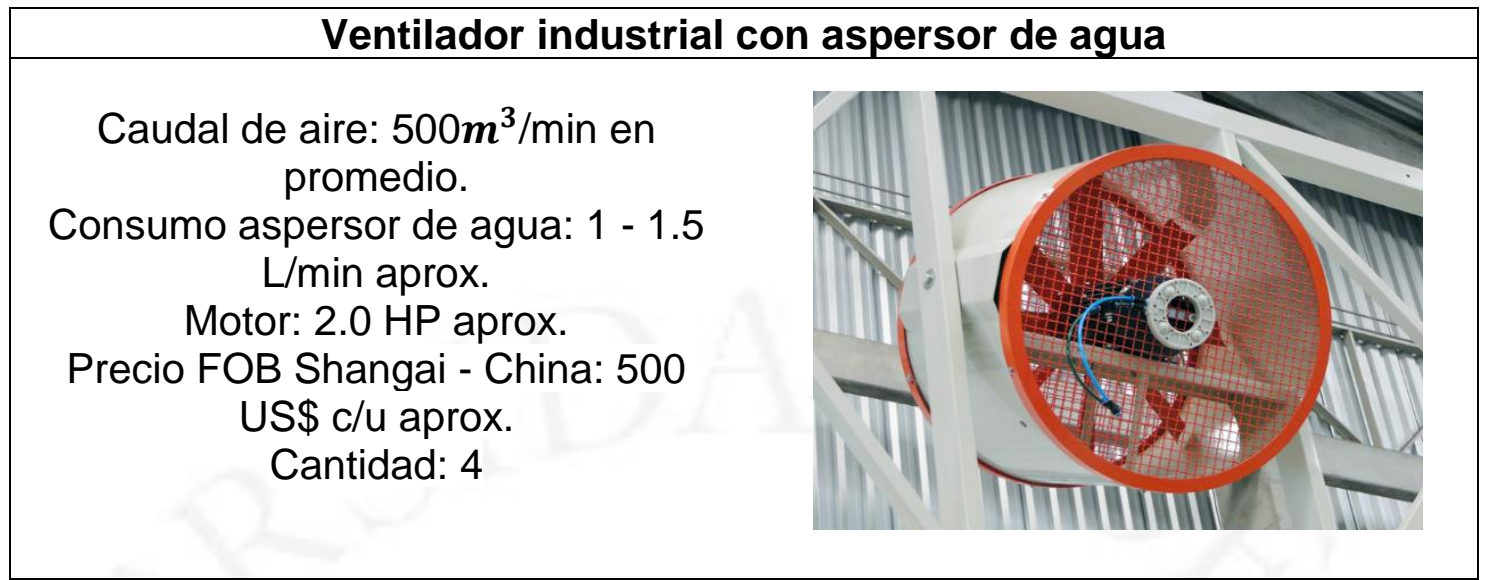

Fuente: Rotoline (2017)

Figura 5.3.4 Trompo mezclador

\section{Trompo mezclador}

Capacidad: 200 Lts aprox.

Motor eléctrico: 1.5 - $2 \mathrm{HP}$ aproximadamente.

Velocidad: 25 - 30 RPM.

Precio en Lima: S/. 1,000.00 aprox.

Cantidad: 1

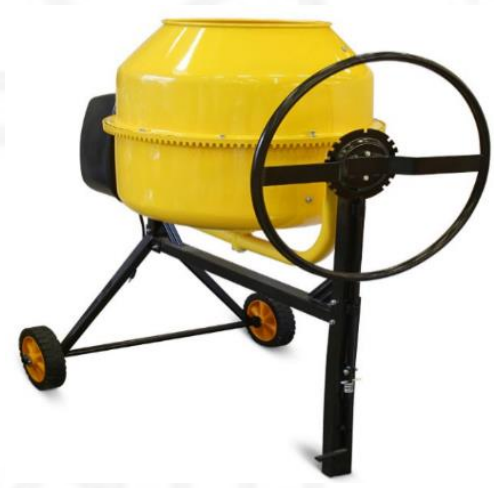

Fuente: Promart (2017)

Figura 5.3.5 Balanza electrónica de plataforma

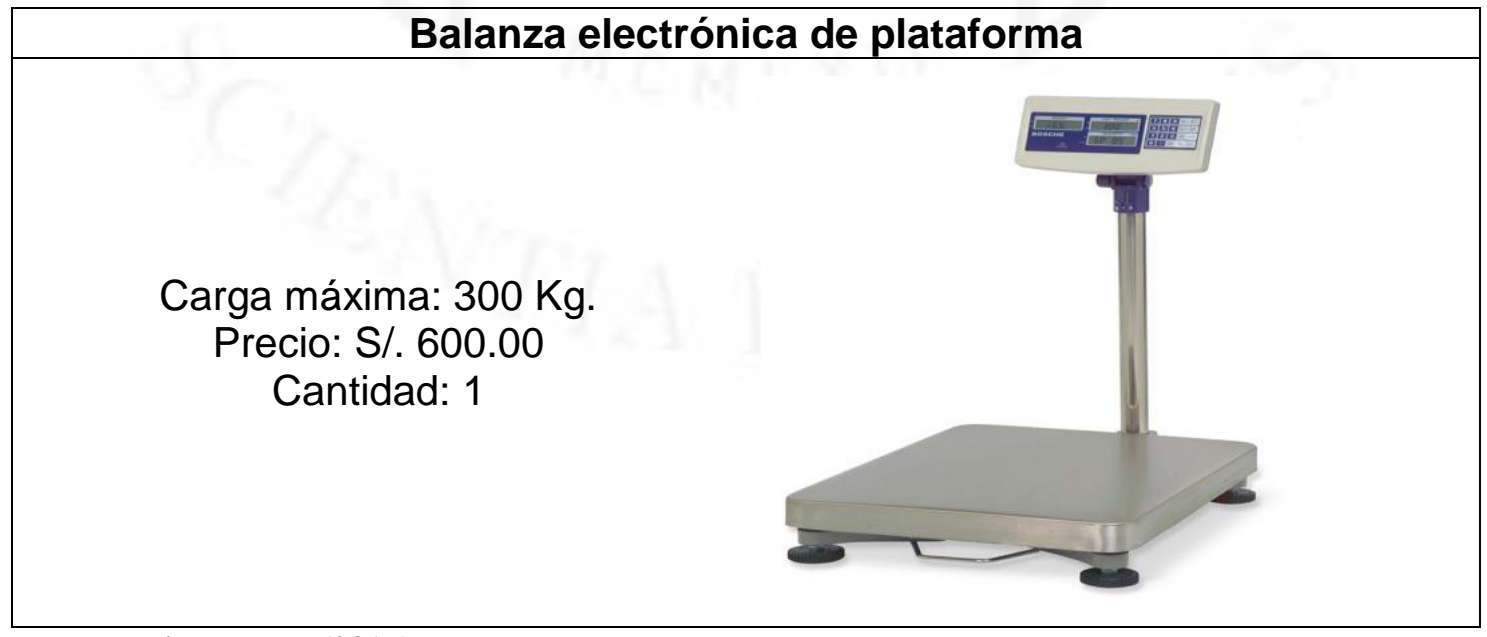

Fuente: Balanzasperu (2016) 
Figura 5.3.6 Tanque de gas

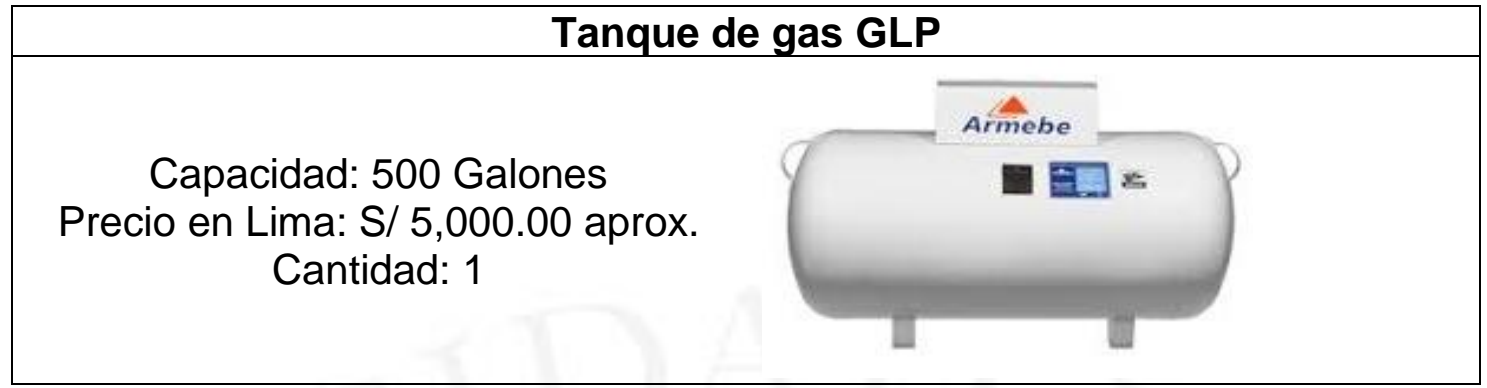

Fuente: Armebe (2015)

Figura 5.3.7 Estoca hidráulica

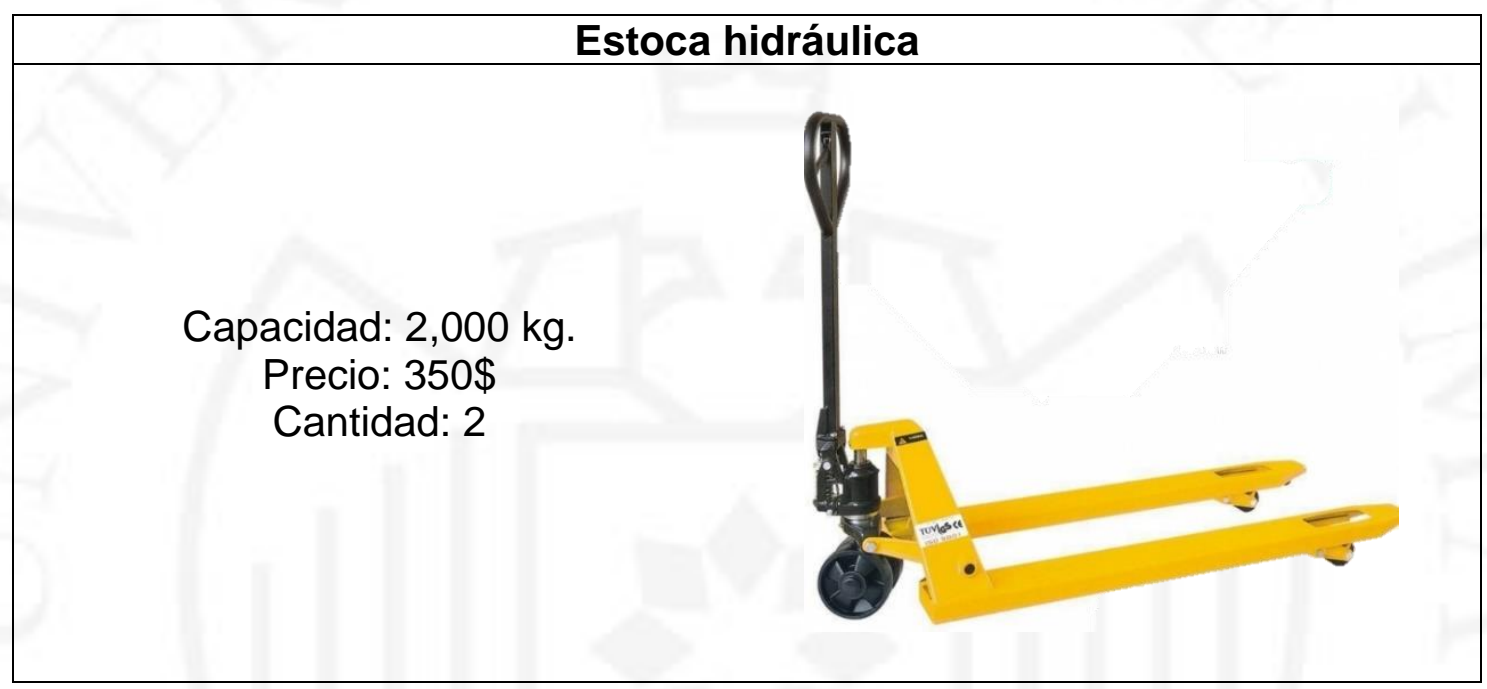

Fuente: bennotomaquinarias (2015)

\subsection{Capacidad instalada}

\subsubsection{Cálculo detallado del número de máquinas y operarios requeridos}

Para calcular de forma detallada la cantidad de máquinas y operarios que se requieren para la fabricación del presente proyecto, se tendrá en cuenta el total de horas que se utilizarán para fabricar aplicando la utilización para la maquinaría y la eficiencia para los operarios (Diaz, Jarufe, y Noriega, 2014).

A continuación, se define el cálculo total de horas por año.

$$
\begin{gathered}
\text { Horas }=8 \frac{\text { horas }}{\text { turno }} \times 3 \frac{\text { turnos }}{\text { día }} \times 6 \frac{\text { días }}{\text { semana }} \times 52 \frac{\text { semanas }}{a \tilde{n} o} \\
\text { Horas }=7,488 \text { horas } / \text { año }
\end{gathered}
$$


Para hallar la utilización de la maquinaría se considerará la desviación que existe entre el número de horas reales (NHR) y el número de horas productivas (NHP). El número de horas reales será de 8 horas por día, a las horas productivas se le descontará 1 hora diaria para cubrir el mantenimiento de los equipos, el habilitado de materias primas y diversas situaciones que puedan generarse en el día a día.

$$
U=\frac{N H P}{N H R}=\frac{8-1}{8}=0.875
$$

Para la eficiencia, se considera el factor de 0.80 dado que los operarios no requieren un nivel alto de conocimiento para la fabricación del producto a fabricar. Con los datos antes mencionados se realizará el cálculo de las máquinas requeridas. En el año 2025 la planificación de producción de tanques de agua sería de 7,004 tanques, su equivalente en kilogramos es de $120640 \mathrm{Kg}$.

Tabla 5.4.1 Cálculo de máquinas requeridas

\begin{tabular}{|c|c|c|c|c|c|c|c|}
\hline Operación & Capacidad & Horas/año & $\mathbf{U}$ & $\mathbf{E}$ & $\begin{array}{l}\text { Demanda } \\
\text { atendida }\end{array}$ & $\begin{array}{c}\# \\
\text { Máquinas }\end{array}$ & $\begin{array}{c}\# \\
\text { Máquinas }\end{array}$ \\
\hline Pigmentar & $500 \mathrm{~kg} /$ hora & 7,488 & 0.875 & 0.80 & $\begin{array}{l}99,150 \\
\text { kg/hora }\end{array}$ & 0.04 & 1 \\
\hline $\begin{array}{c}\text { Pesar y roto } \\
\text { moldear }\end{array}$ & $80 \mathrm{~kg} /$ hora & 7,488 & 0.875 & 0.80 & $\begin{array}{l}141,176 \\
\mathrm{~kg} / \mathrm{hora}\end{array}$ & 0.34 & 1 \\
\hline Enfriar & $5 \mathrm{TQ} /$ hora & 7,488 & 0.875 & 0.80 & $\begin{array}{c}\text { 7,004 } \\
\text { TQ/hora }\end{array}$ & 0.27 & 1 \\
\hline Colocar & $12 \mathrm{Pza} /$ hora & 7,488 & 0.875 & 0.80 & $\begin{array}{c}\text { 7,004 } \\
\text { pza/hora }\end{array}$ & 0.11 & 1 \\
\hline
\end{tabular}

Elaboración propia

Debido a que el proceso de fabricación es altamente operativo, no requiere de ningún conocimiento previo para operar la maquinaria, se optará por utilizar 3 operarios. El proceso de pigmentado se realizará 1 vez a la semana, por ende, no se requiere de mayor cantidad de operarios. Para los procesos de pesado, roto moldeado, enfriado y colocado se requerirán de sólo 3 operarios, 1 operario que se encargue de ejecutar el proceso en la máquina en el panel de control y 2 operarios que se encargarán de manipular la materia prima durante el proceso de roto moldeo. 


\subsubsection{Cálculo de la capacidad instalada}

Para el cálculo de la capacidad instalada se tomará en cuenta el número de máquinas, la utilización, la eficiencia y el tiempo de trabajo.

Tabla 5.4.2 Cálculo de la capacidad instalada

\begin{tabular}{|c|c|c|c|c|c|c|c|c|c|c|}
\hline Operación & QS & $\mathbf{P}$ & $\mathbf{M}$ & $\mathbf{H} / \mathbf{T}$ & $\mathbf{T / D}$ & $\mathbf{D} / \mathbf{S}$ & $\mathbf{S} / \mathbf{A}$ & $\mathbf{U}$ & $\mathbf{E}$ & $\begin{array}{c}\text { CO } \\
\text { (TQ/año) }\end{array}$ \\
\hline Pigmentar & $\begin{array}{c}99,150 \mathrm{~kg} . \\
\text { /año }\end{array}$ & 500 & 1 & 8 & 3 & 6 & 52 & 0.875 & 0.80 & 187,200 \\
\hline $\begin{array}{c}\text { Pesar y roto } \\
\text { moldear }\end{array}$ & $\begin{array}{c}141,176 \mathrm{~kg} . \\
\text { /año }\end{array}$ & 80 & 1 & 8 & 3 & 6 & 52 & 0.875 & 0.80 & 20,966 \\
\hline $\begin{array}{c}7,004 \\
\text { TQ/año }\end{array}$ & 5 & 1 & 8 & 3 & 6 & 52 & 0.875 & 0.80 & 26,208 \\
\hline Colocar & $\begin{array}{c}7,004 \\
\text { pzas/año }\end{array}$ & 12 & 1 & 8 & 3 & 6 & 52 & 0.875 & 0.80 & 62,899 \\
\hline Pt & \multicolumn{7}{|c|}{7,004 TQ/año }
\end{tabular}

\begin{tabular}{|c|c|}
\hline Operación & COPT (TQ/año) \\
\hline Pigmentar & 187,200 \\
Pesar y roto moldear & 20,966 \\
Enfriar & 26,208 \\
Colocar & 62,899 \\
\hline
\end{tabular}

\begin{tabular}{|c|c|}
\hline QS & Cantidad saliente \\
\hline $\mathbf{P}$ & $\begin{array}{c}\text { Capacidad de producción por hora de maquinaria u } \\
\text { operarios }\end{array}$ \\
\hline $\mathbf{M}$ & Número actual de máquinas u operarios \\
\hline $\mathbf{H} / \mathbf{T}$ & Horas por turno \\
\hline T/D & Turnos por día \\
\hline $\mathbf{D} / \mathbf{S}$ & Días por semana \\
\hline $\mathbf{S} / \mathbf{A}$ & Semanas por año \\
\hline $\mathbf{U}$ & Factor de utilización \\
\hline $\mathbf{E}$ & Factor de eficiencia \\
\hline $\mathrm{CO}$ & Capacidad de producción por cada operación \\
\hline COPT & $\begin{array}{c}\text { Capacidad de producción en unidades de producto } \\
\text { terminado para cada operación }\end{array}$ \\
\hline
\end{tabular}

Elaboración propia 


\subsection{Resguardo de la calidad y/o inocuidad del producto}

\subsubsection{Calidad de la materia prima, de los insumos, del proceso y del producto}

La materia prima requerida es un polietileno virgen de baja densidad ambas aprobadas por la FDA de USA. Con número de aprobación 21 CFR 177 1520, y puede ser usado en artículos fabricados para el contacto con alimentos. Identificado en la sección 177.1520 (a) (3) (i) (a) (1) y (a) (2) y conocido de la especificación en 177.1520(c). Puntos (3.1a) y 3.2(a). El compuesto de polietileno virgen también cumple con los requerimientos establecidos en:

- ASTM D1505 (Standard Test Method for Density of Plastics by the DensityGradient Technique)

- ASTM D1238 (Standard Test Method for Melt Flow Rates of Thermoplastics by Extrusion Plastometer)

- $\quad$ ASTM D368 (Standard Test Method for Specific Gravity of Creosote and Oil-Type Preservatives (Withdrawn 2006))

- ASTM D790 (Standard Test Methods for Flexural Properties of Unreinforced and Reinforced Plastics and Electrical Insulating Materials)

- $\quad$ ASTM D648 (Standard Test Method for Deflection Temperature of Plastics Under Flexural Load in the Edgewise Position)

- $\quad$ ASTM D1693 (Standard Test Method for Environmental Stress-Cracking of Ethylene Plastics)

El polietileno virgen contiene un estabilizador de U.V.8, es decir que la materia prima absorberá, bloqueara y/o dispersan los rayos ultravioletas del sol hasta un nivel 8 siendo de 8-10 niveles muy altos de radiación y a partir de 11+ una radiación extrema. Lo que generará este bloqueo de U.V.8 es evitar la formación de algas dentro del tanque. 


\subsection{Estudio del Impacto Ambiental}

El producto de la presente investigación tiene dos beneficios para el medio ambientales.

- Utilización de material reciclado

La fabricación del producto constara de $70 \%$ de polietileno reciclado (14 kg.), a comparación de las demás empresas, las cuales utilizan 100\% polietileno virgen, lo que genera un menor uso de plástico virgen.

\section{- Consumo de agua}

El proceso productivo utiliza pequeñas cantidades de agua en la actividad del enfriado, el cual por efecto de las altas temperaturas termina evaporándose. Sin embargo, es necesario realizar una matriz de aspectos e impactos ambientales y así poder hallar las actividades que generarían impacto en el medio ambiente.

Tabla 5.6.1 Matriz de aspectos e impactos ambientales

\begin{tabular}{|c|c|c|c|c|c|}
\hline Entrada & $\begin{array}{l}\text { Actividades } \\
\text { productivas }\end{array}$ & Salida & $\begin{array}{c}\text { Aspectos } \\
\text { ambientales }\end{array}$ & $\begin{array}{c}\text { Impactos } \\
\text { ambientales }\end{array}$ & $\begin{array}{c}\text { Norma } \\
\text { ambiental } \\
\text { aplicable }\end{array}$ \\
\hline $\begin{array}{c}\text { Polietileno } \\
\text { reciclado }\end{array}$ & Pigmentado & $\begin{array}{c}\text { Partículas de } \\
\text { plástico }\end{array}$ & $\begin{array}{c}\text { Emisión de } \\
\text { partículas de } \\
\text { aire }\end{array}$ & $\begin{array}{c}\text { Deterioro de la } \\
\text { salud de los } \\
\text { trabajadores }\end{array}$ & $\begin{array}{c}\text { Ley general } \\
\text { de residuos } \\
\text { solidos }\end{array}$ \\
\hline- & Pesado & & - & - & \\
\hline GLP & $\begin{array}{c}\text { Roto } \\
\text { moldeado }\end{array}$ & $\mathrm{CO}_{2}$ & $\begin{array}{c}\text { Generación de } \\
\mathrm{CO}_{2}\end{array}$ & $\begin{array}{l}\text { Contaminación } \\
\text { atmosférica }\end{array}$ & ECA de aire \\
\hline Agua & Enfriado & $\begin{array}{l}\text { Vapor de } \\
\text { agua }\end{array}$ & $\begin{array}{l}\text { Generación de } \\
\text { vapor }\end{array}$ & $\begin{array}{c}\text { Contaminación } \\
\text { atmosférica }\end{array}$ & ECA de aire \\
\hline- & Cortado & - & - & - & \\
\hline . & Colocado & - & & & \\
\hline
\end{tabular}

Elaboración propia

Se identificó que las actividades de pigmentación, roto moldeo y enfriado representan un problema para el medio ambiente, por tal motivo es necesario realizar la matriz de Leopold para cuantificar y evaluar el riesgo que representa dichas actividades dentro del proceso productivo y detectar el tipo de impacto que generaría al medio ambiente. Los impactos se categorizan según la siguiente escala. 
Tabla 5.6.2 Escala por tipo de impacto

\begin{tabular}{|c|c|}
\hline $\mathbf{1}-\mathbf{3}$ & Impacto negativo insignificante \\
$\mathbf{4 - 6}$ & Impacto negativo medio \\
$\mathbf{7 - 1 0}$ & Impacto negativo alto \\
\hline
\end{tabular}

Elaboración propia

La matriz a emplear mide dos tipos de riesgos, los riesgos negativos y los riesgos. Además, mide la magnitud del impacto medio ambiental de la actividad con respecto al factor a considerar. 
Tabla 5.6.3 Matriz de Leopold

\begin{tabular}{|c|c|c|c|c|c|c|c|c|c|}
\hline \multirow{3}{*}{ Factor } & \multicolumn{8}{|c|}{ Actividad } & \multirow{3}{*}{ Evaluación } \\
\hline & \multicolumn{2}{|c|}{ Construcción } & \multicolumn{6}{|c|}{ Operación } & \\
\hline & $\begin{array}{l}\text { Transformación } \\
\text { del suelo }\end{array}$ & Construcción & Pigmentar & Pesar & Roto moldeo & Enfriar & Cortar & Colocar & \\
\hline Agua & $-2 / 4$ & $-2 / 3$ & 0 & 0 & 0 & $-2 / 3$ & 0 & 0 & -20 \\
\hline Suelo & $-4 / 4$ & $-2 / 4$ & $-1 / 2$ & 0 & 0 & 0 & 0 & 0 & -26 \\
\hline Aire & $-3 / 5$ & $-3 / 3$ & $-2 / 3$ & 0 & $-1 / 4$ & $-2 / 3$ & 0 & 0 & -40 \\
\hline Ruido & $-5 / 6$ & $-5 / 6$ & $-2 / 2$ & 0 & $-1 / 3$ & $-1 / 2$ & 0 & 0 & -69 \\
\hline Salud & $-3 / 4$ & $-3 / 4$ & $-4 / 3$ & 0 & $-4 / 5$ & $-1 / 2$ & 0 & 0 & -58 \\
\hline Evaluación & -81 & -65 & -24 & $\mathbf{0}$ & -27 & -16 & 0 & 0 & 213 \\
\hline
\end{tabular}

Elaboración propia 


\section{- Etapa de construcción}

Se presentan los impactos negativos más altos en la etapa de construcción, ya que en la zona se encuentran varias plantas de producción. Además, existen zonas aledañas al proyecto de población urbana, las cuales podrían resultar afectadas por el proyecto en caso no se lleguen a mapear adecuadamente todos los grupos de interés y sobre todo sus necesidades.

La transformación de suelos y su posterior construcción representan un impacto moderado ya que la implementación de la planta industrial no requiere de grandes perforaciones de suelos ni de innumerables transportes de materiales y herramientas para su puesta en marcha. en resumen, la etapa de construcción de la fábrica consta de la sedimentación del área, construir paredes y techos, esto afecta la tierra, agua, atmósfera y flora de manera moderada, debido a que la zona elegida es una zona industrial donde estos factores se encuentran ya adaptados para la posible transformación del terreno en una planta de producción.

\section{- Actividades del proceso}

Los procesos que presentan impactos negativos ligeros son el pigmentado que afecta a la atmosfera, la salud de los operarios y su seguridad, al respirar pequeñas partículas de roto moldeo, el roto moldeado el cual genera $\mathrm{CO}_{2}$, utilizando GLP, y el enfriado que genera vapor de agua el cual termina evaporándose por las altas temperaturas.

Cabe resaltar que, a pesar de presentar impactos negativos ligeros, se deben tener en cuenta las medidas de prevención establecidas por la ley de residuos sólidos y el reglamento ambiental.

\subsection{Seguridad y Salud ocupacional}

La empresa cumplirá con la Ley de Seguridad y Salud en el trabajo (Ley No 29783). Por ello, todos los trabajadores deben tener conocimiento de la normativa para que se cumpla. Además, se capacitará a todos los trabajadores para cumplir con las siguientes funciones.

- Aprobar el reglamento que se realiza en la empresa de Seguridad y salud del trabajador de forma anual.

- Realizar inspecciones a las máquinas para prevenir accidentes. 
- Investigar las causas de los accidentes y de las enfermedades en el ambiente laboral y luego realizar las recomendaciones para evitarlas en el futuro.

- Para cumplir con el plan de seguridad y salud ocupacional, se procederá a elaborar la matriz IPERC y así poder cuantificar las actividades que generen riesgo y poder mitigarlas mediante la mejora de procedimientos $\mathrm{e}$ implementando el correcto uso de EPP's. 
Tabla 5.7.1 Matriz IPERC

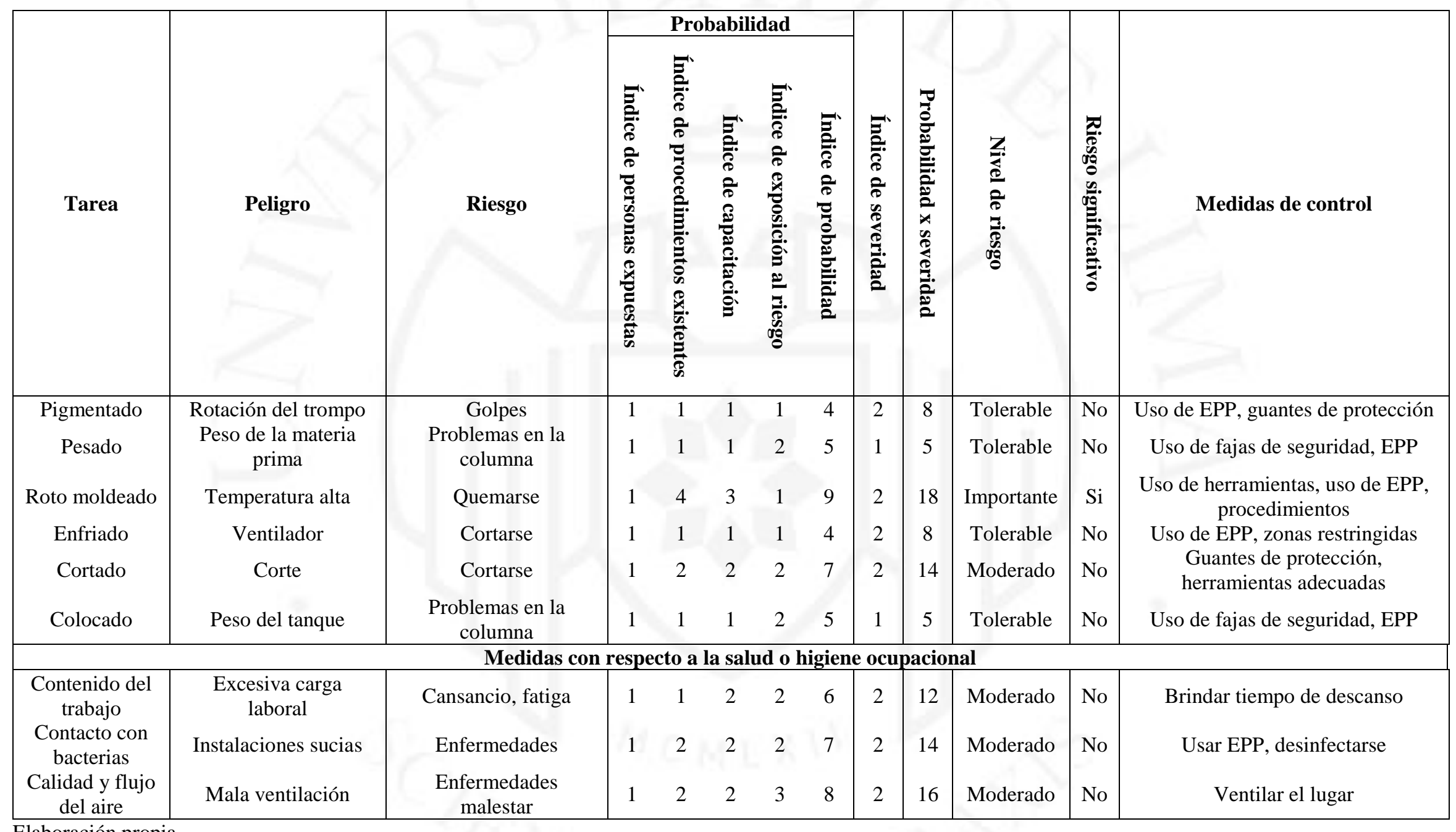

Elaboración propia 
Tabla 5.7.2 Índice de severidad

\begin{tabular}{|c|c|c|c|c|c|}
\hline \multirow[b]{2}{*}{ Índice } & \multicolumn{4}{|c|}{ Probabilidad } & \multirow[b]{2}{*}{ Severidad (Consecuencia) } \\
\hline & $\begin{array}{l}\text { Personas } \\
\text { expuestas }\end{array}$ & Procedimientos existentes & Capacitación & Exposición al riesgo & \\
\hline 1 & 1 a 3 & $\begin{array}{c}\text { Existen son satisfactorios } \\
\text { y suficientes. }\end{array}$ & $\begin{array}{l}\text { Personal entrenado, conoce } \\
\text { el peligro y lo previene }\end{array}$ & $\begin{array}{l}\text { Al menos una vez al } \\
\text { año. } \\
\text { ESPORADICAMENTE. }\end{array}$ & $\begin{array}{l}\text { Lesión de incapacidad. } \\
\text { DISCONFORT/ INCOMODIDAD }\end{array}$ \\
\hline 2 & 4 a 12 & $\begin{array}{c}\text { Existen parcialmente y no } \\
\text { son satisfactorios o } \\
\text { suficientes. }\end{array}$ & $\begin{array}{l}\text { Personal parcialmente } \\
\text { entrenado, conoce el peligro, } \\
\text { pero no toma acciones de } \\
\text { control }\end{array}$ & $\begin{array}{l}\text { Al menos una vez al } \\
\text { mes. } \\
\text { EVENTUALMENTE. }\end{array}$ & $\begin{array}{l}\text { Lesión con incapacidad temporal. } \\
\text { DAÑO A LA SALUD REVERSIBLE }\end{array}$ \\
\hline 3 & 12 a más & No existe & $\begin{array}{l}\text { Personal no entrenado, no } \\
\text { conoce el peligro, no toma } \\
\text { acciones de control }\end{array}$ & $\begin{array}{l}\text { Al menos una vez al día. } \\
\text { PERMANENTE. }\end{array}$ & $\begin{array}{c}\text { Lesión con incapacidad permanente. } \\
\text { DAÑO A LA SALUD } \\
\text { IRREVERSIBLE }\end{array}$ \\
\hline
\end{tabular}

Elaboración propia

Tabla 5.7.3 Calificación del riesgo

\begin{tabular}{|c|c|}
\hline Calificación del riesgo & Tipo de riesgo \\
\hline 4 & Trivial \\
De 5 a 8 & Tolerable \\
De 9 a 16 & Moderado \\
De 17 a 24 & Importante \\
De 25 a 36 & Intolerable \\
\hline
\end{tabular}

Elaboración propia 


\subsection{Sistema de mantenimiento}

Se emplearán 3 tipos de mantenimientos para el siguiente proyecto.

El uso del sistema de mantenimiento en nuestro proyecto va a permitir lo siguiente:

- Mejorar e incrementar la disponibilidad y la vida útil de las maquinas

- Reducir los costos operativos y administrativos.

- Evitar fallas imprevistas que puedan paralizar el proceso de manufactura

A continuación, se presenta un cuadro con los diversos mantenimientos autónomos y preventivos que se tomaran en cuenta.

Tabla 5.8.1 Mantenimientos autónomos y preventivos

\begin{tabular}{|c|c|c|}
\hline Máquina & Mantenimiento autónomo & Mantenimiento preventivo \\
\hline $\begin{array}{l}\text { Horno a llama } \\
\text { abierta de roto } \\
\text { moldeo }\end{array}$ & $\begin{array}{l}\text { Engrasado de engranajes, piñón, } \\
\text { chumacera y guías } \\
\text { Ajuste de tuercas }\end{array}$ & $\begin{array}{l}\text { Reemplazo de los engranajes y del } \\
\text { piñón } \\
\text { Reemplazo de las tuercas } \\
\text { Mantenimiento de motor }\end{array}$ \\
\hline $\begin{array}{l}\text { Molde de tanque } \\
\text { de 1,200 litros }\end{array}$ & Revisión de restos de polietileno & Reemplazo de los pernos y tuercas \\
\hline $\begin{array}{l}\text { Ventilador } \\
\text { industrial con } \\
\text { aspersor de agua }\end{array}$ & $\begin{array}{l}\text { Revisión en los niveles de agua } \\
\text { Revisión de alguna pieza dentro } \\
\text { del ventilador }\end{array}$ & $\begin{array}{l}\text { Reemplazo de tuercas } \\
\text { Reemplazo de mangueras }\end{array}$ \\
\hline $\begin{array}{l}\text { Trompo } \\
\text { mezclador }\end{array}$ & $\begin{array}{c}\text { Engrasado de engranajes, piñón. } \\
\text { Limpieza externa }\end{array}$ & $\begin{array}{l}\text { Reemplazo de pernos y tuercas } \\
\text { Reemplazo de piñón } \\
\text { Mantenimiento de motor }\end{array}$ \\
\hline $\begin{array}{l}\text { Balanza } \\
\text { electrónica de } \\
\text { plataforma }\end{array}$ & $\begin{array}{l}\text { Revisión de calibración de la } \\
\text { balanza con un peso calibrado }\end{array}$ & Mantenimiento de balanza \\
\hline $\begin{array}{l}\text { Tanque de gas } \\
\text { GLP }\end{array}$ & Revisión del medidor de gas & Reemplazo de válvulas \\
\hline Estoca hidráulica & Ajuste de tuercas & $\begin{array}{l}\text { Reemplazo de las llantas delanteras } \\
\text { y traseras }\end{array}$ \\
\hline
\end{tabular}

Elaboración propia

Finalmente, se busca reducir al máximo los mantenimientos reactivos, por ende, se espera tener una cantidad de ocurrencia de mantenimiento reactivo del $20 \%$ y su complemento de mantenimiento preventivos. 


\subsection{Diseño de la cadena de suministro}

La cadena de suministro para el trabajo de investigación se muestra a continuación.

Figura 5.9.1 Cadena de suministro

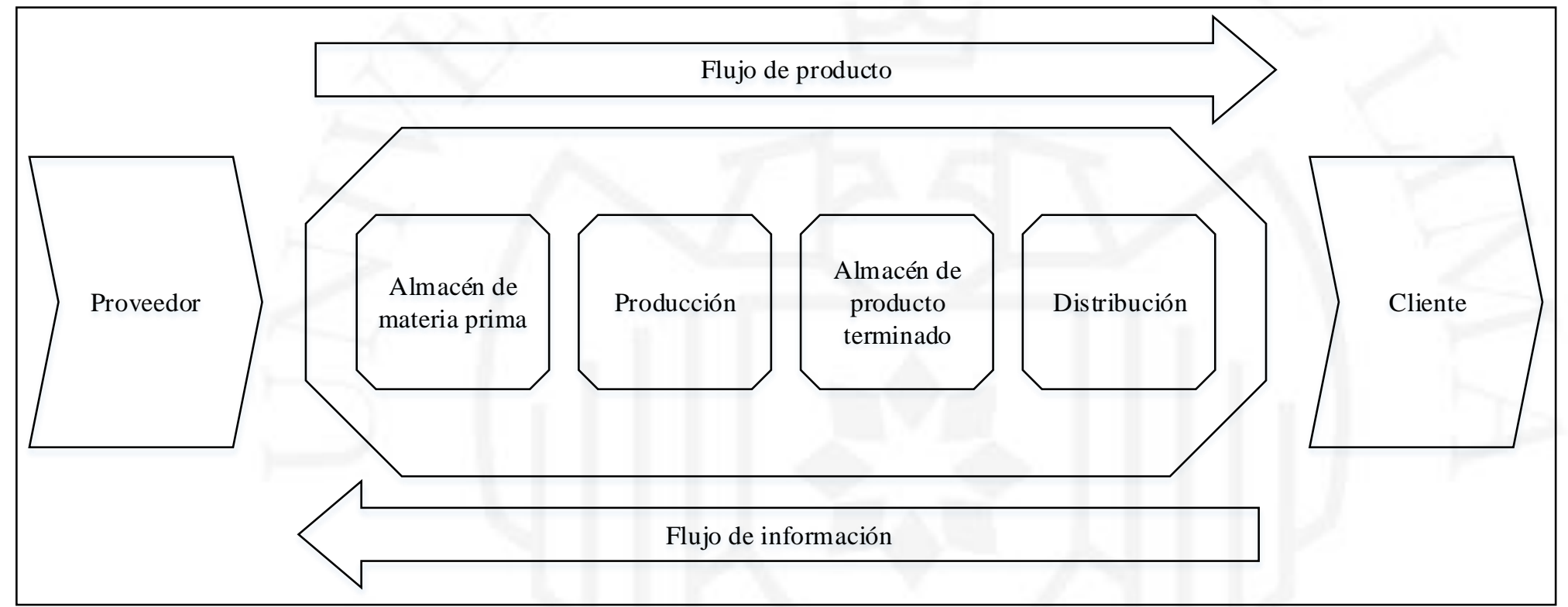

Elaboración propia 
La empresa contará con 2 proveedores esenciales de materia prima siendo ambos extranjeros. El proveedor para polietileno virgen se ubica en México y sus proveedores principales vienen a ser las principales petroquímicas de Estados Unidos de América. El proveedor para polietileno reciclado se ubica en China y sus proveedores principales son aquellas industrias que utilizan en su proceso polietileno. También se requiere de 1 insumo de procedencia nacional. Luego de recibir las materias primas e insumos se almacenarán en su respectivo almacén a la espera de ingresar al proceso productivo. Luego que se ejecuta el proceso productivo los productos terminados se almacenaran en su respectivo almacén para finalmente ser enviados a los clientes. Los cuales son el cliente final y las ferreterías.

\subsection{Programa de producción}

Se considerará una política de inventarios para los tanques de 1 mes correspondiente a la demanda del siguiente año y para el plan de requerimiento de materias primas se considerará un stock de seguridad de 1 mes correspondiente a la demanda del siguiente año. En la siguiente tabla se muestra el programa de producción y el plan de requerimiento de materias primas.

Tabla 5.10.1 Plan de producción

\begin{tabular}{|c|c|c|c|c|c|c|c|}
\cline { 2 - 8 } \multicolumn{1}{c|}{} & 2019 P & $\mathbf{2 0 2 0}$ P & $\mathbf{2 0 2 1} \mathbf{P}$ & $\mathbf{2 0 2 2} \mathbf{P}$ & $\mathbf{2 0 2 3} \mathbf{P}$ & $\mathbf{2 0 2 4} \mathbf{P}$ & $\mathbf{2 0 2 5} \mathbf{P}$ \\
\hline Plan de la Demanda (un.) & 3,352 & 3,912 & 4,534 & 5,218 & 5,964 & 6,771 & 7,641 \\
Política de Inventarios (un.) & 326 & 378 & 435 & 497 & 564 & 637 & - \\
\hline Plan de Producción (un.) & $\mathbf{3 , 6 7 8}$ & $\mathbf{3 , 9 6 4}$ & $\mathbf{4 , 5 9 1}$ & $\mathbf{5 , 2 8 0}$ & $\mathbf{6 , 0 3 1}$ & $\mathbf{6 , 8 4 4}$ & $\mathbf{7 , 0 0 4}$ \\
\hline
\end{tabular}

Elaboración propia

Tabla 5.10.2 Plan de requerimiento

\begin{tabular}{|c|c|c|c|c|c|c|c|}
\cline { 2 - 8 } \multicolumn{1}{c|}{} & $\mathbf{2 0 1 9}$ P & $\mathbf{2 0 2 0}$ P & $\mathbf{2 0 2 1}$ P & $\mathbf{2 0 2 2}$ P & $\mathbf{2 0 2 3}$ P & $\mathbf{2 0 2 4}$ P & $\mathbf{2 0 2 5}$ P \\
\hline N.B de p. Reciclado (kg.) & 51,492 & 55,494 & 64,274 & 73,922 & 84,438 & 95,809 & 98,060 \\
N.B de p. Virgen (kg.) & 22,068 & 23,783 & 27,546 & 31,681 & 36,188 & 41,061 & 42,026 \\
N.B de pigmento (kg.) & 572 & 617 & 714 & 821 & 938 & 1,065 & 1,090 \\
\hline Necesidades brutas (kg.) & 74,132 & 79,893 & 92,534 & 106,425 & 121,563 & 137,935 & 141,175 \\
Stock de seguridad (kg.) & 6,658 & 7,711 & 8,869 & 10,130 & 11,495 & 11,765 & - \\
\hline Plan de requerimiento (kg.) & $\mathbf{8 0 , 7 9 0}$ & $\mathbf{8 0 , 9 4 7}$ & $\mathbf{9 3 , 6 9 2}$ & $\mathbf{1 0 7 , 6 8 6}$ & $\mathbf{1 2 2 , 9 2 7}$ & $\mathbf{1 3 8 , 2 0 5}$ & $\mathbf{1 2 9 , 4 1 0}$ \\
\hline
\end{tabular}

Elaboración propia 


\subsection{Requerimientos de insumos, servicios y personal indirecto}

- Materia prima, insumos y otros materiales

La materia prima requerida en kilogramo por año para el proyecto es la siguiente.

Tabla 5.11.1 Materia prima

\begin{tabular}{|c|c|c|c|c|c|}
\hline Año & $\begin{array}{c}\text { Plan de } \\
\text { producción } \\
\text { (un.) }\end{array}$ & $\begin{array}{c}\text { PEBD } \\
\text { reciclado } \\
\text { (kg.) }\end{array}$ & $\begin{array}{c}\text { PEBD } \\
\text { virgen (kg.) }\end{array}$ & $\begin{array}{c}\text { Pigmento } \\
\text { negro (kg.) }\end{array}$ & $\begin{array}{c}\text { Brida } \\
\text { (un.) }\end{array}$ \\
\hline 2019 P & 3,678 & 51,492 & 22,068 & 572 & 3,678 \\
$\mathbf{2 0 2 0}$ P & 3,964 & 55,494 & 23,783 & 617 & 3,964 \\
$\mathbf{2 0 2 1}$ P & 4,591 & 64,274 & 27,546 & 714 & 4,591 \\
$\mathbf{2 0 2 2}$ P & 5,280 & 73,922 & 31,681 & 821 & 5,280 \\
$\mathbf{2 0 2 3}$ P & 6,031 & 84,438 & 36,188 & 938 & 6,031 \\
$\mathbf{2 0 2 4}$ P & 6,844 & 95,809 & 41,061 & 1,065 & 6,844 \\
$\mathbf{2 0 2 5}$ P & 7,004 & 98,060 & 42,026 & 1,090 & 7,004 \\
\hline
\end{tabular}

Elaboración propia

- Diagrama de Gozinto

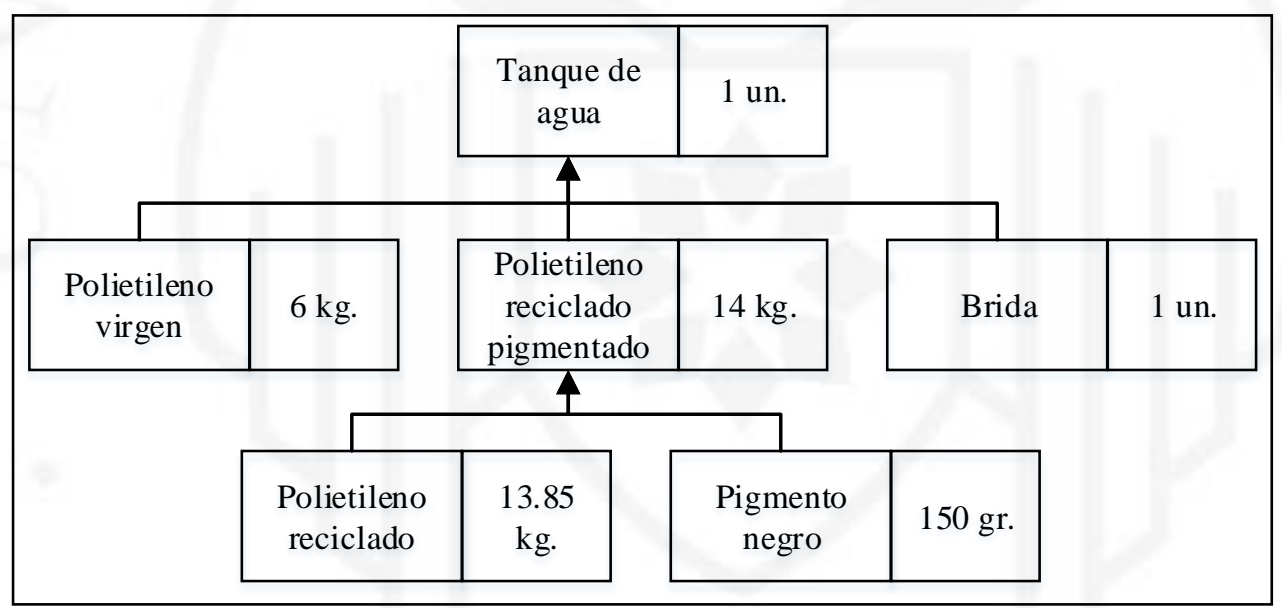

Elaboración propia

\subsubsection{Servicios: energía eléctrica, agua, vapor, combustible}

- Energía eléctrica

El horno de roto moldeo cuenta con 2 motores y ambos consumen $1.5 \mathrm{Kw}$-h cada uno.

- GLP

El horno de roto moldeo funciona con gas GLP para los quemadores. 


\subsubsection{Determinación del número de trabajadores indirectos}

La cantidad de trabajadores indirectos requeridos para el proyecto es la siguiente.

Tabla 5.11.2 Trabajadores indirectos

\begin{tabular}{|c|c|}
\hline Trabajadores indirectos & $\begin{array}{c}\text { Número de } \\
\text { trabajadores }\end{array}$ \\
\hline Gerente general & 1 \\
Administrador & 1 \\
Almacenero facturador & 1 \\
Contador/a & 1 \\
Chofer & 1 \\
Vendedor Lima Norte & 1 \\
Vendedor Lima Sur & 1 \\
\hline Total & 7 \\
\hline
\end{tabular}

Elaboración propia

\subsubsection{Servicios de terceros}

Se requieren de 5 servicios de terceros.

- Telefonía móvil.

- Internet

- Vigilancia

- Limpieza

- Montacargas industriales

Para el proyecto no se requerirá del uso de telefonía fija, toda comunicación se realizará a través de los teléfonos móviles. Se contará con routers inalámbricos no fijos para poder acceder a internet en las instalaciones. Los servicios de vigilancia las 24 horas y de limpieza de las instalaciones 1 vez a la semana serán tercerizados. También, se alquilarán montacargas industriales por hora para poder descargar las parihuelas de materia prima cuando lleguen los contenedores de importación. 


\subsection{Disposición de planta}

\subsubsection{Características físicas del proyecto}

\section{- Factor material}

Para elaborar el tanque de polietileno reciclado en la capa exterior se necesita de los siguientes materiales.

Tabla 5.12.1 Descripción de materiales

\begin{tabular}{|c|c|c|c|c|c|}
\hline $\begin{array}{l}\text { Producto: } \\
\text { Tanque de }\end{array}$ & \multicolumn{5}{|c|}{ Descripción del factor material } \\
\hline Materiales & $\begin{array}{c}\text { Estado } \\
\text { del } \\
\text { material }\end{array}$ & $\begin{array}{c}\text { Forma de } \\
\text { presentación/car } \\
\text { acterísticas } \\
\text { Físicas }\end{array}$ & Dimensiones & $\begin{array}{l}\text { Cantidad/uni } \\
\text { dad de carga }\end{array}$ & $\begin{array}{c}\text { Riesgo o } \\
\text { cuidados } \\
\text { especiales }\end{array}$ \\
\hline $\begin{array}{c}\text { PEBD } \\
\text { Reciclado }\end{array}$ & Solido & $\begin{array}{l}\text { Granulado en } \\
\text { sacos de } \\
\text { polipropileno }\end{array}$ & $\begin{array}{c}\text { Zaranda de malla } \\
2 \text { mm., estándar } \\
\text { americano }\end{array}$ & $\begin{array}{c}\text { Sacos de } 20 \\
\text { kg. }\end{array}$ & $\begin{array}{l}\text { Proteger de } \\
\text { la humedad }\end{array}$ \\
\hline $\begin{array}{l}\text { PEBD } \\
\text { Virgen }\end{array}$ & Solido & $\begin{array}{l}\text { Granulado en } \\
\text { sacos de } \\
\text { polipropileno }\end{array}$ & $\begin{array}{c}\text { Zaranda de malla } \\
2 \mathrm{~mm} ., \text { estándar } \\
\text { americano }\end{array}$ & $\begin{array}{c}\text { Sacos de } 20 \\
\text { kg. }\end{array}$ & $\begin{array}{l}\text { Proteger de } \\
\text { la humedad }\end{array}$ \\
\hline $\begin{array}{l}\text { Pigmento } \\
\text { negro }\end{array}$ & Solido & $\begin{array}{l}\text { Granulado en } \\
\text { sacos de } \\
\text { polipropileno }\end{array}$ & $\begin{array}{c}\text { Zaranda de malla } \\
2 \mathrm{~mm} . \text {, estándar } \\
\text { americano }\end{array}$ & $\begin{array}{c}\text { Sacos de } 20 \\
\mathrm{~kg} .\end{array}$ & $\begin{array}{l}\text { Proteger de } \\
\text { la humedad }\end{array}$ \\
\hline Brida & Solido & $\begin{array}{c}\text { Material } \\
\text { Polietileno, sello } \\
\text { EPDM }\end{array}$ & $\begin{array}{l}\text { Diámetro exterior } \\
\text { 3", Tamaño del } \\
\text { agujero } 1 \frac{1 / 2 "}{}\end{array}$ & $\begin{array}{l}\text { Caja de } 50 \\
\text { unidades }\end{array}$ & $\begin{array}{c}\text { Evitar } \\
\text { amontonar }\end{array}$ \\
\hline
\end{tabular}

Elaboración propia

Cada saco de materia prima contiene $20 \mathrm{~kg}$ y en una parihuela de $1.00 \mathrm{~m}$ x $1.20 \mathrm{~m}$ entran 40 sacos, lo que equivale a $800 \mathrm{~kg}$ de materia prima. Cada rack de almacenamiento tiene una medida de $0.90 \mathrm{~m}$ x $3 \mathrm{~m}$ x $4.50 \mathrm{~m}$ en donde se ubicarán 6 parihuelas y puede soportar un peso total de 6 toneladas sin contar las 2 parihuelas que se ubicarán en el piso. Es decir, cada rack de almacenamiento puede almacenar 4,800 kg. De materia prima. Se contará con 2 meses de stock de materia prima más 1 mes de stock de seguridad. En los racks se almacenará el total de materia prima y de los insumos, es decir el PEBD virgen, PEBD reciclado y el pigmento negro. 
Tabla 5.12.2 Cantidad de racks

\begin{tabular}{|c|c|c|c|}
\hline Año & $\begin{array}{c}\text { Plan de } \\
\text { producción } \\
\text { (un.) }\end{array}$ & $\begin{array}{c}\text { Materia } \\
\text { prima e } \\
\text { insumos } \\
\text { (kg.) }\end{array}$ & $\begin{array}{c}\text { Racks a } \\
\text { utilizar } \\
\text { (un.) }\end{array}$ \\
\hline 2019 P & 3,678 & 18,533 & 4 \\
$\mathbf{2 0 2 0}$ P & 3,964 & 19,973 & 5 \\
$\mathbf{2 0 2 1}$ P & 4,591 & 23,134 & 5 \\
2022 P & 5,280 & 26,606 & 6 \\
$\mathbf{2 0 2 3}$ P & 6,031 & 30,391 & 7 \\
$\mathbf{2 0 2 4}$ P & 6,844 & 34,484 & 8 \\
2025 P & 7,004 & 35,294 & 8 \\
\hline
\end{tabular}

Elaboración propia

En conclusión, se requerirán de 8 racks industriales con las medidas antes mencionadas para almacenar 2 meses de stock de materia prima y 1 mes de stock de seguridad de materia prima utilizando la demanda del último año del proyecto.

Figura 5.12.1 Rack industrial

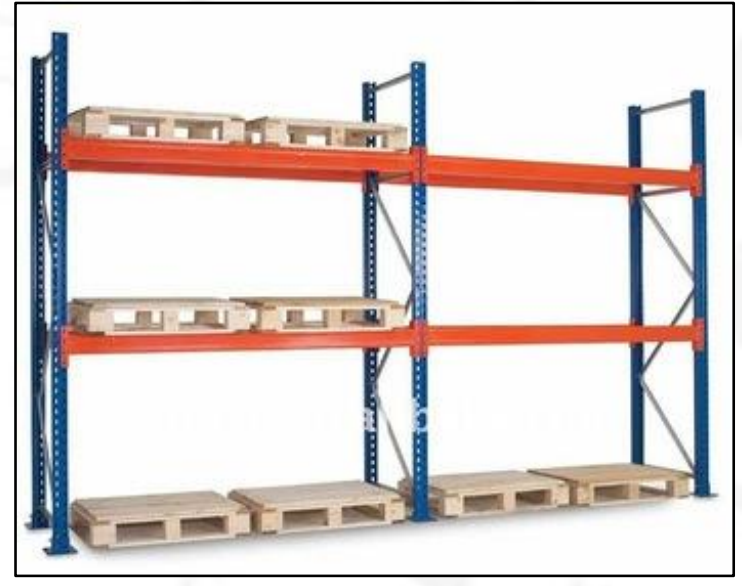

Fuente: Noegasystems (2015) 


\section{- Factor máquina}

En la siguiente tabla se muestra el análisis de Guerchet, en el cual se detalla las dimensiones de la maquinaria a utilizar. Se considerará el ventilador industrial y la estoca hidráulica como elementos estáticos debido a que estarán dentro del área de producción.

Tabla 5.12.3 Análisis de Guerchet elementos estáticos

\begin{tabular}{|c|c|c|c|c|c|c|c|c|c|c|c|}
\hline Estáticos & n & $\mathbf{N}$ & $\mathbf{l}(\mathbf{m})$ & $\mathbf{a}(\mathbf{m})$ & $\mathbf{h}(\mathbf{m})$ & Ss & $\mathbf{S g}$ & Ss $\times n \times h$ & Ss $\times$ n & Se & St \\
\hline $\begin{array}{l}\text { Balanza } \\
\text { electrónica }\end{array}$ & 1 & 1 & 0.5 & 0.5 & 1.5 & 0.25 & 0.25 & 0.375 & 0.25 & 0.2 & 0.7 \\
\hline $\begin{array}{l}\text { Trompo } \\
\text { mezclador }\end{array}$ & 1 & 1 & 1 & 1.5 & 1.5 & 1.5 & 1.5 & 2.25 & 1.5 & 1.3 & 4.3 \\
\hline $\begin{array}{c}\text { Almacén } \\
\text { temporal de } \\
\text { materia prima }\end{array}$ & 3 & 2 & 1.2 & 1 & 0.85 & 1.2 & 2.4 & 3.06 & 3.6 & 1.6 & 15.6 \\
\hline $\begin{array}{l}\text { Horno de llama } \\
\text { abierta }\end{array}$ & 1 & 2 & 3 & 2 & 2.5 & 6 & 12 & 15 & 6 & 8.0 & 26.0 \\
\hline Tanque de gas & 1 & 1 & 2 & 1 & 1.5 & 2 & 2 & 3 & 2 & 1.8 & 5.8 \\
\hline Molde 1200 & 4 & 1 & 1 & 1 & 1.5 & 1 & 1 & 6 & 4 & 0.9 & 11.6 \\
\hline $\begin{array}{l}\text { Ventilador } \\
\text { industrial }\end{array}$ & 4 & 1 & 0.5 & 0.5 & 1 & 0.25 & 0.25 & 1 & 1 & 0.2 & 2.9 \\
\hline $\begin{array}{c}\text { Estoca } \\
\text { hidráulica }\end{array}$ & 2 & 1 & 1.3 & 0.5 & 1.2 & 0.65 & 0.65 & 1.56 & 1.3 & 0.6 & 3.8 \\
\hline Total & & & & & & & & 26.56 & 14.30 & & 70.6 \\
\hline
\end{tabular}

Elaboración propia

Tabla 5.12.5 Análisis Guerchet elementos móviles

\begin{tabular}{|c|c|c|c|c|c|c|c|}
\hline Móviles & $\mathbf{n}$ & $\mathbf{I}(\mathbf{m})$ & $\mathbf{a}(\mathbf{m})$ & $\mathbf{h}(\mathbf{m})$ & Ss & Ss x n x h & Ss x n \\
\hline Operarios & 3 & - & - & 1.65 & 0.5 & 2.48 & 1.5 \\
\hline Total & \multicolumn{7}{|c|}{} \\
\hline
\end{tabular}

\begin{tabular}{|l|l|}
\hline$n$ & Número de elementos de un tipo \\
\hline $\mathrm{N}$ & Número de lados \\
\hline $\mathrm{St}$ & Superficie total \\
\hline $\mathrm{Ss}$ & Superficie estática \\
\hline $\mathrm{Sg}$ & Superficie de gravitación \\
\hline $\mathrm{Se}$ & Superficie de evolución \\
\hline
\end{tabular}

Elaboración propia 
Se calcula el coeficiente de evolución (k) siendo:

$$
k=\frac{h_{e m}}{2\left(h_{e e}\right)}
$$

Donde $h_{e m}$ es el promedio de alturas de los elementos móviles y se calcula de la siguiente manera:

$$
\begin{gathered}
h_{e m}=\frac{\sum(S S * n * h)}{\sum(S S * n)} \\
h_{e m}=1.65
\end{gathered}
$$

Y $h_{e e}$ es el promedio de alturas de máquinas o equipos fijos y se calcula de la siguiente manera:

$$
\begin{aligned}
& h_{e e}=\frac{\sum(S s * n * h)}{\sum(S s * n)} \\
& h_{e e}=1.86
\end{aligned}
$$

Entonces:

$$
k=0.44
$$

En conclusión, se requieren de $71.00 \mathrm{~m}^{2}$ para poder ubicar toda la maquinaria requerida.

- $\quad$ Factor edificio

La planta para la fabricación del producto contará con dos zonas importantes, la zona de producción en donde se tendrá que utilizar concreto armado constituido por piedra chancada, arena, fierro y cemento para poder colocar toda la maquinaría que se requiere. En la segunda zona se ubicará la parte administrativa y esta contará con concreto simple y paredes de drywall para el tránsito peatonal y el tránsito del vehículo de los trabajadores o clientes.

La planta contara con un pasillo combinado principal de 12 pies de ancho que empieza en la puerta del local y termina dentro de la planta, esto para poder ser eficientes cuando lleguen los contenedores de materia prima y se descarguen todos los sacos para almacenarlos directo en los racks industriales. Las puertas de acceso al local serán del tipo batientes dobles, cuando ingresen vehículos pequeños se abrirá una hoja, y cuando 
lleguen los camiones de importaciones se abrirán ambas hojas. Finalmente, el techo será de estructuras metálicas.

\section{- $\quad$ Factor espera}

Para la presenta planta se tendrán 2 tipos de almacén. Un almacén para las materias primas y otro para almacenar los productos terminados. En ambos casos se tendrá en cuenta stock de seguridad y políticas de inventario.

Finalmente, se contará con 3 puntos de espera, el primer punto de espera será para el polietileno reciclado y el pigmento antes de ser mezclados en el trompo giratorio, el segundo punto de espera será antes del roto moldeo, donde se tendrán listos los sacos, previamente pesados, de polietileno reciclado pigmentado y polietileno virgen, el ultimo almacén temporal es para el producto final, el cual se ira apilando para luego ser llevado a su respectivo almacén.

- Factor servicio

Se contará con 3 baños en el local, un baño para el área de gerencia, un baño para el área de oficina, y un baño con ducha y vestidor para el área de producción.

- Servicios de alimentación

Se contará con un comedor para toda la planta

- Iluminación

El local contará lámparas de techo y de pared para la iluminación en general.

\subsubsection{Determinación de las zonas físicas requeridas}

El local contará con las siguientes áreas:

- Recepción al cliente y ventas

- Sala de reunión

- Administración y finanzas

- Gerencia general

- $\quad$ SS. HH de gerencia

- Comedor

- $\quad$ SS. HH de oficina

- Área de producción 
- Almacén materia prima

- Almacén producto terminado

- $\quad$ SS. HH de área productiva

- $\quad$ Patio de maniobras

- Vigilancia

\subsubsection{Cálculo de áreas para cada zona}

- Área de administración

Esta área está compuesta por la oficina del gerente general, el área de contabilidad, atención a los clientes, el área administrativa del almacén y facturación, el área de la sala de reuniones con el espacio para los vendedores, la caseta de seguridad y los respectivos servicios sanitarios.

Tabla 5.12.4 Áreas de la zona administrativa

\begin{tabular}{|c|c|}
\hline Áreas & $\boldsymbol{m}^{\mathbf{2}}$ \\
\hline Gerencia General - 2do piso & $25 \mathrm{~m}^{2}$ \\
Servicios sanitarios de gerencia - 2do piso & $5 \mathrm{~m}^{2}$ \\
Comedor - 2do piso & $15 \mathrm{~m}^{2}$ \\
Administración y finanzas - 2do piso & $15 \mathrm{~m}^{2}$ \\
Recepción al cliente y ventas - 2do piso & $15 \mathrm{~m}^{2}$ \\
Sala de reunión - 2do piso & $15 \mathrm{~m}^{2}$ \\
Servicios sanitarios de oficina - 2do piso & $10 \mathrm{~m}^{2}$ \\
Vigilancia - 1er piso & $1.5 \mathrm{~m}^{2}$ \\
\hline Área total de administración & $\mathbf{1 0 1 . 5} \mathrm{m}^{2}$ \\
\hline
\end{tabular}

Elaboración propia 


\section{- Área de producción}

Esta área está compuesta por el patio de maniobras, el área de producción, el área de almacén de materia prima y productos terminados y los servicios sanitarios de la planta.

Tabla 5.12.5 Áreas de la zona de producción

\begin{tabular}{|c|c|}
\hline Áreas & $\boldsymbol{m}^{\mathbf{2}}$ \\
\hline Patio de maniobras - 1er piso & $54 \mathrm{~m}^{2}$ \\
Área de producción - 1er piso & $71 \mathrm{~m}^{2}$ \\
Almacén de materias primas - 1er piso & $37 \mathrm{~m}^{2}$ \\
Almacén de productos terminados - 1er piso & $30 \mathrm{~m}^{2}$ \\
Servicios sanitarios de planta - 2do piso & $15 \mathrm{~m}^{2}$ \\
\hline Área total de producción & $\mathbf{2 0 7} \mathbf{~ m 2}$ \\
\hline
\end{tabular}

Elaboración propia

Finalmente, se detallará el área total requerida para el proyecto de investigación.

Tabla 5.12.6 Área total requerida

\begin{tabular}{|c|c|}
\hline Área & $\boldsymbol{m}^{\mathbf{2}}$ \\
\hline Patio de maniobras & $54 \mathrm{~m}^{2}$ \\
Área de producción & $71 \mathrm{~m}^{2}$ \\
Almacén de materias primas & $37 \mathrm{~m}^{2}$ \\
Almacén de productos terminados & $30 \mathrm{~m}^{2}$ \\
Área de producción - 1er piso & $\mathbf{1 9 2} \mathbf{m}^{\mathbf{2}}$ \\
Vigilancia & $1.5 \mathrm{~m}^{2}$ \\
\hline Área total de terreno & $\mathbf{1 9 3 . 5} \mathbf{m}^{\mathbf{2}}$ \\
Factor de seguridad (8\%) & $208.98 \mathrm{~m}^{2}$ \\
\hline Área total requerida & $\approx \mathbf{2 1 0} \mathrm{m}^{2}$ \\
\hline
\end{tabular}

Elaboración propia

En conclusión, se requiere de un área de terreno de $210 \mathrm{~m}^{2}$ para el presente proyecto.

\subsubsection{Dispositivos de seguridad industrial y señalización}

La planta de fabricación contara con dispositivos de seguridad industrial, para así alertar sobre siniestros y tener una respuesta rápida y señalizaciones que permitan la correcta advertencia a los operarios sobre los cuidados que deben tener presente para así evitar toda clase de accidentes.

\section{- Sistemas de alarmas industriales}

Los sistemas de alarmas más importantes son los siguientes que se utilizarán serán los siguientes. 
- Control de acceso

- Alarmas contra ladrones

○ Señales de comienzo y termino de la jornada

- Sistemas instrumentados de seguridad

- Sistemas contra incendios

El sistema de alarma más conveniente para la apertura de la planta serán las alarmas automáticas que detectan humo y activa la alarma, con forme el giro del negocio vaya generando ingresos se ira invirtiendo en mayor tecnología. 
- Señales de seguridad

Se colocarán las siguientes señales en cada área que le corresponda y según la norma técnica peruana NTP 399.010-1 del 2004 Señales de seguridad, se clasifican en:

- Señales de equipos contra incendios

Figura 5.12.2 Equipos contra incendios

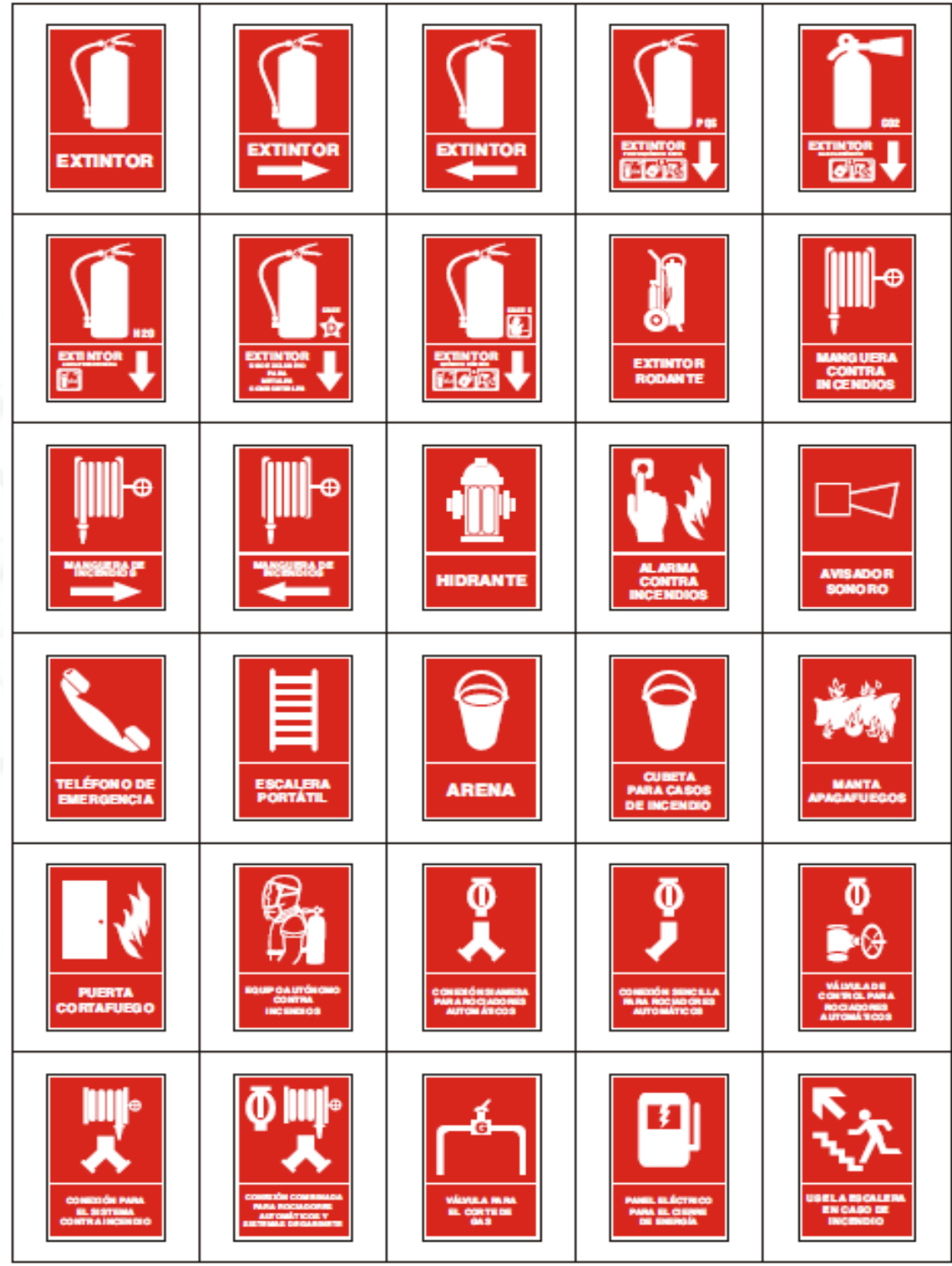

Elaboración propia 
- Señales de prohibición

Figura 5.12.3 Señales de prohibición

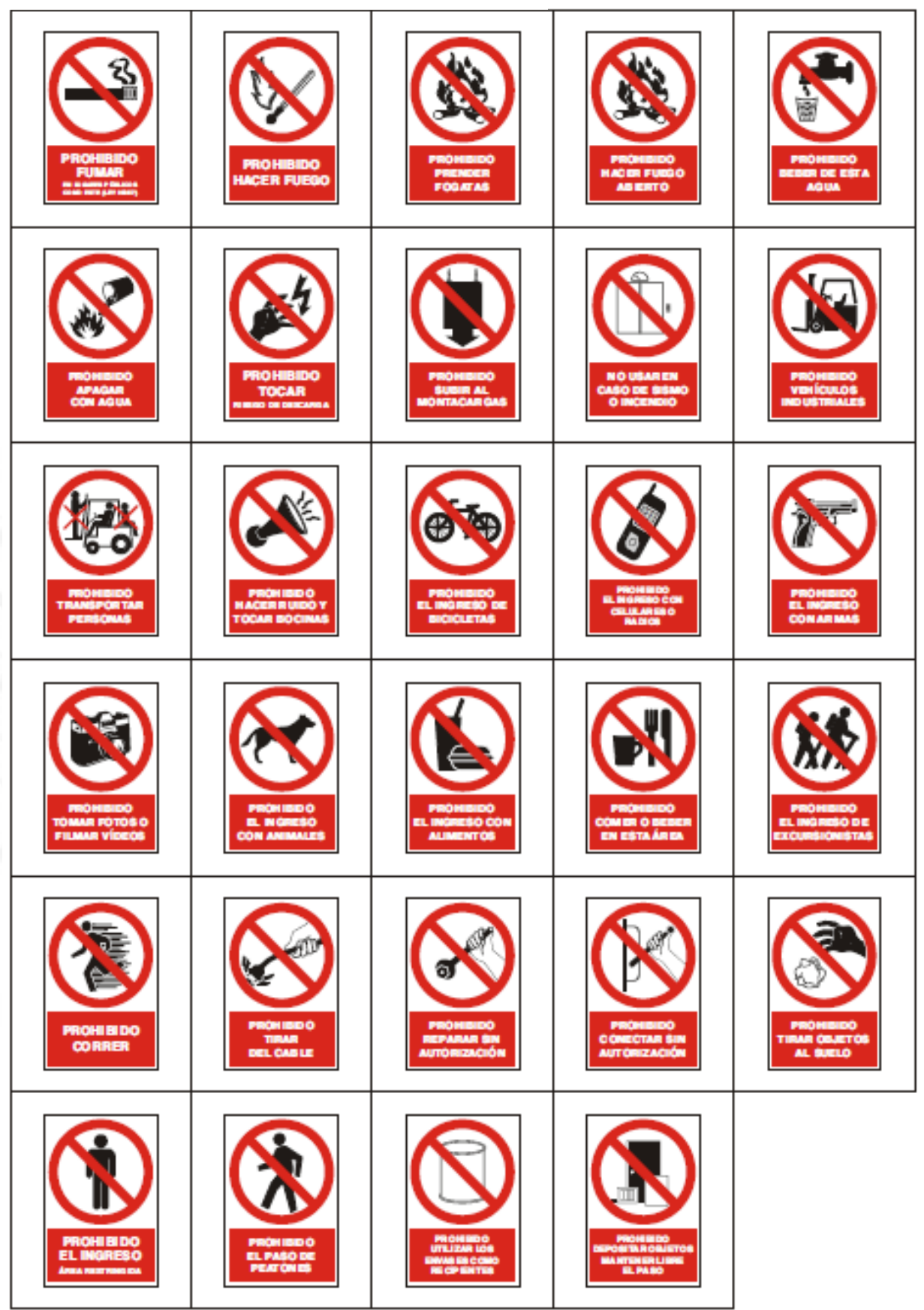

Elaboración propia 
- Señales de advertencia

Figura 5.12.4 Señales de advertencia

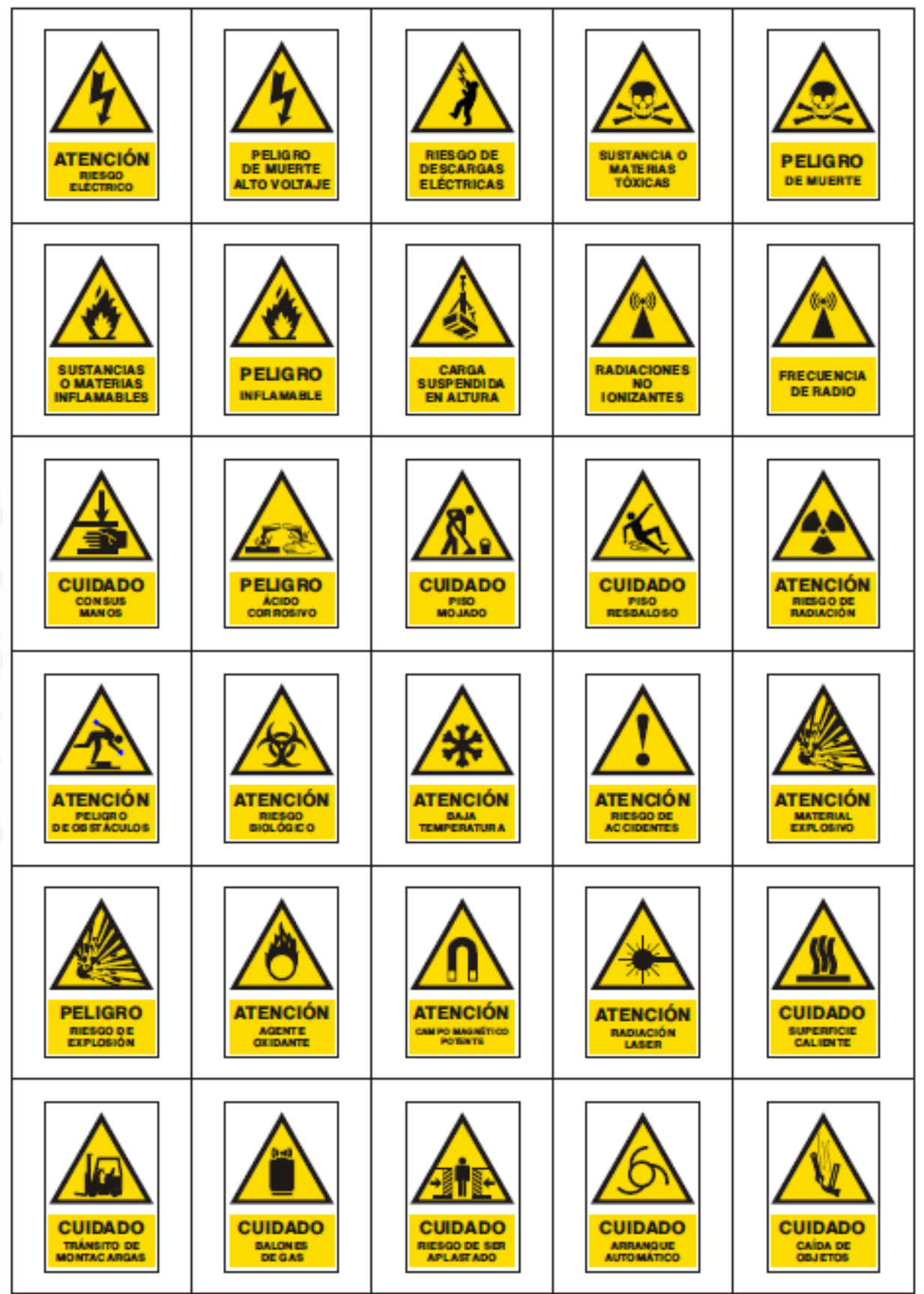

Elaboración propia 
- Señales de obligación

Figura 5.12.5 Señales de obligación

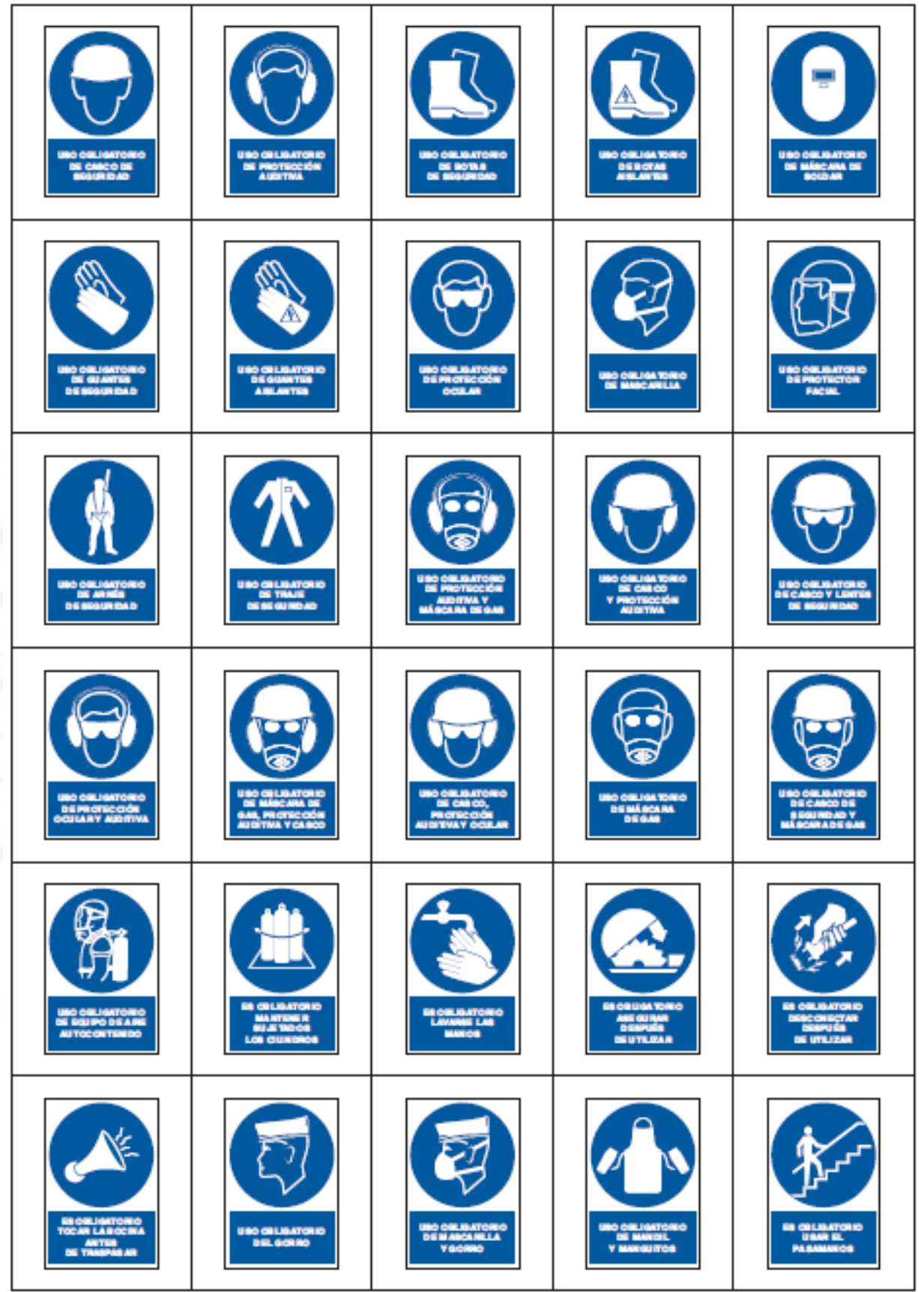

Elaboración propia 
- Señales de evacuación y emergencia

Figura 5.12.6 Señales de evacuación y emergencia

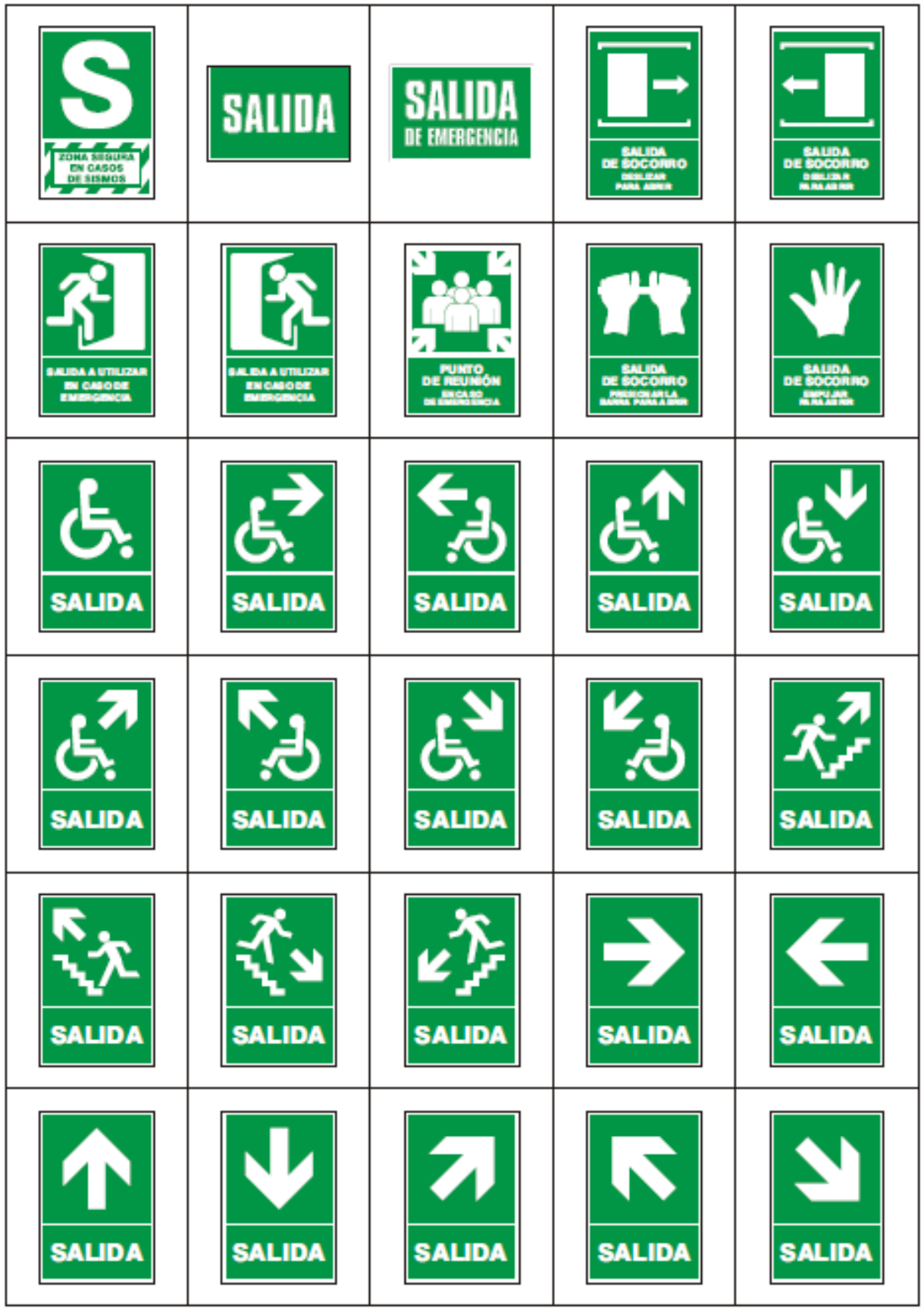

Elaboración propia 


\subsubsection{Disposición de detalle de la zona productiva}

Figura 5.12.7 Análisis relacional

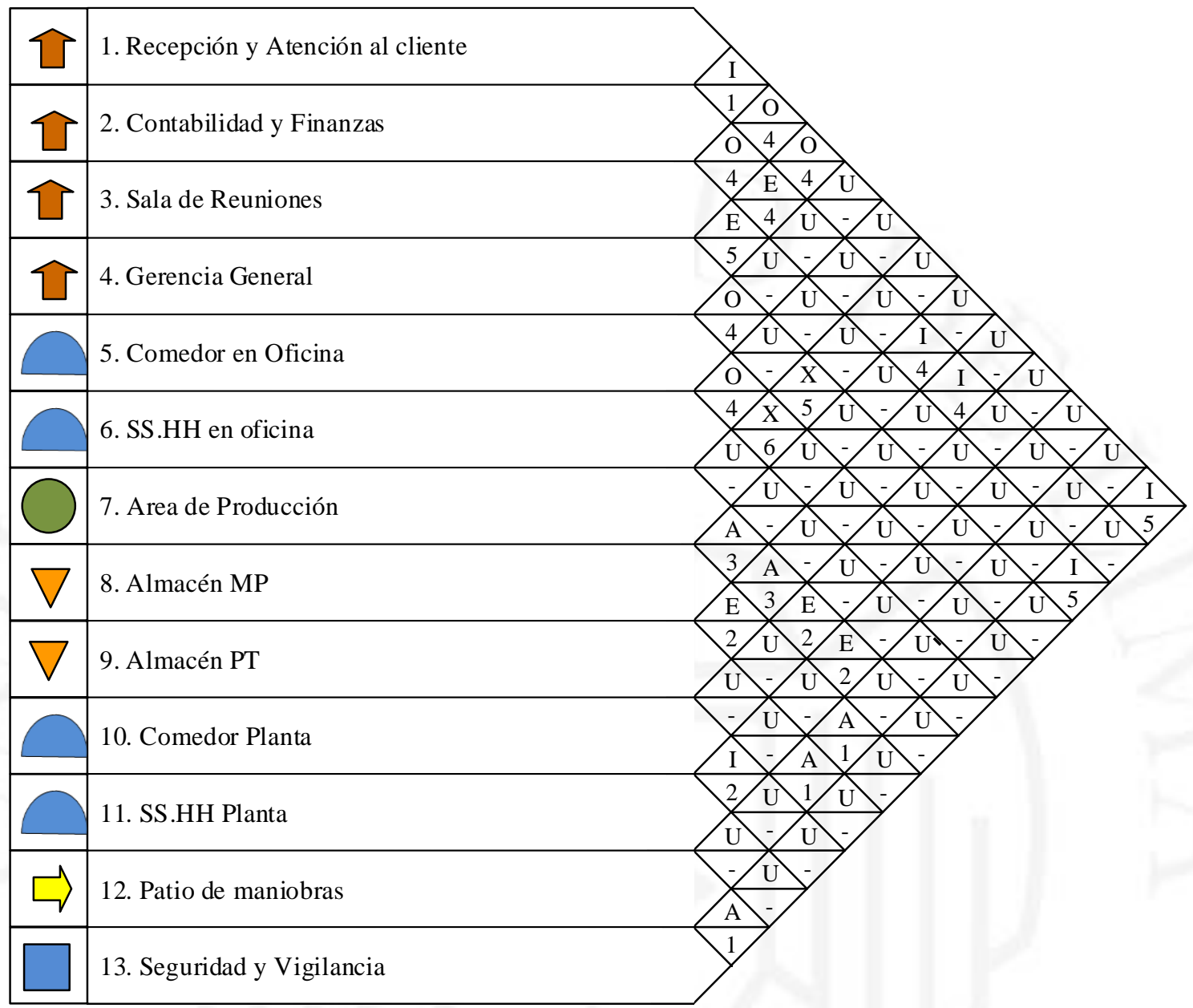

Elaboración propia

Tabla 5.12.7 Lista de motivos

\begin{tabular}{|c|c|}
\hline Código & Motivo \\
\hline $\mathbf{1}$ & Recepción y despacho \\
$\mathbf{2}$ & Mismo personal \\
$\mathbf{3}$ & Flujo de materiales \\
$\mathbf{4}$ & Flujo de comunicación \\
$\mathbf{5}$ & Atención a clientes \\
$\mathbf{6}$ & Posible contaminación \\
\hline
\end{tabular}

Elaboración propia 
Tabla 5.12.7 Valores y códigos de proximidad

\begin{tabular}{|c|c|c|c|}
\hline Código & Valor de proximidad & Color & $\mathbf{N}^{\circ}$ de líneas \\
\hline $\mathbf{A}$ & Absolutamente necesario & Rojo & 4 rectas \\
$\mathbf{E}$ & Especialmente necesario & Amarillo & 3 rectas \\
$\mathbf{I}$ & Importante & Verde & 2 rectas \\
$\mathbf{O}$ & Normal u ordinario & Azul & 1 recta \\
$\mathbf{U}$ & Sin importancia & - & - \\
$\mathbf{X}$ & No deseable & Plomo & 1 zigzag \\
$\mathbf{X X}$ & Altamente no deseable & Negro & 2 zigzag \\
\hline
\end{tabular}

Elaboración propia

Figura 5.12.8 Diagrama relacional

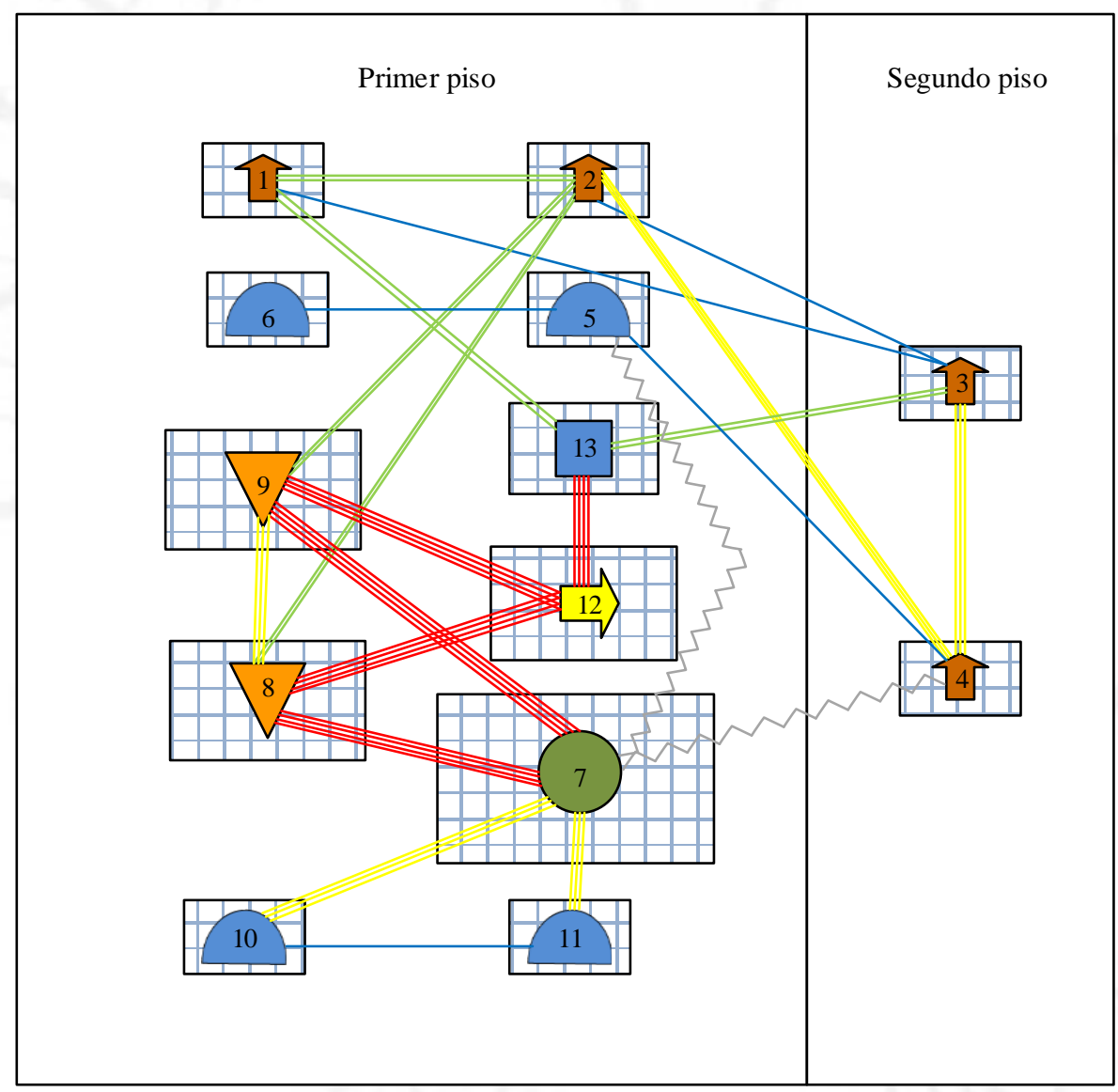

Elaboración propia 


\subsubsection{Disposición general}

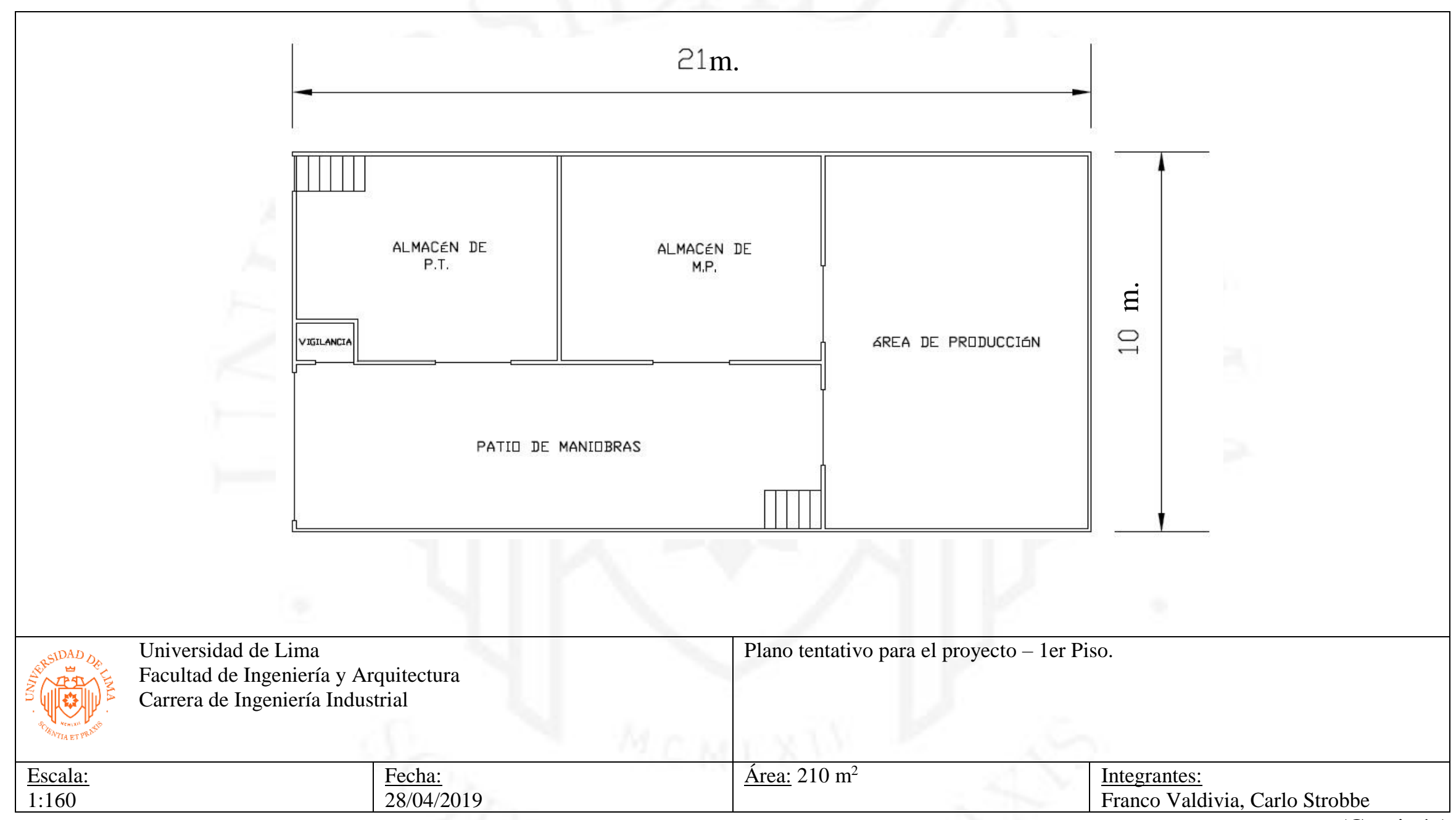

(Continúa) 
(Continuación)

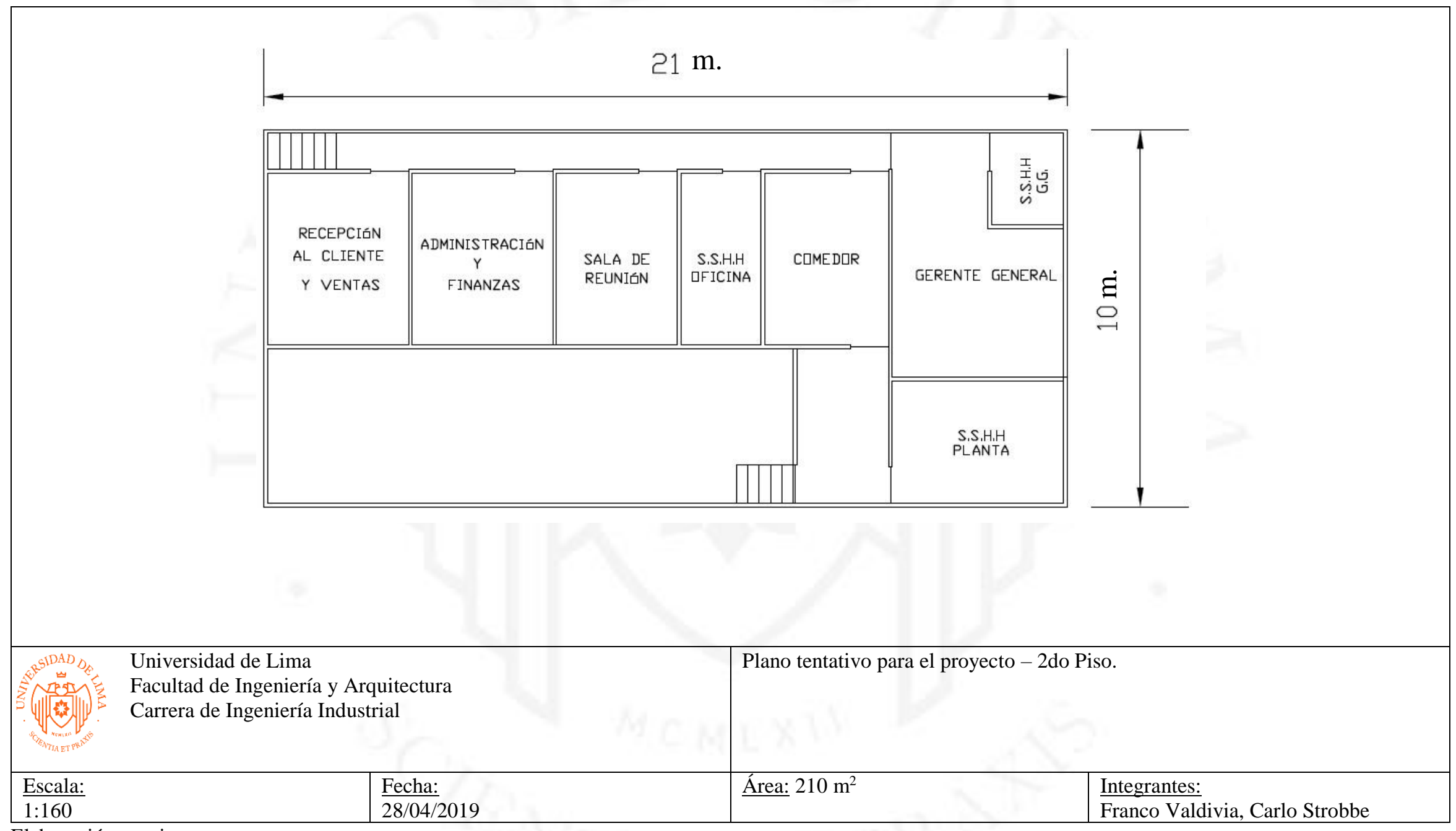

Elaboración propia 


\subsection{Cronograma de implementación del proyecto}

Tabla 5.12.1 Cronograma de implementación del proyecto

\begin{tabular}{|c|c|c|c|c|c|c|c|c|c|c|c|c|c|c|c|}
\hline Id & Nombre de tarea & 15 ene' 18 & $12 \mathrm{feb} \cdot 18$ & $12 \operatorname{mar} 18$ & 09 abr'18 & 07 mav'18 & 04 iun '18 & 02 iul'18 & 30 iul'18 & $27 a 00 \cdot 18$ & $24 \operatorname{sen} 18$ & 22 oct'18 & 19now'18 & 17 dic'18 & 14 ene'19 \\
\hline 1 & MPIEM NTACION DELA PLANTA & & & & & & & & & & & & & & \\
\hline 2 & Estediode Fre Ectibilind & & & & & & & & & & & & & & \\
\hline 3 & Invetigacion de aspectos generales & & & & & & & & & & & & & & \\
\hline 4 & Es tudio de mercado & & & & & & & & & & & & & & \\
\hline 5 & Localizacion de planta & & & & & & & & & & & & & & \\
\hline 6 & Tamriño de planta & & & & & & & & & & & & & & \\
\hline 7 & Ingenieria del proyecto & & & & & & & & & & & & & & \\
\hline 8 & Ogganización y administracion & & & & & & & & & & & & & & \\
\hline 9 & Evahuacion f finaciera del proyecto & & & & & & & & & & & & & & \\
\hline 10 & Evahuacion Social del proyeccto & & & & & & & & & & & & & & \\
\hline 11 & Cons titución de la empresa & & & & & & & & & & & & & & \\
\hline 12 & Financiamiento & & & & & & & & & & & & & & \\
\hline 13 & Adquisición de tenenos & & & & & & & & & & & & & & \\
\hline 14 & Licencia de construcción & & & & & & & & & & & & & & \\
\hline 15 & Ins talaciones básicas & & & & & & & & & & & & & & \\
\hline 16 & Cons trucción de cimientos & & & & & & & & & & & & & & \\
\hline 17 & Cons trucción de ha nave industrial & & & & & & & & & & & & & & \\
\hline 18 & Adquisición de maquimaria & & & & & & & & & & & & & & \\
\hline 19 & Ins talación de equipos & & & & & & & & & & & & & & \\
\hline 20 & Equipamiento de toda la planta & & & & & & & & & & & & & & \\
\hline 21 & Ins talaciones de servicios auxiliares & & & & & & & & & & & & & & \\
\hline 22 & Rechutamiento y s elección de pers onal & & & & & & & & & & & & & & \\
\hline 23 & Inducción y capacitación del personal & & & & & & & & & & & & & & \\
\hline 24 & Prueba de planta & & & & & & & & & & & & & & \\
\hline 25 & NICO DE LAS OPGRACONES DE LAPLANIA & & & & & & & & & & & & & $5 / 12$ & \\
\hline
\end{tabular}

Elaboración propia 


\section{CAPÍTULO VI: ORGANIZACIÓN Y ADMINISTRACIÓN}

En el presente capítulo se detallará toda la organización del personal requerida para el presente proyecto.

\subsection{Formación de la organización empresarial}

Para la formación de la empresa productora de tanques de polietileno reciclado para almacenar agua, se ha elegido la modalidad de persona jurídica y el tipo elegido es el de Sociedad Anónima Cerrada (SAC), ya que es un tipo de empresa dinámica, recomendable para empresas pequeñas y medianas, y además no limita el crecimiento.

\section{- Visión}

Expandirnos por todo el Perú brindando nuestro producto.

- Misión

Brindarles a más peruanos la posibilidad de almacenar agua en sus viviendas.

- Objetivos estratégicos

- Darle al cliente lo que necesita a un precio accesible.

- Mejorar continuamente nuestros procesos para lograr la satisfacción total de nuestros clientes.

- Ayudar a las personas de escasos recurso.

\subsection{Requerimientos de personal directivo, administrativo y de servicios}

- Gerente General

El gerente general es la persona con mayor jerarquía, y el responsable del buen funcionamiento del proyecto. Tiene el deber de asegurar que la empresa esté encaminada de acuerdo a su misión, visión y valores y es la persona que toma las decisiones trascendentes para la empresa como las metas a corto, mediano y largo plazo. También realizará las órdenes de compra con los proveedores, y realizará las gestiones de marketing y publicidad. 


\section{- Contador/a}

La labor del contador es de producir informes contables para la toma de decisiones de la gerencia. También, La tarea de este trabajador será la de realizar las cobranzas y la interactuación directa con los bancos para mantener las cuentas a la fecha.

\section{- Operarios}

Los operarios tienen la labor de realizar los procesos de manufactura para la elaboración de los tanques y manipular la maquinaria asignada a su puesto de trabajo.

\section{- Administrador/a}

La labor de este trabajador será la de comunicar ante cualquier tipo de cliente las propuestas que le puede ofrecer de la empresa. También, se encargará de ingresar todos los pedidos realizados mediante los vendedores al sistema, este generará la hoja de pedido para producción o la orden de despacho para el almacén.

\section{- Chofer}

La labor de este empleado será el de realizar los despachos y la entrega de los pedidos realizados.

\section{- Almacenero facturador}

Se encargará de mantener los inventarios, recibir los pedidos para gestionar los despachos y de realizar la facturación de las ventas.

\section{- Vendedor Lima centro-norte y centro-sur}

Los vendedores se encargarán de realizar las ventas en sus zonas respectivas para poder cubrir con la demanda proyectada. 
6.3 Esquema de la estructura organizacional

Figura 6.3.1 Estructura organizacional

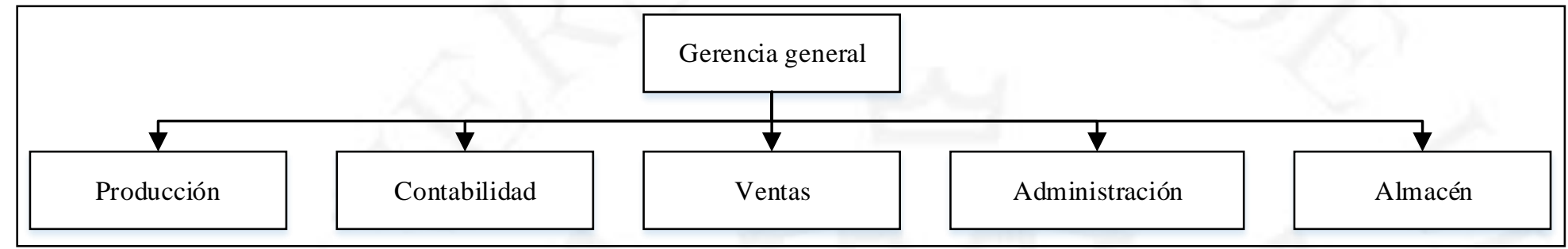

Elaboración propia 


\section{CAPÍTULO VII: PRESUPUESTOS Y EVALUACIÓN DEL PROYECTO}

En el presente capítulo se realizarán diversas evaluaciones financieras para comprobar la viabilidad económica del proyecto.

\subsection{Inversiones}

Para sustentar la inversión del proyecto de investigación se realizará la comparación entre 2 panoramas de ejecución. A continuación, se realizará la comparación entre comprar un local en la zona industrial de Puente Piedra o alquilar un local en la misma zona por 10 años. El diario peruano Gestión, realizó una publicación en el 2016 acerca de la oferta y demanda de los parques industriales en el norte, centro y sur del Perú. En el corredor Puente Piedra la venta de los locales va desde los US\$ 337 por metro cuadrado a US\$ 500 por metro cuadrado. La oferta en el alquiler de locales son en el corredor Puente Piedra y fluctúan entre US\$ 3.50 por m2 y US\$ 4.59 por m2. A continuación, se tomarán los valores máximos para realizar la respectiva comparación.

Tabla 7.1.1 Alquiler de local

\begin{tabular}{|c|c|}
\hline \multicolumn{2}{|c|}{ Alquiler de local } \\
\hline Local & $210 \mathrm{~m}^{2}$ \\
Costo $\left(\boldsymbol{m}^{2} / \mathrm{mes}\right)$ & $\$ 4.59$ \\
Años & 10 \\
\hline Costo total & $\mathbf{\$ 1 1 5 , 6 6 8}$ \\
\hline
\end{tabular}

Elaboración propia

Tabla 7.1.2 Compra de local

\begin{tabular}{|c|c|}
\hline \multicolumn{2}{|c|}{ Compra de local } \\
\hline Local & $210 \mathrm{~m}^{2}$ \\
Costo $\left(\boldsymbol{m}^{\mathbf{2}}\right)$ & $\$ 500$ \\
\hline Costo total & $\mathbf{\$ 1 0 5 , 0 0 0}$ \\
\hline
\end{tabular}

Elaboración propia 
Finalmente, se optará por realizar los cálculos de inversión considerando que se comprará el local a utilizar, debido a que en un plazo de 10 años conviene comprar el local en vez de alquilarlo. Cabe mencionar que se procederá a utilizar un tipo de cambio de dólar a sol de S/ 3.30. 
7.1.1 Estimación de las inversiones de largo plazo

- Activo fijo tangible

\begin{tabular}{|c|c|c|c|c|c|c|c|c|c|c|c|}
\hline & & & Depre & $\begin{array}{l}\text { ación de a } \\
31 \text { de dicie } \\
\text { Expresa }\end{array}$ & $\begin{array}{l}\text { ivos fijos } \\
\text { bre del } 20 \\
\text { en soles }\end{array}$ & $\begin{array}{l}\text { ngibles } \\
\mathrm{P}\end{array}$ & & & & & \\
\hline Activo fijo tangible & $\begin{array}{l}\text { Dep. } \\
\text { (años) }\end{array}$ & Importe & 2019 P & 2020 P & 2021 P & 2022 P & 2023 P & 2024 P & 2025 P & Depreciación & $\begin{array}{c}\text { Valor } \\
\text { residual }\end{array}$ \\
\hline Terreno & 0 & 346,500 & - & - & - & - & - & - & - & - & 346,500 \\
\hline Camión & 5 & 41,949 & 8,390 & 8,390 & 8,390 & 8,390 & 8,390 & - & - & 41,949 & - \\
\hline Construcción en drywall & 20 & 55,932 & 2,797 & 2,797 & 2,797 & 2,797 & 2,797 & 2,797 & 2,797 & 19,576 & 36,356 \\
\hline Rack industrial & 5 & 22,373 & 4,475 & 4,475 & 4,475 & 4,475 & 4,475 & - & - & 22,373 & - \\
\hline Laptops & 5 & 5,085 & 1,017 & 1,017 & 1,017 & 1,017 & 1,017 & - & - & 5,085 & - \\
\hline Escritorios con silla & 5 & 678 & 136 & 136 & 136 & 136 & 136 & - & - & 678 & - \\
\hline Juego comedor con 4 sillas & 5 & 508 & 102 & 102 & 102 & 102 & 102 & - & - & 508 & - \\
\hline Microondas & 5 & 127 & 25 & 25 & 25 & 25 & 25 & - & - & 127 & - \\
\hline Servicio Higiénico & 5 & 847 & 169 & 169 & 169 & 169 & 169 & - & - & - & - \\
\hline Impresora multifuncional & 5 & 720 & 144 & 144 & 144 & 144 & 144 & - & - & 720 & - \\
\hline Horno llama abierta de roto moldeo & 5 & 27,966 & 5,593 & 5,593 & 5,593 & 5,593 & 5,593 & - & - & 27,966 & - \\
\hline Molde tanque $1200 \mathrm{Lts}$ & 5 & 11,186 & 2,237 & 2,237 & 2,237 & 2,237 & 2,237 & - & - & 11,186 & - \\
\hline Ventilador industrial & 5 & 6,600 & 1,320 & 1,320 & 1,320 & 1,320 & 1,320 & - & - & 6,600 & - \\
\hline Trompo mezclador & 5 & 847 & 169 & 169 & 169 & 169 & 169 & - & - & 847 & - \\
\hline Balanza electrónica de plataforma & 5 & 508 & 102 & 102 & 102 & 102 & 102 & - & - & 508 & - \\
\hline Tanque de gas GLP & 5 & 4,237 & 847 & 847 & 847 & 847 & 847 & - & - & 4,237 & - \\
\hline Estoca hidráulica & 5 & 1,958 & 392 & 392 & 392 & 392 & 392 & - & - & 1,958 & - \\
\hline Depreciación no fabril & & & 17,254 & 17,254 & 17,254 & 17,254 & 17,254 & 2,797 & 2,797 & - & - \\
\hline Depreciación fabril & & & 10,661 & 10,661 & 10,661 & 10,661 & 10,661 & - & - & - & - \\
\hline Total del activo fijo tangible & & 528,024 & 500,109 & 472,194 & 444,279 & 416,364 & 388,449 & 385,653 & 382,856 & 144,320 & 382,856 \\
\hline & & & & & & & & & $\begin{array}{r}\text { Valor } \\
\text { Valo }\end{array}$ & $\begin{array}{l}\text { de mercado } \\
\text { r en libros }\end{array}$ & $\begin{array}{l}346,500 \\
382,856\end{array}$ \\
\hline
\end{tabular}

Elaboración propia 
- Activo fijo intangible

\begin{tabular}{|c|c|c|c|c|c|c|c|c|c|c|c|}
\hline \multicolumn{12}{|c|}{$\begin{array}{l}\text { Amortización de activos fijos intangibles } \\
\text { Al } 31 \text { de diciembre del } 2025 \mathrm{P}\end{array}$} \\
\hline Activo fijo intangible & $\begin{array}{l}\text { Amort. } \\
\text { (años) }\end{array}$ & Importe & $2019 P$ & $2020 P$ & $2021 P$ & $2022 P$ & $2023 P$ & $2024 P$ & $2025 P$ & Amortización & $\begin{array}{l}\text { Valor } \\
\text { residual }\end{array}$ \\
\hline Capacitación & 10 & 2,542 & 254 & 254 & 254 & 254 & 254 & 254 & 254 & 1,780 & 763 \\
\hline Constitución de la empresa & 10 & 508 & 51 & 51 & 51 & 51 & 51 & 51 & 51 & 356 & 153 \\
\hline Licencia de funcionamiento & 10 & 50 & 5 & 5 & 5 & 5 & 5 & 5 & 5 & 35 & 15 \\
\hline Registro de marca & 10 & 847 & 85 & 85 & 85 & 85 & 85 & 85 & 85 & 593 & 254 \\
\hline Estudio de pre factibilidad & 10 & 8,475 & 847 & 847 & 847 & 847 & 847 & 847 & 847 & 5,932 & 2,542 \\
\hline Software ERP & 3 & 8,475 & 2,825 & 2,825 & 2,825 & - & - & - & - & 8,475 & - \\
\hline Gastos pre operativos & 10 & 52,802 & 5,280 & 5,280 & 5,280 & 5,280 & 5,280 & 5,280 & 5,280 & 36,962 & 15,841 \\
\hline Contingencias intangibles $(5 \%)$ & 10 & 3,685 & 368 & 368 & 368 & 368 & 368 & 368 & 368 & 2,579 & 1,105 \\
\hline Amortización & - & - & 9,716 & 9,716 & 9,716 & 6,891 & 6,891 & 6,891 & 6,891 & 56,712 & 20,673 \\
\hline Total del activo fijo intangible & - & 77,385 & 67,669 & 57,953 & 48,237 & 41,346 & 34,455 & 27,564 & 20,673 & - & - \\
\hline & & & & & & & & & Val & n libros & 20,673 \\
\hline
\end{tabular}

Elaboración propia 


\subsubsection{Estimación de las inversiones de corto plazo}

La inversión de corto plazo está compuesta en su mayoría por el capital de trabajo. En el presente proyecto de investigación se le debe pagar a los proveedores el 100\% del costo antes del embarque de la materia prima, y a los clientes se les cobrara después de 30 días de haber realizada la compra. Por ende, el capital de trabajo debe cumplir con las obligaciones y poder cubrir 27 días de trabajo. A continuación, se representarán todos los gastos que constituirán el capital de trabajo que se requiere para el presente proyecto de investigación. A continuación, se realizará el cálculo para verificar el ciclo de conversión de efectivo.

Tabla 7.1.3 Ciclo de conversión de efectivo

\begin{tabular}{|c|c|}
\hline Rotación cuentas por cobrar & 30 días \\
Rotación cuentas por pagar & 10 días \\
Rotación de inventario & 7 días \\
Ciclo de conversión de efectivo & 27 días \\
Cuentas por cobrar & $\mathrm{S} / 75,964$ \\
Cuentas por pagar & $\mathrm{S} / 11,182$ \\
Inventario & $\mathrm{S} / 7,827$ \\
\hline $\begin{array}{c}\text { Ciclo de conversión de } \\
\text { efectivo }\end{array}$ & $\mathbf{S} / \mathbf{7 2 , 6 1 0}$ \\
\hline
\end{tabular}

Elaboración propia

La empresa contará con un flujo de caja mínimo mensual de S/ 2,000.00 para poder operar. Luego de analizar el flujo de caja se requiere de S/ 14,591 adicionales para poder cubrir los primeros meses trabajo. Finalmente, el capital de trabajo requerido para el proyecto es la suma del ciclo de conversión de efectivo más el monto requerido por el flujo de caja, es decir S/ 87,201.

\section{- Inversión total}

Tabla 7.1.4 Inversión total

\begin{tabular}{|c|c|}
\hline Activo fijo tangible & S/ 528,024 \\
Activo fijo intangible & S/ 77,385 \\
Ciclo de conversión de efectivo & S/ 72,610 \\
Flujo de caja & S/ 14,591 \\
\hline Inversión total & S/ 692,610 \\
\hline
\end{tabular}

Elaboración propia 


\subsection{Costos de producción}

A continuación, se muestran todos los costos de producción para cada año proyectado.

Tabla 7.2.1 Costos de producción

\begin{tabular}{|c|c|c|c|c|c|c|c|}
\hline & \multicolumn{7}{|c|}{$\begin{array}{l}\text { Costos de producción } \\
\text { Expresado en Soles }\end{array}$} \\
\hline & $2019 P$ & $2020 P$ & $2021 P$ & $2022 P$ & $2023 P$ & $2024 P$ & $2025 P$ \\
\hline MOB & 49,732 & 49,732 & 49,732 & 49,732 & 49,732 & 49,732 & 49,732 \\
\hline MP & 295,919 & 345,356 & 400,267 & 460,651 & 526,509 & 597,752 & 674,556 \\
\hline Accesorios & 31,247 & 36,468 & 42,266 & 48,642 & 55,597 & 63,119 & 71,230 \\
\hline Gas & 4,877 & 5,692 & 6,597 & 7,593 & 8,678 & 9,852 & 11,118 \\
\hline Luz - Producción & 1,522 & 1,776 & 2,058 & 2,369 & 2,708 & 3,074 & 3,469 \\
\hline Mantenimiento - Máquinas & 6,864 & 6,864 & 6,864 & 6,864 & 6,864 & 6,864 & 6,864 \\
\hline $\begin{array}{c}\text { Mantenimiento correctivo } \\
(20 \%)\end{array}$ & 1,716 & 1,716 & 1,716 & 1,716 & 1,716 & 1,716 & 1,716 \\
\hline Costo de producción & 391,877 & 447,604 & 509,501 & 577,566 & 651,803 & 732,109 & 818,685 \\
\hline
\end{tabular}

Elaboración propia

\subsubsection{Costos de las materias primas}

Los costos para la materia prima puestos en el almacén del proyecto se detallarán a continuación.

Tabla 7.2.2 Costo de materia prima

\begin{tabular}{|c|c|c|}
\hline Materia prima & kg. & S/ \\
\hline Polietileno de alta densidad virgen & 1,000 & S/ 6,023 \\
Polietileno de alta densidad reciclado & 1,000 & S/ 3,713 \\
Pigmento negro & 1,000 & S/ 1,100 \\
\hline
\end{tabular}

Elaboración propia 


\subsubsection{Costo de la mano de obra directa}

Se requieren de 3 operarios para la fabricación del producto, este puesto no requiere de ningún conocimiento en específico, por lo que se les asignara sueldo mínimo. Además, se considerará asignación familiar para todos los operarios.

Tabla 7.2.3 Planilla de Remuneraciones MOB

\begin{tabular}{|c|c|c|c|c|c|c|}
\hline \multicolumn{7}{|c|}{$\begin{array}{c}\text { Planilla de remuneraciones } \\
\text { Expresado en soles }\end{array}$} \\
\hline Trabajador & RBC & $\begin{array}{c}\text { CTS } \\
\text { Mayo }\end{array}$ & $\begin{array}{c}\text { CTS } \\
\text { Noviembre }\end{array}$ & $\begin{array}{c}\text { Gratificación } \\
\text { Julio }\end{array}$ & $\begin{array}{c}\text { Gratificación } \\
\text { Diciembre }\end{array}$ & Anual \\
\hline Operario 1 & 1,093 & 638 & 638 & 1,093 & 1,093 & 16,577 \\
Operario 2 & 1,093 & 638 & 638 & 1,093 & 1,093 & 16,577 \\
Operario 3 & 1,093 & 638 & 638 & 1,093 & 1,093 & 16,577 \\
\hline
\end{tabular}

Elaboración propia

\subsubsection{Costo Indirecto de Fabricación}

El costo de los accesorios, el GLP, luz, mantenimiento preventivo y correctivo se detallarán a continuación.

Tabla 7.2.4 Costo Indirecto de Fabricación

\begin{tabular}{|c|c|c|}
\hline CIF & Valor & Unidades \\
S/ & \\
\hline Accesorio - Brida & 5 & Un. \\
Accesorio - Reducción de 1 1/4" a 3/4" & 3 & Un. \\
GLP & 1.46 & tanque \\
Luz & 0.46 & tanque \\
Mantenimiento - Preventivo & 6,864 & año \\
Mantenimiento - Correctivo & 1,716 & año \\
\hline
\end{tabular}

Elaboración propia 


\subsection{Presupuesto Operativo}

\subsubsection{Presupuesto de ingreso por ventas}

Para el presupuesto de ingreso de ventas del proyecto se consideró que el $60 \%$ serían ventas hacia ferreterías y el $40 \%$ serían ventas directas a cliente final.

Tabla 7.3.1 Presupuesto de ingreso por ventas

\begin{tabular}{|c|c|c|c|c|c|c|c|}
\cline { 2 - 8 } \multicolumn{1}{c|}{} & \multicolumn{7}{c|}{ Presupuesto de ingreso por ventas } \\
\cline { 2 - 9 } & $\mathbf{2 0 1 9} \mathbf{P}$ & $\mathbf{2 0 2 0} \mathbf{P}$ & $\mathbf{2 0 2 1} \mathbf{P}$ & $\mathbf{2 0 2 2} \mathbf{P}$ & $\mathbf{2 0 2 3} \mathbf{P}$ & $\mathbf{2 0 2 4} \mathbf{P}$ & $\mathbf{2 0 2 5} \mathbf{P}$ \\
\hline Ventas (un.) & 3,352 & 3,912 & 4,534 & 5,218 & 5,964 & 6,771 & 7,641 \\
Valor venta - Ferretería & 267 & 267 & 267 & 267 & 267 & 267 & 267 \\
Valor venta - Cliente final & 280 & 280 & 280 & 280 & 280 & 280 & 280 \\
\hline Ventas & 911,574 & $1,063,865$ & $1,233,017$ & $1,419,031$ & $1,621,905$ & $1,841,368$ & $2,077,963$ \\
\hline
\end{tabular}

Elaboración propia 


\subsubsection{Presupuesto operativo de costos y gastos}

A continuación, se muestra el presupuesto operativo de costos y gastos proyectado para cada año.

Tabla 7.3.2 Presupuesto operativo de costos y gastos

\begin{tabular}{|c|c|c|c|c|c|c|c|}
\cline { 2 - 8 } & \multicolumn{7}{c|}{ Presupuesto operativo de costos y gastos } \\
\cline { 2 - 8 } & $\mathbf{2 0 1 9} \mathbf{~ P}$ & $\mathbf{2 0 2 0} \mathbf{P}$ & $\mathbf{2 0 2 1} \mathbf{~ P}$ & $\mathbf{2 0 2 2} \mathbf{P}$ & $\mathbf{2 0 2 3}$ P & $\mathbf{2 0 2 4} \mathbf{P}$ & $\mathbf{2 0 2 5}$ P \\
\hline Petróleo - Vehículo & 6,087 & 7,104 & 8,233 & 9,476 & 10,830 & 12,296 & 13,876 \\
Mantenimiento - Vehículo & 2,560 & 3,110 & 3,170 & 5,520 & 3,490 & 4,470 & 5,570 \\
Mantenimiento Correctivo & 640 & 778 & 793 & 1,380 & 873 & 1,118 & 1,393 \\
Pasaje - Vendedores & 5,288 & 5,288 & 5,288 & 5,288 & 5,288 & 5,288 & 5,288 \\
MOI & 285,907 & 285,907 & 285,907 & 285,907 & 285,907 & 285,907 & 285,907 \\
Google Adwords/Facebook & 4,068 & 4,068 & 4,068 & 4,068 & 4,068 & 4,068 & 4,068 \\
Host/Correo web & 5,537 & 5,537 & 5,537 & 5,537 & 5,537 & 5,537 & 5,537 \\
Agua & 1,695 & 1,695 & 1,695 & 1,695 & 1,695 & 1,695 & 1,695 \\
Teléfono/internet & 10,169 & 10,169 & 10,169 & 10,169 & 10,169 & 10,169 & 10,169 \\
Luz - Oficina & 1,017 & 1,017 & 1,017 & 1,017 & 1,017 & 1,017 & 1,017 \\
Vigilancia y limpieza & 36,000 & 36,000 & 36,000 & 36,000 & 36,000 & 36,000 & 36,000 \\
\hline Gastos generales & 358,968 & 360,673 & 361,877 & 366,057 & 364,874 & 367,565 & 370,519 \\
\hline
\end{tabular}

Elaboración propia 
- Mano de Obra Indirecta

Tabla 7.3.3 Planilla de Remuneraciones MOI

\begin{tabular}{|c|c|c|c|c|c|c|}
\hline \multicolumn{7}{|c|}{$\begin{array}{c}\text { Planilla de remuneraciones } \\
\text { Expresado en soles }\end{array}$} \\
\hline Trabajador & RBC & $\begin{array}{c}\text { CTS } \\
\text { Mayo }\end{array}$ & $\begin{array}{c}\text { CTS } \\
\text { Noviembre }\end{array}$ & $\begin{array}{c}\text { Gratificación } \\
\text { Julio }\end{array}$ & $\begin{array}{c}\text { Gratificación } \\
\text { Diciembre }\end{array}$ & Anual \\
\hline Gerente General & 8,093 & 4,721 & 4,721 & 8,093 & 8,093 & 122,744 \\
Contador/a & 2,093 & 1,221 & 1,221 & 2,093 & 2,093 & 31,744 \\
Administrador/a & 2,093 & 1,221 & 1,221 & 2,093 & 2,093 & 31,744 \\
Almacenero facturador & 1,493 & 871 & 871 & 1,493 & 1,493 & 22,644 \\
Vendedor norte & 1,893 & 1,104 & 1,104 & 1,893 & 1,893 & 28,711 \\
Vendedor sur & 1,893 & 1,104 & 1,104 & 1,893 & 1,893 & 28,711 \\
Chofer & 1,293 & 754 & 754 & 1,293 & 1,293 & 19,611 \\
\hline \multicolumn{7}{|c|}{}
\end{tabular}

Elaboración propia 


\subsection{Presupuestos Financieros}

\subsubsection{Presupuesto de Servicio de Deuda}

Se considerará el $40 \%$ de aporte de accionistas y el $60 \%$ restante se financiará con el banco Scotiabank a una tasa efectiva anual del $12 \%$ con cuotas semestrales con plazo de gracia parcial para el primer año. El monto a financiar por el banco es de S/ 415,566.

Tabla 7.4.1 Presupuesto de servicio de deuda

\begin{tabular}{|c|c|c|c|c|}
\hline \multicolumn{5}{|c|}{ Presupuesto de servicio de deuda } \\
Expresado en soles \\
\hline Año & Deuda Capital & Amortización & Intereses & Saldo \\
\hline 2019 P & 415,566 & - & 24,228 & 415,566 \\
2019 P & 415,566 & - & 24,228 & 415,566 \\
2020 P & 415,566 & 41,557 & 24,228 & 374,009 \\
2020 P & 374,009 & 41,557 & 21,805 & 332,453 \\
2021 P & 332,453 & 41,557 & 19,382 & 290,896 \\
2021 P & 290,896 & 41,557 & 16,959 & 249,339 \\
2022 P & 249,339 & 41,557 & 14,537 & 207,783 \\
2022 P & 207,783 & 41,557 & 12,114 & 166,226 \\
2023 P & 166,226 & 41,557 & 9,691 & 124,670 \\
2023 P & 124,670 & 41,557 & 7,268 & 83,113 \\
2024 P & 83,113 & 41,557 & 4,846 & 41,557 \\
2024 P & 41,557 & 41,557 & 2,423 & - \\
\hline Total & \multicolumn{4}{|c|}{} \\
\hline
\end{tabular}

\begin{tabular}{|c|c|c|c|}
\hline Año & Amortización & Interés & Cuota \\
\hline $\mathbf{2 0 1 9} \mathbf{P}$ & - & 48,455 & 48,455 \\
$\mathbf{2 0 2 0} \mathbf{P}$ & 83,113 & 46,033 & 129,146 \\
$\mathbf{2 0 2 1} \mathbf{P}$ & 83,113 & 36,342 & 119,455 \\
$\mathbf{2 0 2 2} \mathbf{P}$ & 83,113 & 26,650 & 109,764 \\
$\mathbf{2 0 2 3} \mathbf{P}$ & 83,113 & 16,959 & 100,073 \\
$\mathbf{2 0 2 4} \mathbf{P}$ & 83,113 & 7,268 & 90,381 \\
\hline
\end{tabular}

\begin{tabular}{|c|c|}
\hline Tasa de interés anual & $12 \%$ \\
Tasa de interés nominal semestral & $5.83 \%$ \\
Amortización en años & 5 \\
Amortización en semestres & 10 \\
Plazo de gracia & 1 \\
Plazo de gracia semestral & 2 \\
Impuesto a la renta & $29.50 \%$ \\
\hline
\end{tabular}

Elaboración propia 


\subsubsection{Presupuesto de estado de resultados}

Tabla 7.4.2 Estado de resultados

\begin{tabular}{|c|c|c|c|c|c|c|c|}
\hline \multicolumn{8}{|c|}{$\begin{array}{c}\text { Estado de resultados } \\
\text { Al } 31 \text { de diciembre del } 2025 \mathrm{P} \\
\text { Expresado en soles }\end{array}$} \\
\hline & $2019 P$ & $2020 \mathrm{P}$ & $2021 P$ & $2022 P$ & $2023 \mathrm{P}$ & $2024 P$ & $2025 \mathrm{P}$ \\
\hline Venta de Activo Fijo & - & - & - & - & - & - & - \\
\hline Venta - Terreno & - & - & - & - & - & - & 346,500 \\
\hline Ventas (un.) & 3,352 & 3,912 & 4,534 & 5,218 & 5,964 & 6,771 & 7,641 \\
\hline Valor Venta. (S/) - Ferretería & 267 & 267 & 267 & 267 & 267 & 267 & 267 \\
\hline Valor Venta. (S/) - Cliente Final & 280 & 280 & 280 & 280 & 280 & 280 & 280 \\
\hline Ventas & 911,574 & $1,063,865$ & $1,233,017$ & $1,419,031$ & $1,621,905$ & $1,841,368$ & $2,424,463$ \\
\hline MOB & 49,732 & 49,732 & 49,732 & 49,732 & 49,732 & 49,732 & 49,732 \\
\hline MP & 295,919 & 345,356 & 400,267 & 460,651 & 526,509 & 597,752 & 674,556 \\
\hline Accesorios & 31,247 & 36,468 & 42,266 & 48,642 & 55,597 & 63,119 & 71,230 \\
\hline Gas & 4,877 & 5,692 & 6,597 & 7,593 & 8,678 & 9,852 & 11,118 \\
\hline Luz - Producción & 1,522 & 1,776 & 2,058 & 2,369 & 2,708 & 3,074 & 3,469 \\
\hline Mantenimiento - Máquinas & 6,864 & 6,864 & 6,864 & 6,864 & 6,864 & 6,864 & 6,864 \\
\hline Mantenimiento correctivo (20\%) & 1,716 & 1,716 & 1,716 & 1,716 & 1,716 & 1,716 & 1,716 \\
\hline Depreciación fabril & 10,661 & 10,661 & 10,661 & 10,661 & 10,661 & - & - \\
\hline Costo de producción. & 402,538 & 458,264 & 520,161 & 588,227 & 662,463 & 732,109 & 818,685 \\
\hline Utilidad bruta & 509,036 & 605,601 & 712,856 & $\mathbf{8 3 0 , 8 0 4}$ & 959,442 & $1,109,258$ & $1,605,779$ \\
\hline Petróleo - Vehículo & 6,087 & 7,104 & 8,233 & 9,476 & 10,830 & 12,296 & 13,876 \\
\hline Mantenimiento - Vehículo & 2,560 & 3,110 & 3,170 & 5,520 & 3,490 & 4,470 & 5,570 \\
\hline Mantenimiento correctivo (20\%) & 640 & 778 & 793 & 1,380 & 873 & 1,118 & 1,393 \\
\hline Pasaje - Vendedores & 5,288 & 5,288 & 5,288 & 5,288 & 5,288 & 5,288 & 5,288 \\
\hline MOI & 285,907 & 285,907 & 285,907 & 285,907 & 285,907 & 285,907 & 285,907 \\
\hline
\end{tabular}

(Continúa) 
(Continuación)

\begin{tabular}{|c|c|c|c|c|c|c|c|}
\hline Google Adwords/Facebook & 4,068 & 4,068 & 4,068 & 4,068 & 4,068 & 4,068 & 4,068 \\
\hline Host/Correo web & 5,537 & 5,537 & 5,537 & 5,537 & 5,537 & 5,537 & 5,537 \\
Agua & 1,695 & 1,695 & 1,695 & 1,695 & 1,695 & 1,695 & 1,695 \\
Teléfono/internet & 10,169 & 10,169 & 10,169 & 10,169 & 10,169 & 10,169 & 10,169 \\
Luz - Oficina & 1,017 & 1,017 & 1,017 & 1,017 & 1,017 & 1,017 & 1,017 \\
Vigilancia y limpieza & 36,000 & 36,000 & 36,000 & 36,000 & 36,000 & 36,000 & 36,000 \\
Valor en libros - Terreno & - & - & - & - & - & - & 382,856 \\
Depreciación no fabril & 17,254 & 17,254 & 17,254 & 17,254 & 17,254 & 2,797 & 2,797 \\
Amortización de intangibles & 9,716 & 9,716 & 9,716 & 6,891 & 6,891 & 6,891 & 6,891 \\
\hline Gastos generales & 385,939 & 387,643 & 388,847 & 390,202 & 389,019 & 377,252 & 763,063 \\
\hline Utilidad operativa - EBIT & $\mathbf{1 2 3 , 0 9 7}$ & $\mathbf{2 1 7 , 9 5 8}$ & $\mathbf{3 2 4 , 0 0 9}$ & $\mathbf{4 4 0 , 6 0 1}$ & $\mathbf{5 7 0 , 4 2 2}$ & $\mathbf{7 3 2 , 0 0 6}$ & $\mathbf{8 4 2 , 7 1 6}$ \\
\hline Gasto de interés & 48,455 & 46,033 & 36,342 & 26,650 & 16,959 & 7,268 & - \\
Utilidad antes de impuestos & 74,642 & 171,925 & 287,667 & 413,951 & 553,463 & 724,738 & 842,716 \\
Impuesto a la renta (29.50\%) & 22,019 & 50,718 & 84,862 & 122,116 & 163,272 & 213,798 & 248,601 \\
\hline Utilidad neta & $\mathbf{5 2 , 6 2 3}$ & $\mathbf{1 2 1 , 2 0 7}$ & $\mathbf{2 0 2 , 8 0 5}$ & $\mathbf{2 9 1 , 8 3 5}$ & $\mathbf{3 9 0 , 1 9 1}$ & $\mathbf{5 1 0 , 9 4 0}$ & $\mathbf{5 9 4 , 1 1 5}$ \\
\hline
\end{tabular}

Elaboración propia 


\subsubsection{Presupuesto de estado de situación financiera}

Tabla 7.4.3 Balance general

\begin{tabular}{|c|c|c|c|c|c|c|c|c|c|c|c|c|c|}
\hline & & & & & $\begin{array}{r}\text { Ba } \\
\mathrm{Al} 31 \mathrm{de} \\
\quad \text { Exp } \\
\end{array}$ & $\begin{array}{l}\text { ance gene } \\
\text { iciembre d } \\
\text { esado en s }\end{array}$ & $\begin{array}{l}\text { al } \\
\text { el } 2019 \mathrm{P} \\
\text { oles }\end{array}$ & & & & & & \\
\hline & $2018 P$ & Enero & Febrero & Marzo & Abril & Mayo & Junio & Julio & Agosto & Setiembre & Octubre & Noviembre & $2019 P$ \\
\hline Cuentas por cobrar & - & 974 & 1,948 & 2,922 & 3,896 & 4,870 & 5,843 & 6,817 & 7,791 & 8,765 & 9,739 & 10,713 & 75,964 \\
\hline Existencias & - & 192 & 275 & 358 & 442 & 525 & 608 & 691 & 774 & 857 & 941 & 1,024 & 7,827 \\
\hline Total activo & 692,610 & 658,972 & 632,512 & 613,383 & 601,587 & 597,123 & 599,180 & 606,407 & 618,803 & 636,368 & 659,103 & 687,007 & 756,414 \\
\hline & & & & & & & & & & & & & \\
\hline $\begin{array}{c}\text { Pasivo } \\
\text { Cuentas por pagar }\end{array}$ & - & 274 & 393 & 512 & 631 & 750 & 868 & 987 & 1,106 & 1,225 & 1,344 & 1,462 & 11,182 \\
\hline Total pasivo corriente & - & 274 & 393 & 512 & 631 & 750 & 868 & 987 & 1,106 & 1,225 & 1,344 & 1,462 & 11,182 \\
\hline Deuda & 415,566 & 415,566 & 415,566 & 415,566 & 415,566 & 415,566 & 415,566 & 415,566 & 415,566 & 415,566 & 415,566 & 415,566 & 415,566 \\
\hline Total pasivo + patrimonio & 692,610 & 658,972 & 632,512 & 613,383 & 601,587 & 597,123 & 599,180 & 606,407 & 618,803 & 636,368 & 659,103 & 687,007 & 756,414 \\
\hline Check & - & - & - & - & - & - & - & - & - & - & - & - & - \\
\hline
\end{tabular}

Elaboración propia 


\subsubsection{Flujo de fondos netos}

Tabla 7.4.4 Flujo de fondos

\begin{tabular}{|c|c|c|c|c|c|c|c|c|}
\hline \multicolumn{9}{|c|}{$\begin{array}{c}\text { Flujo de fondos } \\
\text { Al } 31 \text { de diciembre del } 2025 \mathrm{P} \\
\text { Expresado en soles } \\
\end{array}$} \\
\hline & $2018 \mathrm{H}$ & $2019 P$ & $2020 P$ & $2021 P$ & $2022 \mathrm{P}$ & $2023 P$ & $2024 \mathrm{P}$ & $2025 P$ \\
\hline Utilidad operativa & - & 123,097 & 217,958 & 324,009 & 440,601 & 570,422 & 732,006 & 842,716 \\
\hline (-) Impuestos & - & $-36,314$ & $-64,298$ & $-95,583$ & $-129,977$ & $-168,275$ & $-215,942$ & $-248,601$ \\
\hline NOPAT & - & $\mathbf{8 6 , 7 8 4}$ & 153,660 & 228,426 & 310,624 & 402,148 & 516,064 & 594,115 \\
\hline (+) Amortización de intangibles & - & 9,716 & 9,716 & 9,716 & 6,891 & 6,891 & 6,891 & 6,891 \\
\hline (+) Depreciación fabril & - & 10,661 & 10,661 & 10,661 & 10,661 & 10,661 & - & - \\
\hline (+) Depreciación no fabril & - & 17,254 & 17,254 & 17,254 & 17,254 & 17,254 & 2,797 & 2,797 \\
\hline (-) Inversión & $-692,610$ & - & - & - & - & 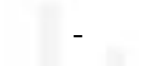 & - & - \\
\hline (+) Valor en libros & - & - & - & - & - & - & - & 403,529 \\
\hline (+) Recupero del capital de trabajo & - & - & - & - & - & - & - & 87,201 \\
\hline Flujo de caja económico & $-692,610$ & 124,414 & 191,291 & 266,057 & $\mathbf{3 4 5 , 4 3 0}$ & 436,954 & $\mathbf{5 2 5 , 7 5 2}$ & $1,094,532$ \\
\hline (+) Préstamo & 277,044 & - & 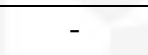 & 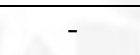 & - & 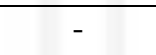 & - & - \\
\hline (-) Cuota & & $-48,455$ & $-129,146$ & $-119,455$ & $-109,764$ & $-100,073$ & $-90,381$ & - \\
\hline (+) Escudo fiscal del interés & & 14,294 & 13,580 & 10,721 & 7,862 & 5,003 & 2,144 & - \\
\hline Flujo de caja financiero & $-415,566$ & 90,253 & 75,725 & 157,323 & 243,528 & 341,884 & 437,515 & $1,094,532$ \\
\hline
\end{tabular}




\subsection{Evaluación económica}

Tabla 7.5.1 Evaluación económica

\begin{tabular}{|c|c|c|c|c|c|c|c|c|}
\hline \multicolumn{9}{|c|}{ Evaluación económica } \\
\hline \multicolumn{9}{|c|}{ Expresado en soles } \\
\hline & 2018 H & 2019 P & $2020 \mathrm{P}$ & $2021 P$ & $2022 P$ & $2023 \mathrm{P}$ & $2024 \mathrm{P}$ & $2025 P$ \\
\hline Periodo & $\mathbf{0}$ & 1 & 2 & 3 & 4 & 5 & 6 & 7 \\
\hline Factor de actualización & 1 & 1.17 & 1.37 & 1.60 & 1.87 & 2.18 & 2.55 & 2.98 \\
\hline VAN al ke (18\%) & $-692,610$ & 106,430 & 139,985 & 166,554 & 184,984 & 200,172 & 206,036 & 366,930 \\
\hline FNFF descontado acumulada & - & 106,430 & 246,415 & 412,969 & 597,953 & 798,125 & $1,004,161$ & $1,371,091$ \\
\hline Valor actual neto & - & $-586,179$ & $-446,194$ & $-279,640$ & $-94,656$ & 105,515 & 311,551 & 678,481 \\
\hline
\end{tabular}

\begin{tabular}{|c|c|}
\hline VAN Económico & 678,481 \\
Relación b/c & 1.98 \\
TIR & $36.63 \%$ \\
Periodo de recuperación & 4.49 años \\
Kc & $16.90 \%$ \\
\hline
\end{tabular}

Elaboración propia 


\subsection{Evaluación Financiera}

Tabla 7.6.1 Evaluación Financiera

\begin{tabular}{|c|c|c|c|c|c|c|c|c|}
\hline \multicolumn{9}{|c|}{ Evaluación financiera } \\
\hline Expresado en soles & 2018 H & $2010 \mathrm{P}$ & $2020 P$ & $2021 P$ & 2022 P & $2023 \mathbf{P}$ & 2024 P & 2025 D \\
\hline Periodo & $\mathbf{0}$ & 1 & 2 & 3 & 4 & 5 & 6 & 7 \\
\hline Factor de actualización & 1 & 1.17 & 1.37 & 1.60 & 1.87 & 2.18 & 2.55 & 2.98 \\
\hline VAN al ke $(18 \%)$ & $-415,566$ & 77,207 & 55,415 & 98,486 & 130,414 & 156,620 & 171,456 & 366,930 \\
\hline FNFF descontado & 0 & 77,207 & 132,622 & 231,107 & 361,521 & 518,141 & 689,597 & $1,056,528$ \\
\hline Valor actual neto & 0 & $-338,359$ & $-282,944$ & $-184,458$ & $-54,045$ & 102,575 & 274,032 & 640,962 \\
\hline
\end{tabular}

\begin{tabular}{|c|c|}
\hline VAN Económico & 640,962 \\
Relación b/c & 2.54 \\
TIR & $42.55 \%$ \\
Periodo de recuperación & 4.40 años \\
Kc & $16.90 \%$ \\
\hline
\end{tabular}

Elaboración propia 


\subsubsection{Análisis de ratios}

Tabla 7.6.2 Ratios financieros

\begin{tabular}{|c|c|c|c|c|c|c|c|}
\hline \multicolumn{8}{|c|}{$\begin{array}{c}\text { Ratios financieros } \\
\text { Al } 31 \text { de diciembre del } 2025 \mathrm{P}\end{array}$} \\
\hline & 2019 & $2020 \mathrm{P}$ & $2021 \mathrm{P}$ & $2022 \mathrm{P}$ & $2023 \mathrm{P}$ & $2024 \mathrm{P}$ & $2025 \mathrm{P}$ \\
\hline ROE & $16 \%$ & $27 \%$ & $31 \%$ & $31 \%$ & $29 \%$ & $28 \%$ & $24 \%$ \\
\hline ROA & $7 \%$ & $15 \%$ & $22 \%$ & $26 \%$ & $27 \%$ & $27 \%$ & $24 \%$ \\
\hline Ratio corriente & 16.87 & 20.89 & 29.41 & 41.03 & 55.12 & 71.49 & 108.33 \\
\hline Solvencia & 1.77 & 2.31 & 3.48 & 6.18 & 14.16 & 91.81 & 108.33 \\
\hline Ratio de cobertura & 3.32 & 5.55 & 9.95 & 17.84 & 35.69 & 102.04 & - \\
\hline Apalancamiento financiero & 2.59 & 1.30 & 0.69 & 0.35 & 0.14 & - & - \\
\hline \multicolumn{8}{|l|}{ Margen } \\
\hline Margen EBITDA & $18 \%$ & $24 \%$ & $29 \%$ & $34 \%$ & $37 \%$ & $40 \%$ & $35 \%$ \\
\hline Margen EBIT & $14 \%$ & $20 \%$ & $26 \%$ & $31 \%$ & $35 \%$ & $40 \%$ & $35 \%$ \\
\hline Margen Bruto & $56 \%$ & $57 \%$ & $58 \%$ & $59 \%$ & $59 \%$ & $60 \%$ & $66 \%$ \\
\hline
\end{tabular}

Elaboración propia

\section{- $\quad$ ROE}

Por cada sol invertido el accionista tendrá un retorno del 16\% para el primer año.

- ROA

El valor del ROA es mayor al 7\% para el primero año, por lo tanto, es un indicador positivo.

\section{- Ratio corriente}

Por cada sol que la empresa tiene de deuda, cuanta con 16.87 soles para pagarla en el primer año.

\section{- Solvencia}

La empresa cuenta en sus activos con 1.77 soles por cada sol que tiene de deuda para el primer año.

\section{- Ratio de cobertura}

El valor obtenido en el primer año es mayor a 1, es decir, la empresa es solvente y puede pagar a sus accionistas.

\section{- Apalancamiento financiero}

Para los 2 primeros años es conveniente recurrir a préstamos debido a que su valor supera a 1. 


\subsubsection{Análisis de Sensibilidad}

\begin{tabular}{|c|c|c|c|c|c|c|}
\hline \multicolumn{7}{|c|}{$\begin{array}{c}\text { Análisis de sensibilidad } \\
\text { Al } 31 \text { de diciembre del } 2025 \text { P }\end{array}$} \\
\hline \multicolumn{7}{|c|}{ VAN Económico } \\
\hline & & \multicolumn{5}{|c|}{ Precios } \\
\hline & & $-10 \%$ & $-5 \%$ & $0 \%$ & $5 \%$ & $10 \%$ \\
\hline \multirow{5}{*}{ 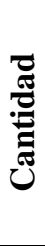 } & $-10 \%$ & 122,416 & 286,743 & 451,070 & 615,397 & 779,724 \\
\hline & $-5 \%$ & 217,862 & 391,318 & 564,775 & 738,231 & 911,687 \\
\hline & $\mathbf{0}$ & 313,310 & 495,896 & 678,481 & 861,067 & $1,043,652$ \\
\hline & $5 \%$ & 408,758 & 600,472 & 792,187 & 983,902 & $1,175,617$ \\
\hline & $10 \%$ & 504,205 & 705,049 & 905,893 & $1,106,737$ & $1,307,581$ \\
\hline & & & & & & \\
\hline \multicolumn{7}{|c|}{ VAN Financiero } \\
\hline & & \multicolumn{5}{|c|}{ Precios } \\
\hline & & $-10 \%$ & $-5 \%$ & $0 \%$ & $5 \%$ & $10 \%$ \\
\hline \multirow{5}{*}{ שֶّ } & $-10 \%$ & 85,664 & 249,805 & 413,947 & 578,089 & 742,231 \\
\hline & $-5 \%$ & 180,932 & 354,193 & 527,454 & 700,714 & 873,975 \\
\hline & 0 & 276203 & 458,582 & 640,962 & 823,342 & $1,005,721$ \\
\hline & $5 \%$ & 371,472 & 562,971 & 754,470 & 945,968 & $1,137,467$ \\
\hline & $10 \%$ & 466,742 & 667,360 & 867,977 & $1,068,595$ & $1,269,213$ \\
\hline
\end{tabular}

Elaboración propia

En conclusión, el análisis de sensibilidad permite demostrar que en cualquiera de los 25 escenarios el proyecto sigue siendo rentable. 


\section{CAPÍTULO VIII: EVALUACION SOCIAL DEL PROYECTO}

En el presente capitulo se identificarán los beneficios y costos para la sociedad que generará el proyecto, determinando rentabilidades y contribuciones al bienestar del país.

\subsection{Indicadores sociales}

Tabla 8.1.1 Indicadores sociales

\begin{tabular}{|c|c|}
\hline \multicolumn{2}{|c|}{ Evaluación Social } \\
\hline Valor agregado & 777,493 \\
Densidad de capital & 70,828 \\
Productividad M.O. & 534 \\
Intensidad de capital & 0.911 \\
Producto - Capital & 1.10 \\
\hline
\end{tabular}

Elaboración propia

\subsection{Interpretaciones de indicadores sociales}

- Valor agregado

Según el indicador de valor agregado, el proyecto aportará a la comunidad un monto de S/ 777,493, esto gracias al aporte que se realizará en insumos y materias primas a utilizar en la transformación del producto y también en sueldos, intereses, depreciaciones y utilidades a pagar.

\section{- Densidad de capital}

La densidad de capital es de S/ 70,828 por puesto de trabajo, es la relación de la inversión total con el personal necesario para mantener el giro del negocio.

\section{- Productividad de mano de obra}

La capacidad de la mano de obra empleada para generar la producción del bien a fabricar es de 534 tanques de agua por personal al mes en el primer año.

\section{- Intensidad de capital}

La relación de la inversión total contra el valor agregado es de 0.911 en el primer año, es decir, para poder producir un sol de valor agregado se debe invertir S/ 0.911 nuevos soles. 
- Relación producto-capital

El coeficiente de capital es de 1.10, es decir, el valor agregado representa el $10 \%$ de la inversión total. 


\section{CONCLUSIONES}

A continuación, se detallarán las conclusiones:

- Se determinó la viabilidad de mercado, tecnológica, social, económica y financiera de la implementación de una planta de tanques de agua cónicos apilables de polietileno reciclado en su exterior.

- La intensión e intensidad de compra que arrojo la encuesta es elevada, es decir, el público objetivo está dispuesto a comprarlo.

- La localización óptima del proyecto se ubicará puente piedra, al norte de lima.

- El tamaño de mercado es el óptimo para el tamaño de planta del proyecto.

- El hecho de usar materiales reciclables e innovar en el diseño del producto permite acceder a una buena posición competitiva.

- El proyecto es rentable debido a que el análisis de sensibilidad refleja un VAN positivo en todos los escenarios establecidos, además presenta una TIR mayor a la tasa de descuento establecido en los mismos escenarios.

- A pesar de no tener buenos indicadores sociales, el aspecto social más importante que atiende el proyecto es el de brindar la posibilidad de que las personas menos favorecida económicamente puedan almacenar agua y satisfagan la necesidad que esta brinda. 


\section{RECOMENDACIONES}

A continuación, se detallarán las recomendaciones:

- A la hora de aumentar la producción, se recomienda solo contratar mano de obra, mas no invertir en maquinaria, ya que el incremento en mano de obra es mucho menor al de comprar maquinaria nueva.

- A pesar de tener un proceso limpio, es importante monitorearlo constantemente el proceso para así asegurar que se mantengan los lineamientos establecidos.

- Se recomienda que las plantas productivas se construyan en zonas centralizadas, cercanas a vías centrales $\mathrm{y}$, además, cerca de puertos marítimos, para así atender los requerimientos de materiales y las órdenes de compra, reduciendo costos de transporte.

- Se recomienda tener políticas de inventarios y stocks de seguridad para así poder atender pedidos de compra que no han sido planeados en su momento y representen volúmenes grandes.

- Por la extrema radiación UV que existe en el Perú, se le recomiendo al usuario final instalar su tanque bajo sombra para garantizar una opacidad completa dentro del tanque. 


\section{REFERENCIAS}

Actualidad ambiental. (Febrero del 2017). Debemos consumir 100 litros de agua al día por persona, pero consumimos hasta 250 litros. Recuperado de: http://www.actualidadambiental.pe/?p=42982

Anguita Delgado, Ramón. Moldeo por inyección. Madrid. Editorial Blume.

Automotive, C. (2018). http://www.cieautomotive.com. Recuperado de: http://www.cieautomotive.com: http://www.cieautomotive.com/-/technologyplastic

APEIM. (Agosto del 2017). Niveles Socioeconómicos 2017. Recuperado de: http://www.apeim.com.pe/wp-content/themes/apeim/docs/nse/APEIM-NSE2017.pdf

ARELlanO, Rolando. (2000). Los estilos de vida en el Perú. Recuperado de: http://www.arellanomarketing.com/inicio/estilos-de-vida/

A. R. Ruberto (Noviembre de 2006). GUIA METODOLOGICA PARA LA EVALUACION DEL IMPACTO AMBIENTAL. Madrid, España.

Armebe. Tanques Estacionarios Recuperado de: https://armebe.mx/productos/estacionarios

Balanzas Perú. BALANZA DE PLATAFORMA INDUSTRIAL. Recuperado de: http://balanzasperu.com/balanza-de-plataforma-en-lima.html

Banco de Desarrollo de América Latina. (07 de junio de 2017). América Latina, una región económicamente escasa de agua. Recuperado de: https://www.caf.com/es/actualidad/noticias/2017/06/america-latina-una-regioneconomicamente-escasa-de-agua/

Barletta, F., Pereira, M., Robert, V., y Yoguel, G. (2013). Argentina: dinámica reciente del sector de software y servicios informáticos. Revista de la CEPAL(110), 137155.

Recuperado de: http://www.cepal.org/publicaciones/xml/1/50511/RVE110Yoqueletal.pdf 
Bennotomaquinarias. Productos de Estocas Recuperado de: http://www.bennotomaquinarias.com/productos/venta-de-estocas-transpaletashidraulicas-4

Bregar, B. (2010). Rotomolding called a low-cost process. Plastics News, 22(11), 151NULL. Recuperado de: http://search.ebscohost.com/login.aspx?direct=true \&db=b9h\&AN=51796100\&l ang $=$ es\&site $=$ ehost-live

Casique, J. J. (Junio de 2009). Estudio de pre factibilidad para la implementación de una planta de producción y comercialización de escamas de PET reciclado.

Choy, M., y Chang, G. (2014). Medidas macroprudenciales aplicadas en el Perú. Lima: Banco Central de Reserva del Perú. Recuperado de http://www.bcrp.gob.pe/docs/Publicaciones/Documentos-deTrabajo/2014/documento-de-trabajo-07-2014.pdf

Diaz, B., Jarufe, B., y Noriega, M. T. (2014). Disposicion de Planta. Lima: Universidad de lima fondo editorial.

Díaz, S., Ortega, Z., McCourt, M., Kearns, M. P., y Benítez, A. N. (2018). Recycling of polymeric fraction of cable waste by rotational moulding. Waste Management, 76, 199-206. Recuperado de: https://doi.org/10.1016/j.wasman.2018.03.020

EBSCO. (2010). Rotomolding called a low-cost process. Plastics News.

Eternit Perú. (2017). Nosotros. Recuperado de: http://www.eternit.com.pe/es-es

Eurotanque. (08 de setiembre del 2017). Recuperado de: https://www.eurotanque.com.pe/

Farplast. (10 de Abril de 2019). Farplast. Recuperado de http://farplast.pe/work/tanquepara-agua-colores/

García Nieto, J. P. (2013). Consturye tu Web comercial: de la idea al negocio. Madrid: RA-MA.

Gestión. (Marzo del 2015). Pacífico ofrece seguros para proteger negocios de las pymes desde S/.20 al mes. Recuperado de: http://gestion.pe/tu-dinero/ofrecen-segurosproteger-negocios-pymes-desde-s20-al-mes-2125817 
Gestión. (Junio del 2016). Terrenos industriales. Recuperado de: https://gestion.pe/suplemento/comercial/terrenos-industriales/parquesindustriales-norte-centro-y-sur-pais-1002233/m

Hernández Sampieri Roberto, C. F. (2014). Metodología de la investigación. México D.F.: Mc Graw-Hill.

Huda, Z. (2017). Chapter 6: Plastic Molding Processes. Foundations of Materials Science y Engineering, 93, 83-96. Recuperado de: http://search.ebscohost.com/login.aspx?direct=true\&db=egs\&AN=131446036\& lang=es\&site=ehost-live

Indiamart. Plastic Water Tank Vertical Mould. Recuperado de: https://m.indiamart.com/proddetail/plastic-water-tank-vertical-mould13867635888.html

INEI. (30 de junio de 2015). Día Mundial de la Población. Lima, Lima, Perú.

Instituto Nacional de Estadística e Informática. (Enero del 2010). Clasificación Industrial Internacional Uniforme. Recuperado de: https://www.inei.gob.pe/media/MenuRecursivo/publicaciones_digitales/Est/Lib 0883/Libro.pdf

Instituto Nacional de Estadística e Informática. (Setiembre del 2014). Una Mirada a Lima Metropolitana. Recuperado de: https://www.inei.gob.pe/media/MenuRecursivo/publicaciones_digitales/Est/Lib 1168/libro.pdf

Instituto Nacional de Estadística e Informática. (2015). Día Mundial de la Población. Recuperado de: https://www.inei.gob.pe/media/MenuRecursivo/publicaciones_digitales/Est/Lib 1251/Libro.pdf

IPSOS. (2007). Censo de Establecimientos Comerciales. Lima: IPSOS.

Lesur, Luis. Manual de moldeo de plásticos I: una guía paso a paso. México: Trillas, 2011.

Lesur, Luis. Manual de moldeo de plásticos II: una guía paso a paso. México: Trillas, 2011. 
Lizárraga, J. L. (31 de Mayo de 2014). SISTEMAS DE ALARMAS INDUSTRIALES. Mazlatan, Sinaloa, México.

Mantyobras. (Marzo de 2017). http://www.mantyobras.com. Recuperado de http://www.mantyobras.com: http://www.mantyobras.com/blog/lurin-preciodel-terreno-urbano-en-metro-cuadrado

Mantyobras. (Abril de 2017). http://www.mantyobras.com. Recuperado de http://www.mantyobras.com: http://www.mantyobras.com/blog/ventanillaprecio-del-terreno-urbano-en-metros-cuadrados

Mantyobras. (Enero de 2017). http://www.mantyobras.com. Recuperado de http://www.mantyobras.com: http://www.mantyobras.com/blog/puente-piedrael-precio-del-terreno-urbano-en-metros-cuadradados

Marco Normativo para la Implementación de Sistema de Gestión de Seguridad y Salud en el Trabajo dirigido al Sector Público. (s.f.). Recuperado de Ministerio de Trabajo y Promoción del empleo: http://www.ino.org.pe/COMITE_SST2012/Presentacion\%20MARCO\%20NOR MATIVO\%20SGSST\%20-\%20CSS.pdf

Nicoll. (10 de Abril De 2019). Nicoll. Recuperado de http://nicoll.com.pe/tanques/

Noegasystems. (15 de Junio de 2015). Estantería Convencional o Rack Selectivo. Recuperado de https://www.noegasystems.com/blog/estanterias/estanteriaconvencional-o-rack-selectivo-el-sistema-de-almacenaje-universal-para-paletas

Perú 21. (10 de setiembre del 2017). Ocho millones de peruanos aún no tienen acceso al agua. Recuperado de: https://peru21.pe/opinion/ocho-millones-peruanos-accesoagua-150089

Polymer Database. (10 de Abril de 2019). Polymer Database. Recuperado de https://polymerdatabase.com/Polymer\%20Brands/Plastic\%20Manufacturers.ht $\mathrm{ml}$

Polimers México. (2017). El nuevo Rotolene. Recuperado de: http://www.polimers.com/productos/rotolene/index.html

Promart. Trompo mezclador de concreto. Recuperado de: https://www.promart.pe/mezcladora-de-concreto/p 
Rotoline. Cooling

Fan.

Recuperado

de: https://www.rotoline.com/en/rotomolding/accessorie/fans

Rotoplas México. (22 de setiembre del 2014). Rotoplas más que Tinacos. Video. Recuperado de: https://www.youtube.com/watch?v=YGyuZnFfwro

Rotoplas Perú. (2017). Nosotros. Recuperado de: https://rotoplas.com/

Ruiz Ruiz, M. F. (2001). Estudio de pre factibilidad para la elaboración de fibra de poliéster a partir de botellas desechadas de bebidas gaseosas.

RPP Noticias. (16 de diciembre del 2014). Perú consume 250 litros por persona, casi 50\% más que Madrid. Recuperado de: http://rpp.pe/lima/actualidad/peruconsume-250-litros-por-persona-casi-50-mas-que-madrid-noticia-751470

RPP Noticias. (10 de julio del 2015). Día de la Población: Lima concentra el 32\% de habitantes según INEI. Recuperado de: http://rpp.pe/lima/actualidad/dia-de-la-poblacion-lima-concentra-el-32-dehabitantes-segun-inei-noticia-815942

SODIMAC. (10 de Abril de 2019). SODIMAC. Recuperado de https://www.sodimac.com.pe/sodimac-pe/category/cat10422/Tanques,-fosas-ycisternas?sTerm=tanque $\% 20$ agua $\&$ sScenario=BRD_tanque $\% 20$ agua

Surco Valencia, C. B., Vargas Figueroa, F. D. (2014). Estudio de pre factibilidad para la instalación de una planta productora de parihuelas de madera plástica.

sul, U. d. (2013). Aplicación de la motodología de producción más limpia en un proceso de moldeo rotacional como herramienta sostenible aplicado a la seguridad laboral. Santa Cruz do sul, Brazil.

TEXTOSCIENTIFICOS. (10 de junio de 2012). Máquinas de rotomoldeo. Recuperado de https://www.textoscientificos.com/polimeros/rotomoldeo/maquinas

Vélez, A., Espinal, F., Mejía, R., y Vélez, H. (1970). UN SISTEMA ECONOMICO DE FLUORACION DEL AGUA EN COMUNIDADES RURALES. Medellin, Colombia. 
Wittmann, R. (2006). ¿Hubo una revolución en la lectura a finales del siglo XVIII? En G. Cavallo, y R. Chartier, Historia de la lectura en el mundo occidental (págs. 435-472). México D.F.: Santillana. 


\section{BIBLIOGRAFÍA}

Arroyo, P., Vásquez, R. (2017). Ingeniería Económica. Lima: Universidad de lima fondo editorial.

Bonilla, E., Noriega, M. T. (2018). Manual para el Diseño de Instalaciones Manufacturas y de Servicios. Lima: Universidad de lima fondo editorial.

Bonilla, E., Diaz, B., Kleeberg, F., Noriega, M. T. (2017). Mejora Continua de los Procesos. Lima: Universidad de lima fondo editorial.

Diaz, B., Jarufe, B., y Noriega, M. T. (2014). Disposicion de Planta. Lima: Universidad de lima fondo editorial.

Hernández Sampieri, Roberto. C. F. (2014). Metodología de la investigación. México D.F.: Mc Graw-Hill.

Sapag Chain, N., Sapag Chain, R., Sapag Puelma. J. M. (2018). Preparación y Evaluación de Proyectos. México D.F.: Mc Graw-Hill. 